SANDIA REPORT

SAND93-2094 • UC-702

Unlimited Release

Printed February 1996
PECEIVED
MAR O $419{ }^{\circ}$
OSTI

\title{
Accelerator Production of Tritium Programmatic Environmental Impact Statement Input Submittal
}

LeAnn A. Miller, George A. Greene, Brent E. Boyack

Prepared by

Sandia National Laboratories

Albuquerque, New Mexico 87185 and Livermore, California 94550

for the United States Department of Energy

under Contract DE-AC04-94AL85000

Approved for public release; distribution is unlimited.

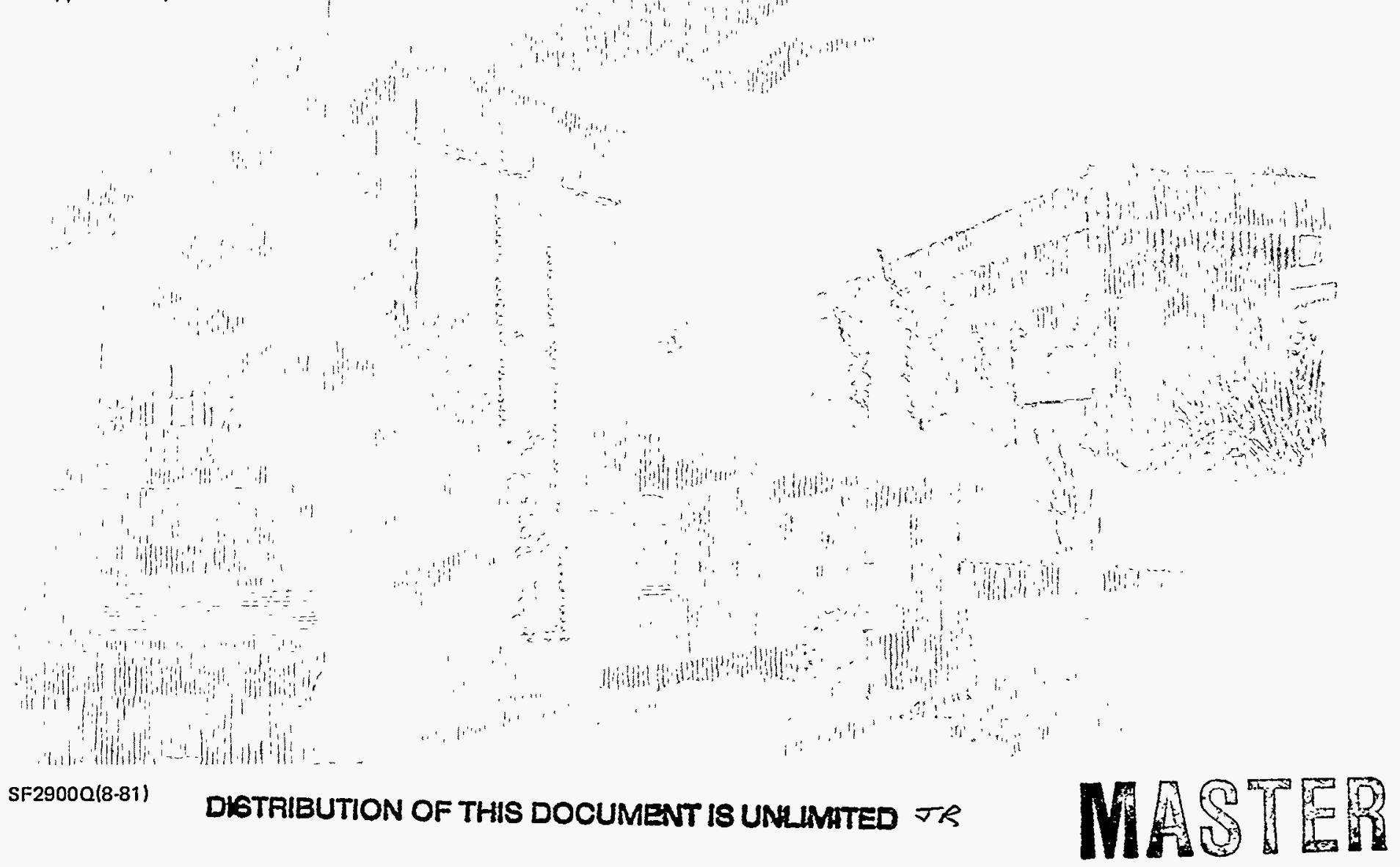


Issued by Sandia National Laboratories, operated for the United States Department of Energy by Sandia Corporation.

NOTICE: This report was prepared as an account of work sponsored by an agency of the United States Government. Neither the United States Government nor any agency thereof, nor any of their employees, nor any of their contractors, subcontractors, or their employees, makes any warranty, express or implied, or assumes any legal liability or responsibility for the accuracy, completeness, or usefulness of any information, apparatus, product, or process disclosed, or represents that its use would not infringe privately owned rights. Reference herein to any specific commercial product, process, or service by trade name, trademark, manufacturer, or otherwise, does not necessarily constitute or imply its endorsement, recommendation, or favoring by the United States Government, any agency thereof or any of their contractors or subcontractors. The views and opinions expressed herein do not necessarily state or reflect those of the United States Government, any agency thereof or any of their contractors.

Printed in the United States of America. This report has been reproduced directly from the best available copy.

Available to DOE and DOE contractors from

Office of Scientific and Technical Information

PO Box 62

Oak Ridge, TN 37831

Prices available from (615) 576-8401, FTS 626-8401

Available to the public from

National Technical Information Service

US Department of Commerce

5285 Port Royal Rd

Springfield, VA 22161

NTIS price codes

Printed copy: A06

Microfiche copy: A01 
SAND93-2094

Distribution

Unlimited Release

Printed February 1996

Category UC-702

\title{
ACCELERATOR PRODUCTION OF TRITIUM PROGRAMMATIC ENVIRONMENTAL IMPACT STATEMENT INPUT SUBMITTAL
}

\author{
LeAnn A. Miller \\ Nuclear Safety and Systems Analysis Department \\ Sandia National Laboratories \\ Albuquerque, NM \\ George A. Greene \\ Brookhaven National Laboratories \\ Upton, NY \\ Brent E. Boyack \\ Los Alamos National Laboratory \\ Los Alamos, NM
}

\begin{abstract}
The Programmatic Environmental Impact Statement (PEIS) for Tritium Supply and Recycling considers several methods for the production of tritium. One of these methods is the Accelerator Production of Tritium (APT). This report summarizes the design characteristics of APT including the accelerator, target/blanket, tritium extraction facility, and the balance of plant. Two spallation targets are considered: (1) a tungsten neutron-source target and (2) a lead neutron-source target. In the tungsten target concept, the neutrons are captured by the circulating He-3, thus producing tritium; in the lead target concept, the tritium is produced by neutron capture by Li- 6 in a surrounding lithium-aluminum blanket. This report also provides information to support the PEIS including construction and operational resource needs, waste generation, and potential routine and accidental releases of radioactive material.

The focus of the report is on the impacts of a facility that will produce $3 / 8$ th of the baseline goal of tritium. However, some information is provided on the impacts of APT facilities that would produce smaller quantities.
\end{abstract}




\section{ACKNOWLEDGMENTS}

This report represents the work of many individuals at several organizations who performed the technical analyses to quantify the input presented in this report. We are particularly grateful to the following for their hard work and cooperation. From Bechtel Group Inc. we acknowledge Jerry McDaniel, Bob Taussig, John Cunliffe, Sunil Ghose, and Tom Carlson. From Los Alamos National Laboratory we acknowledge Don Siebe, Gordon Willcutt, Sewell Rose, John Ireland, Charlie Cummings, Jim Barnes, and George Lawrence. From Brookhaven National Laboratory we acknowledge Eena-Mai Franz, Narinder Tutu, and Greg Van Tuyle. From Sandia National Laboratories we acknowledge Phyllis Peterson, Kevin Boyack, John Kelly, Gina Rightley, Dave Williams, and Susan Carson.

Several people were involved in producing this document. Maureen Lincoln (SNL) assisted in integrating previous versions of the input submittal. Reeta Garber (SNL) and Don Hente (Tech Reps) performed the final editing. Josephine Graf, Amber Vieth, Evalee Harley, and Edith Hendrix (SNL) all provided the word processing skills necessary to complete the report.

The draft and the past eight revisions of this report were not published as a SAND report. They were used, however, as coordination copies among the many individuals acknowledged in the above paragraphs. Design changes resulted in new revisions until this 9 th Revision was used as the basis for the Tritium Supply and Recycle Programmatic Environmental Impact Statement. 


\section{CONTENTS}

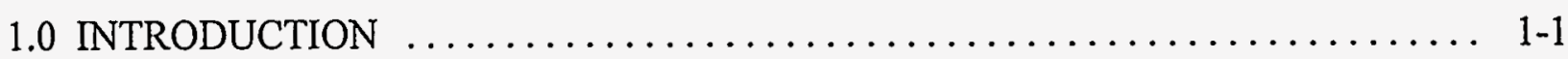

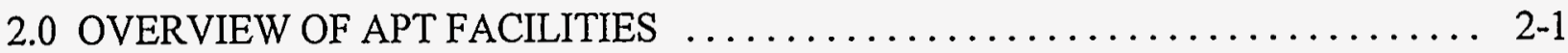

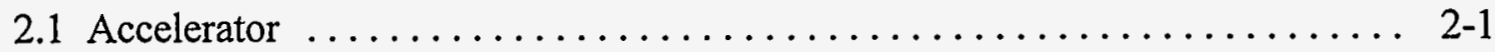

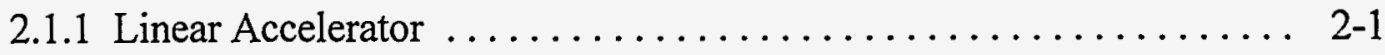

2.1.2 Beam Transport and Switchyard $\ldots \ldots \ldots \ldots \ldots \ldots \ldots \ldots \ldots .2-1$

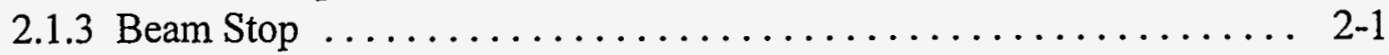

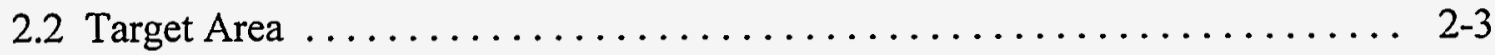

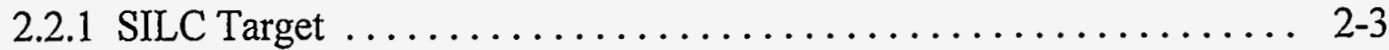

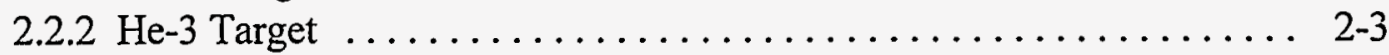

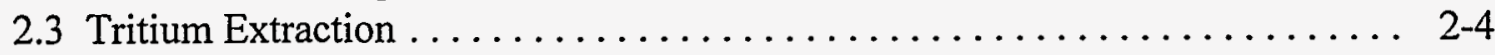

2.3.1 SILC Tritium Extraction $\ldots \ldots \ldots \ldots \ldots \ldots \ldots \ldots \ldots \ldots \ldots \ldots \ldots \ldots \ldots \ldots, 2-4$

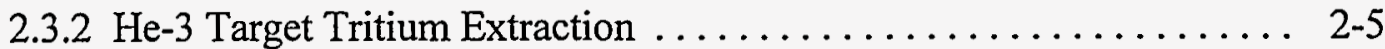

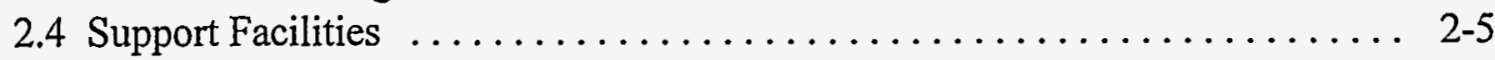

2.4.1 Secondary Cooling Facilities $\ldots \ldots \ldots \ldots \ldots \ldots \ldots \ldots \ldots \ldots \ldots \ldots \ldots$

2.4.2 Electric Substations $\ldots \ldots \ldots \ldots \ldots \ldots \ldots \ldots \ldots \ldots \ldots \ldots \ldots \ldots \ldots \ldots, 2-5$

2.4.3 Emergency Power Building .................... 2-5

2.4.4 Administration and Simulator and Training Buildings ......... 2-6

2.4.5 Operations Building $\ldots \ldots \ldots \ldots \ldots \ldots \ldots \ldots \ldots \ldots \ldots \ldots \ldots \ldots \ldots \ldots \ldots \ldots, 2-6$

2.4.6 Maintenance Facilities $\ldots \ldots \ldots \ldots \ldots \ldots \ldots \ldots \ldots \ldots \ldots \ldots \ldots \ldots \ldots \ldots, 2-6$

2.4 .7 Waste-Treatment Facility ........................ 2-6

2.4.8 Radioactive Waste-Processing Building $\ldots \ldots \ldots \ldots \ldots \ldots \ldots .2-6$

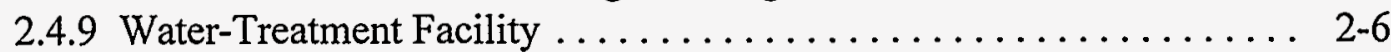

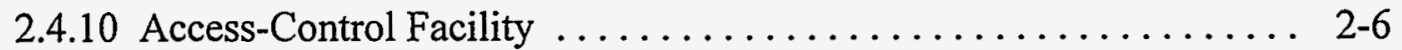

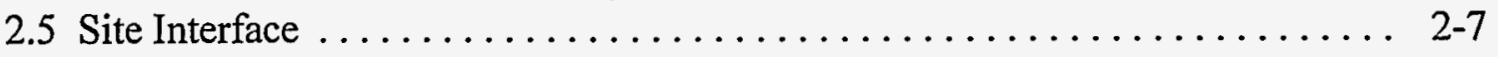

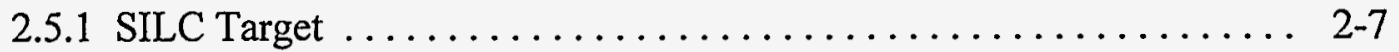

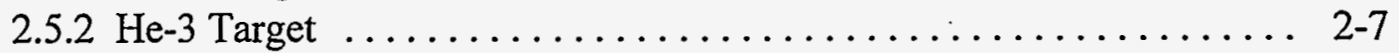

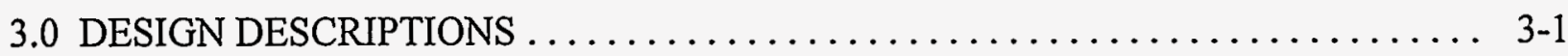

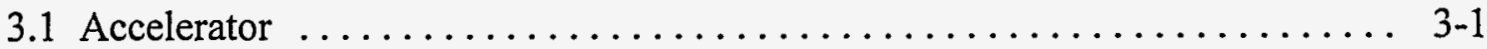

3.1.1 Protection Systems ............................ 3-1

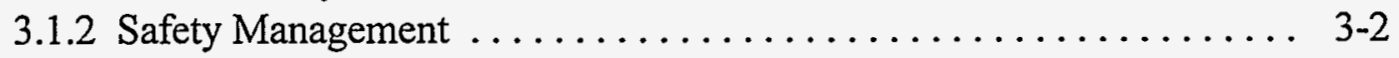

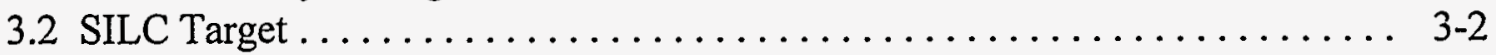

3.2.1 Target Systems Design Description ................... 3-3

3.2.1.1 Source Array .......................... 3-5

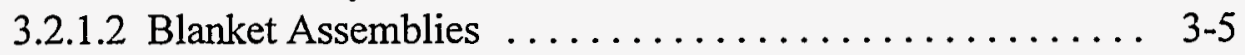

3.2.1.2.1 U-Blanket ..................... 3-6

3.2.1.2.2 L-Blanket .................... 3-6

3.2.1.3 Beam Expander Duct ................... 3-6

3.2.2 Coolant Systems Design Description ................... 3-6

3.2.2.1 Source Cooling Systems .................. 3-6

3.2.2.2 Blanket Cooling Systems ................. 3-8 
3.2.2.3 Window and Expander Cooling Systems . . . . . . . . . 3-9

3.2.2.4 Target Cavity Flood System ................. 3-9

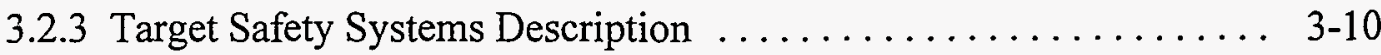

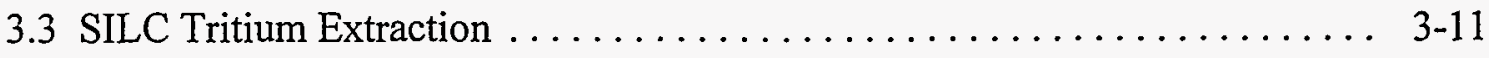

3.3.1 LiAl Plate Receiving and Spent-Melt Handling $\ldots \ldots \ldots \ldots \ldots$ 3-11

3.3.2 Extraction Furnace $\ldots \ldots \ldots \ldots \ldots \ldots \ldots \ldots \ldots \ldots \ldots \ldots \ldots, 3-11$

3.3.3 Gas Accountability ............................. 3-11

3.3.4 Inert-Separation System ......................... 3-12

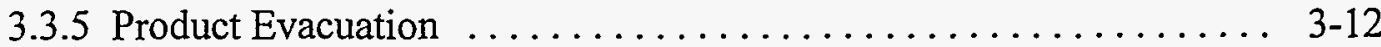

3.3.6 Thermal Cycling Absorption Process $\ldots \ldots \ldots \ldots \ldots \ldots \ldots . . \ldots \ldots .12$

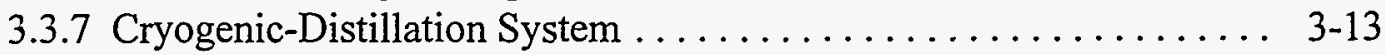

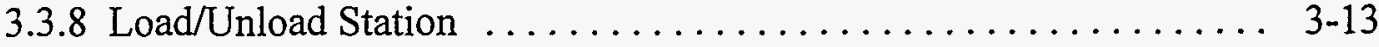

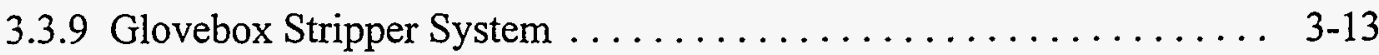

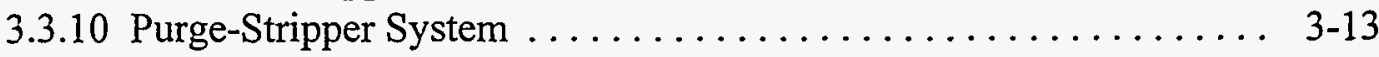

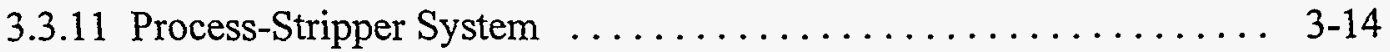

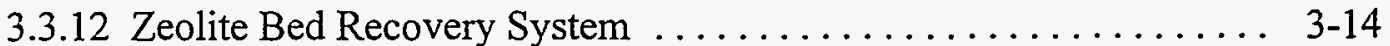

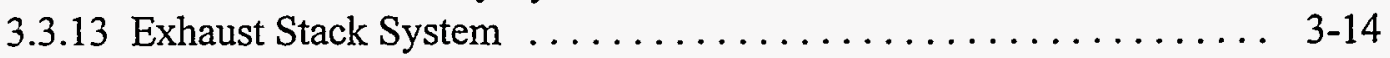

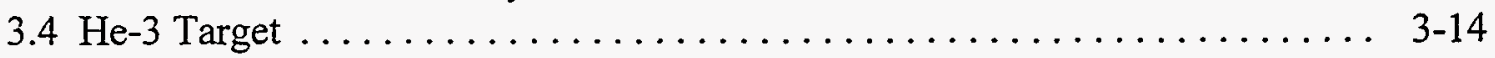

3.4.1 Target/Blanket Heat-Removal Systems ................. 3-17

3.4.1.1 Tungsten Heat-Transport System .............. 3-18

3.4.1.2 Moderator Tank Heat-Transport System . . . . . . . . 3-20

3.4.1.3 He-3 Heat-Transport System ............... 3-20

3.4.2 Plant Protection and Inherent Safety Features ............ 3-20

3.5 He-3 Target Tritium Extraction $\ldots \ldots \ldots \ldots \ldots \ldots \ldots \ldots \ldots \ldots \ldots \ldots \ldots \ldots . .21$

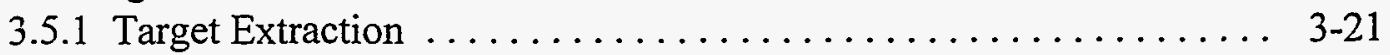

3.5 .2 Isotope Separation $\ldots \ldots \ldots \ldots \ldots \ldots \ldots \ldots \ldots \ldots \ldots \ldots .3-22$

3.5.3 Tritium Storage $\ldots \ldots \ldots \ldots \ldots \ldots \ldots \ldots \ldots \ldots \ldots \ldots \ldots . \ldots \ldots . .22$

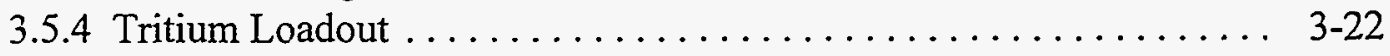

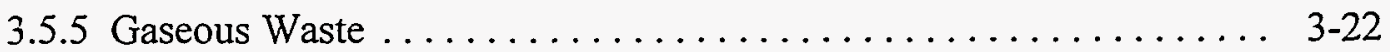

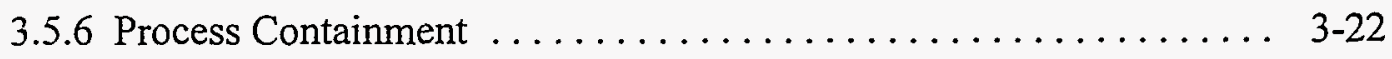

3.5.7 Room Detritiation $\ldots \ldots \ldots \ldots \ldots \ldots \ldots \ldots \ldots \ldots \ldots \ldots . . .22$

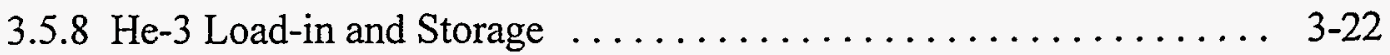

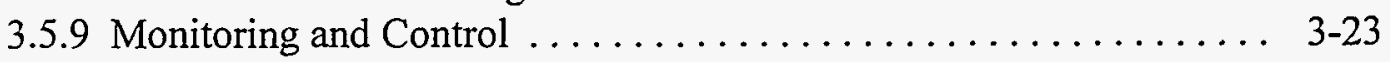

3.5.10 Analytical Laboratory $\ldots \ldots \ldots \ldots \ldots \ldots \ldots \ldots \ldots \ldots . \quad 3-23$

4.0 RESOURCE NEEDS DURING CONSTRUCTION .................... 4-1

4.1 Construction Resource Needs for the Accelerator $\ldots \ldots \ldots \ldots \ldots \ldots \ldots$. $4-1$

4.2 Construction Resource Needs for the SILC Target ................ 4-1

4.3 Construction Resource Needs for the SILC Tritium-Extraction System . . . . . 4-2

4.4 Construction Resource Needs for the He-3 Target . . . . . . . . . . . . . . 4-2

4.5 Construction Resource Needs for the He-3 Tritium-Extraction System ....... 4-3

4.6 Construction Needs for the Balance-of-Plant . ................. 4-4

5.0 RESOURCE NEEDS DURING OPERATIONS $\ldots \ldots \ldots \ldots \ldots \ldots \ldots \ldots \ldots \ldots . \ldots \ldots \ldots \ldots$

5.1 Operational Resource Needs for the Accelerator . ................ 5-1 
5.2 Operational Resource Needs for the SILC Target $\ldots \ldots \ldots \ldots \ldots \ldots \ldots .5-1$

5.3 Operational Needs for the SILC Tritium-Extraction System $\ldots \ldots \ldots \ldots \ldots .5-2$

5.4 Operational Resource Needs for the He-3 Target ............... 5-2

5.5 Operational Resource Needs for the He-3 Tritium-Extraction System . . . . . . 5 5-3

5.6 Operational Resource Needs for the Balance-of-Plant .............. 5-4

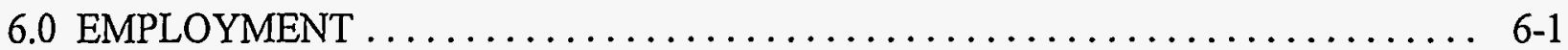

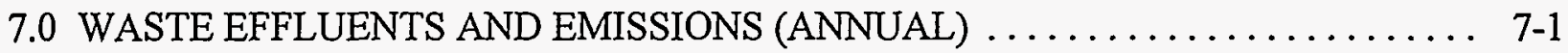

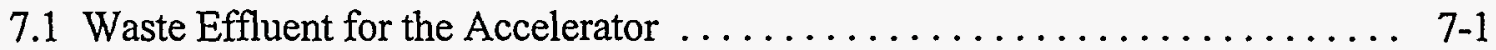

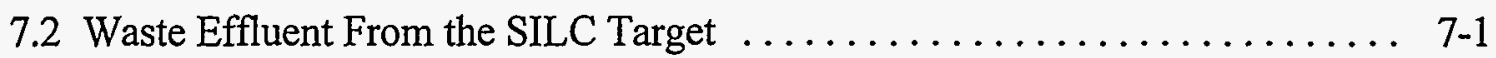

7.3 Waste Effluent From the SILC Target Tritium-Extraction System ........ 7-2

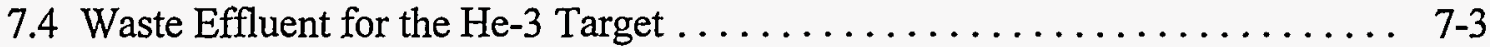

7.5 Waste Effluent for the He-3 Target Tritium-Extraction System ......... . 7-3

8.0 HAZARD ANALYSIS AND RADIOACTIVE RELEASES $\ldots \ldots \ldots \ldots \ldots \ldots .8$ 8-

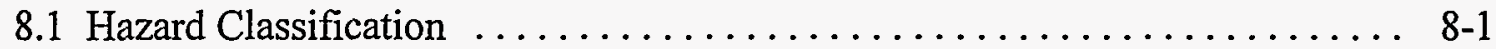

8.1 .1 Accelerator $\ldots \ldots \ldots \ldots \ldots \ldots \ldots \ldots \ldots \ldots \ldots \ldots, 8,1$

8.1 .2 SILC Target $\ldots \ldots \ldots \ldots \ldots \ldots \ldots \ldots \ldots \ldots \ldots \ldots \ldots \ldots, 8-1$

8.1.3 SILC Target Tritium Extraction $\ldots \ldots \ldots \ldots \ldots \ldots \ldots \ldots \ldots \ldots$ 8-2

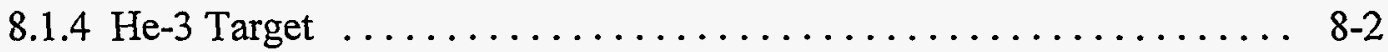

8.1.5 He-3 Target Tritium Extraction $\ldots \ldots \ldots \ldots \ldots \ldots \ldots \ldots \ldots \ldots, 8-2$

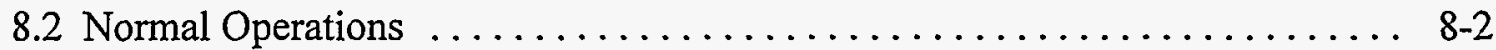

8.2.1 Anticipated Operational Occurrences $\ldots \ldots \ldots \ldots \ldots \ldots \ldots \ldots \ldots$. 8-2

8.2.2 Anticipated Annual Releases .................... 8-3

8.2.2.1 Anticipated Annual Releases From the Accelerator ..... 8-4

8.2.2.2 SILC Target Tritium Extraction ............... 8-4

8.2.2.3 He-3 Target Tritium Extraction ................ 8-4

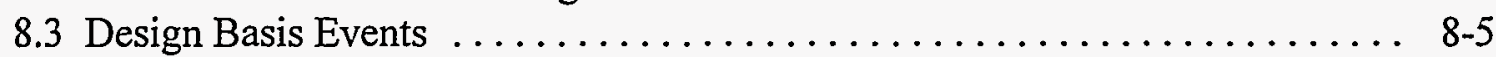

8.3 .1 Accelerator $\ldots \ldots \ldots \ldots \ldots \ldots \ldots \ldots \ldots \ldots \ldots \ldots \ldots \ldots, 8.5$

8.3.2 SILC Target System ........................... 8-5

8.3.2.1 Window Failure $\ldots \ldots \ldots \ldots \ldots \ldots \ldots \ldots \ldots .6 .6$

8.3.2.2 LBLOCA: One Active Cooling System Responding ..... 8-6

8.3.2.3 Fire in Radioactive Waste System ............. 8-6

8.3.3 SILC Target Tritium Extraction ..................... 8-6

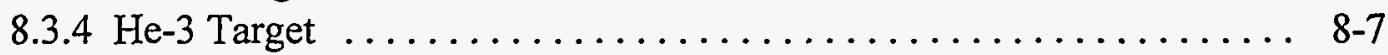

8.3.4.1 Single Helium-Tube Break ............... 8-7

8.3 .4 .2 Window Failure $\ldots \ldots \ldots \ldots \ldots \ldots \ldots \ldots .6 .7$

8.3.4.3 Fire in Radioactive Waste System ............ 8-8

8.3.4.4 LBLOCA With One Active Residual Heat-Removal System ............................ 8-8

8.3.5 He-3 Target Tritium Extraction ................... 8-8

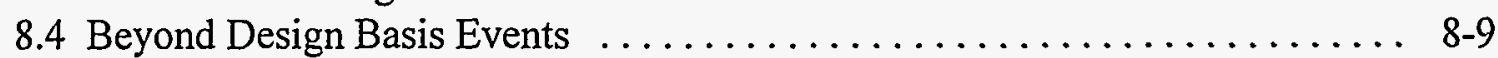

8.4 .1 Accelerator $\ldots \ldots \ldots \ldots \ldots \ldots \ldots \ldots \ldots \ldots \ldots \ldots \ldots, 8,9$

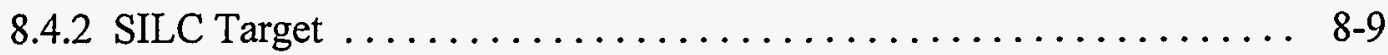


8.4.2.1 Single-Assembly Flow Blockage With Delayed Beam-

Trip ............................ $8-10$

8.4.2.2 SBLOCA With Delayed Beam-Trip ........... 8-10

8.4.2.3 LBLOCA: Total Failure of Active Cooling Systems, Passive Cooling Systems Available ........... 8-11

8.4.2.4 LBLOCA: Total Failure of Active Cooling Systems, Passive Cooling Systems Available, Loss of Confinement ..................... 8-12

8.4.2.5 LBLOCA: Total Failure of Active Cooling Systems Plus Nonmechanistic Failure to Establish Natural Circulation in the Unbroken Loop ...................

8.4.2.6 LBLOCA: Total Failure of Active Cooling Systems Plus Nonmechanistic Failure to Establish Natural Circulation in the Unbroken Loop, Loss of Confinement ....... 8-15

8.4.3 SILC Target Tritium Extraction ..................... 8-15

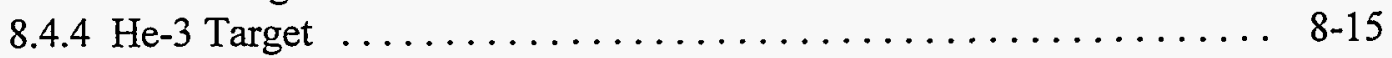

8.4.4.1 Single-Assembly Flow Blockage With Delayed BeamTrip ......................... 8-16

8.4.4.2 Multiple Helium-Tube Break or Chamber Failure ..... 8-19

8.4.4.3 LBLOCA With Total Failure of Active Emergency Cooling System (ECS) ................. 8-19

8.4.4.4 LBLOCA With Total Failure of Active Emergency Cooling System (ECS) and Loss of Confinement ..... 8-20

8.4.4.5 LBLOCA With Total Failure of Active ECS and Loss-ofHeat Sink .................... $8-20$

8.4.4.6 LBLOCA With Total Failure of Active ECS and Loss-ofHeat Sink and Loss of Confinement $\ldots \ldots \ldots \ldots \ldots$ 8-21

8.4.5 He-3 Target Tritium-Extraction System $\ldots \ldots \ldots \ldots \ldots \ldots \ldots . \quad 8-21$

9.0 DESIGN APPROACH FOR MEETING A RANGE OF PRODUCTION GOALS $\ldots . \quad 9-1$

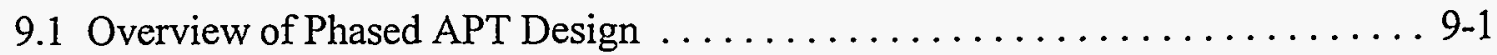

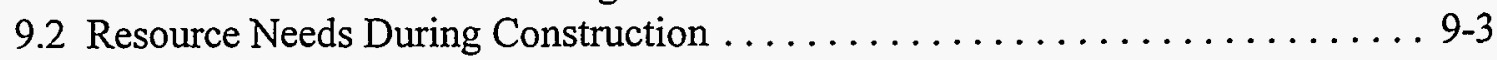

9.2.1 Construction Resource Needs for the Accelerator ............. 9-3

9.2.2 Construction Resource Needs for the He-3 Target . . . . . . . . . 9-3

9.2.3 Construction Resource Needs for the He-3 Tritium Extraction Facility . 9-4

9.2.4 Construction Resource Needs for the Balance of Plant ........... 9-4

9.3 Resource Needs During Operation $\ldots \ldots \ldots \ldots \ldots \ldots \ldots \ldots \ldots \ldots . . .49 .4$

9.3.1 Operational Resource Needs for the Accelerator ............. 9-4

9.3.2 Operational Resource Needs for the He-3 Target . ........... 9-5

9.3.3 Operational Resource Needs for the He-3 Tritium Extraction Facility .. 9-5

9.3.4 Operational Resource Needs for the Balance of Plant ........... 9-6

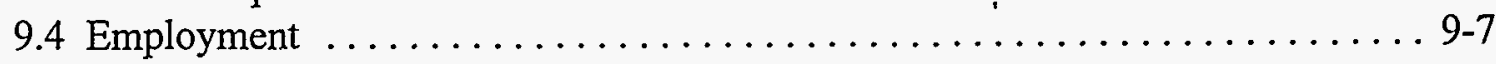

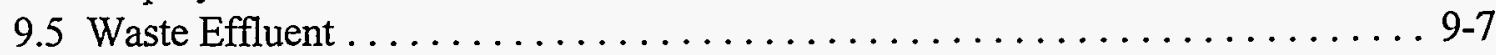

9.5.1 Waste Effluent for the Accelerator .................. 9-7

9.5.2 Waste Effluent for the He-3 Target $\ldots \ldots \ldots \ldots \ldots \ldots \ldots \ldots$ 9-7 
9.5.3 Waste Effluent for the He-3 Target Tritium Extraction Facility . . . . . 9-8

9.6 Radioactive Releases . . . . . . . . . . . . . . . . . . . . . . 9-9

9.6.1 Routine Releases ... . . . . . . . . . . . . . . . . . . . . . . 9-9

9.6.2 He-3 Source Term ........................... 9-9

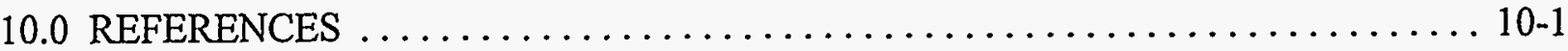




\section{LIST OF FIGURES}

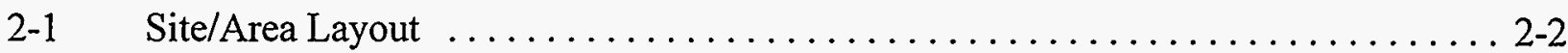

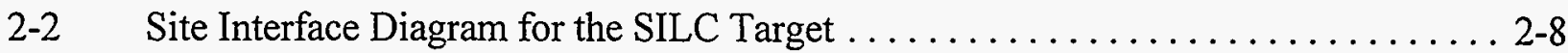

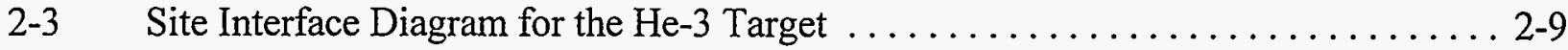

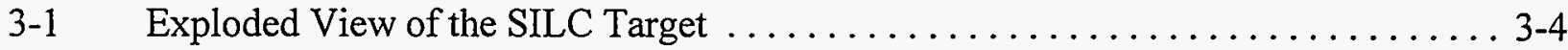

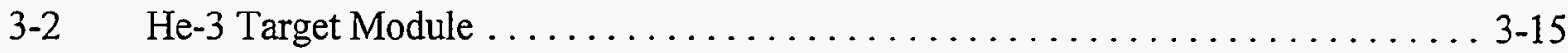

5-1 Annual Water Balance - Generic Dry Site .................... 5-6

5-2 Annual Water Balance - Generic Wet Site . . . . . . . . . . . . . . . . . . . 5-7

9-1 Comparison of Phased APT facilities $\ldots \ldots \ldots \ldots \ldots \ldots \ldots \ldots \ldots . \ldots . \ldots .2$

\section{LIST OF TABLES}

3-1 Parameters for SILC Target Neutron Source Array $\ldots \ldots \ldots \ldots \ldots \ldots \ldots \ldots . \ldots \ldots$

3-2 Beam Energy Deposition Summary for the He-3 Target . . . . . . . . . . . . 3-17

4-1 Construction Resource Needs for the Accelerator ................... 4-1

4-2 Construction Resource Needs for the SILC Target $\ldots \ldots \ldots \ldots \ldots \ldots \ldots \ldots$ 4-2

4-3 Construction Resource Needs for the SILC Target

Tritium-Extraction System . ........................ 4-2

4-4 Construction Resource Needs for the He-3 Target $\ldots \ldots \ldots \ldots \ldots \ldots \ldots \ldots$ 4-3

4-5 Construction Resource Needs for the He-3 Tritium-Extraction System . . . . . . . . 4-3

4-6 Construction Resource Needs for the Balance-of-Plant . . . . . . . . . . . . . . . 4-5

5-1 Annual Operational Resource Needs for the Accelerator ............... 5-1

5-2 Annual Operational Resource Needs for the SILC Target .............. 5-1

5-3 Annual Operational Resource Needs for the SILC Tritium-Extraction System . . . . 5 5-2

5-4 Annual Operational Resource Needs for the He-3 Target ............... 5-3

5-5 Annual Operational Resource Needs for the He-3 Tritium-Extraction System . . . . . 5 5-3

5-6 Annual Operational Resource Needs for the Balance-of-Plant . . . . . . . . . . . . 5-4

6-1 Employment Requirements for the APT $\ldots \ldots \ldots \ldots \ldots \ldots \ldots \ldots \ldots .6 .1$

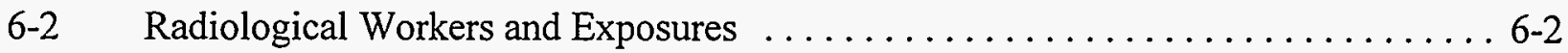

7-1 Annual Waste Effluent From the Accelerator ..................... 7-1

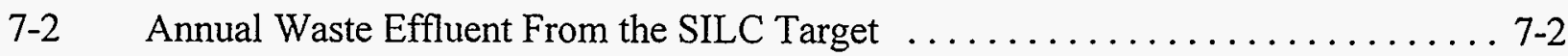

7-3 Annual Waste Effluent From the SILC Tritium-Extraction Facility .......... 7-2

7-4 Innual Waste Fffluent From the He-3 Target ................... 7-3

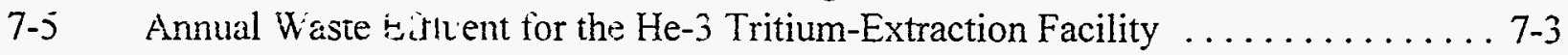

8-1 Cumposition of Iso opes Relcased fiom the Accelerator Tunnel $\ldots \ldots \ldots \ldots . .8-4$

8-2 BDBE Environmental Source Term for the SILC Target With No Confinement Failure $\ldots \ldots \ldots \ldots \ldots \ldots \ldots \ldots \ldots \ldots \ldots \ldots \ldots \ldots \ldots \ldots \ldots .17$

8-3 BDBE Environmental Source Term for the SILC Target With Confinement Failure 8-18

8-4 BDBE Environmen.al Source Term ir the He-3 Target With No Confinement Failure $\ldots \ldots \ldots \ldots \ldots \ldots \ldots \ldots \ldots \ldots . \ldots \ldots .22$

8-5 BDBE Environmental Source Term for the He-3 Target With Confinement Failure 8-23 
9-1 Phased APT Approach Characteristics $\ldots \ldots \ldots \ldots \ldots \ldots \ldots \ldots . \ldots . \ldots . \ldots .6 .1$

9-2 Construction Resource Needs for the Phased APT Accelerator $\ldots . \ldots \ldots \ldots . . .69$

9-3 Construction Resource Needs for the Phased APT He-3 Target . . . . . . . . . . . 9-4

9-4 Operational Resource Needs for the Phased APT Accelerator $\ldots \ldots \ldots \ldots \ldots \ldots$ 9-5

9-5 Operational Resource Needs for the Phased APT He-3 Target .............. 9-5

9-6 Operational Resource Needs for the Phased APT Balance of Plant .......... 9-6

9-7 Waste Effluent for the Phase I Accelerator ...................... 9-7

9-8 Waste Effluent for the Phase II Accelerator ....................... 9-7

9-9 Waste Effluent for the Phase I He-3 Target $\ldots \ldots \ldots \ldots \ldots \ldots \ldots \ldots \ldots .6$.

9-10 Waste Effluent for the Phase II He-3 Target $\ldots \ldots \ldots \ldots \ldots \ldots \ldots \ldots \ldots . . .6$.

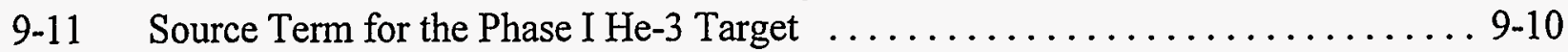

9-12 Source Term for the Phase II He-3 Target .................... 9-11 


\section{ACRONYMS AND ABBREVIATIONS}

$\mathrm{AOO}$

APT

ASME

BCDTL

BCS

BCWS

BDBE

BPCS

BRPCS

BRSCS

BSCS

CCL

CW-RF

$\mathrm{DBE}$

DOE

DTL

ECS

ES\&H

HVAC

HWAS

HWR

LAMPF

LANL

LBLOCA

LOCA

LWR

MHTGR

MTHTS

NEPA

NPDES

NPR

NPSH

NRC
Anticipated Operational Occurrence

Accelerator Production of Tritium

American Society of Mechanical Engineers

Bridge-Coupled Drift-Tube Linac

Blanket Cooling System

Blanket Circulating-Water System

Beyond Design Basis Event

Blanket Primary-Cooling System

Blanket Residual Primary-Cooling System

Blanket Residual Secondary-Cooling System

Blanket Secondary-Cooling System

Coupled-Cavity Linac

Continuous Wave Radio Frequency

Design Basis Event

Department of Energy

Drift-Tube Linac

Emergency Cooling System

Environment, Safety, and Health

Heating, Ventilation, and Air Conditioning

Heavy-Water-Accumulator System

Heavy Water Reactor

Los Alamos Meson Physics Facility

Los Alamos National Laboratory

Large-Break Loss-of-Coolant Accident

Loss-of-Coolant Accident

Light Water Reactor

Modular High-Temperature Gas Reactor

Moderator-Tank Heat-Transport System

National Environmental Policy Act

National Pollutant Discharge Elimination System

New Production Reactor

Net Positive Suction Head

Nuclear Regulatory Commission 


$\begin{array}{ll}\text { PEIS } & \text { Programmatic Environmental Impact Statement } \\ \text { PFR } & \text { Plug Flow Reverser } \\ \text { RF } & \text { Radio Frequency } \\ \text { RFQ } & \text { Radio-Frequency Quadrupole } \\ \text { RHRS } & \text { Residual Heat-Removal System } \\ \text { ROD } & \text { Record of Decision } \\ \text { SBLOCA } & \text { Small-Break Loss-of-Coolant Accident } \\ \text { SCS } & \text { Source Cooling Systems } \\ \text { SCWS } & \text { Source Circulating-Water System } \\ \text { SILC } & \text { Spallation-Induced Lithium Conversion } \\ \text { SNL } & \text { Sandia National Laboratories } \\ \text { SPCS } & \text { Source Primary-Cooling System } \\ \text { SRPCS } & \text { Source Residual Primary-Cooling System } \\ \text { SRS } & \text { Savannah River Site } \\ \text { SRSCS } & \text { Source Residual Secondary-Cooling System } \\ \text { SSCS } & \text { Source Secondary-Cooling System } \\ \text { TCAP } & \text { Thermal Cycling Absorption Process } \\ \text { TCFS } & \text { Target-Cavity Flood System } \\ \text { TCWS } & \text { Tungsten Circulating-Water System } \\ \text { THTS } & \text { Tungsten Heat-Transport System } \\ \text { TPCS } & \text { Tungsten Primary-Coolant System } \\ \text { TPRHRS } & \text { Tungsten Primary Residual Heat-Removal System } \\ \text { TSCS } & \text { Tungsten Secondary-Coolant System } \\ \text { TSRHRS } & \text { Tungsten Secondary Residual Heat-Removal System } \\ \text { TSTA } & \text { Tritium System Test Assembly } \\ \text { WCS } & \text { Window-Cooling Systems } \\ \text { WCWS } & \text { Window Circulating-Water System } \\ \text { WHTS } & \text { Window Heat-Transport System } \\ \text { WPCS } & \text { Window Primary-Cooling System } \\ \text { WSCS } & \text { Window Secondary-Cooling System } \\ & \\ & \end{array}$


Intentionally Left Blank 


\section{ACCELERATOR PRODUCTION OF TRITIUM \\ PROGRAMMATIC ENVIRONMENTAL IMPACT STATEMENT \\ INPUT SUBMITTAL}

\subsection{INTRODUCTION}

The Department of Energy (DOE) is addressing the need for a long-term tritium supply. As part of the decision making process regarding the tritium supply, a Programmatic Environmental Impact Statement (PEIS) on Tritium Supply and Recycling is being prepared in accordance with the amended National Environmental Policy Act (NEPA) of 1969. After completion of the PEIS, a Record of Decision (ROD) will document DOE's programmatic decisions on the tritium supply alternatives.

The Tritium Supply and Recycling PEIS considers several tritium-supply options, one of which is the Accelerator Production of Tritium (APT). This report documents the information on the APT concept. The APT tritium-supply option consists of an accelerator that bombards a spallation target with high-energy protons. Neutrons are produced in the spallation target and are absorbed in a blanket material to produce tritium. Two spallation targets are currently under investigation: (a) a tungsten neutron-source target and (b) a lead neutron-source target. In the tungsten target concept, the neutrons are captured by He-3, which is circulated through the system, thus producing tritium. This target system is referred to as the He-3 target throughout this report. The lead target is surrounded with a lithium-aluminum blanket and the tritium is produced by neutron capture by Li- 6 . This target concept is referred to as the Spallation-Induced Lithium-Conversion (SILC) target. The He-3 target is the primary target while the SILC target is a backup system.

The majority of the information contained in this report pertains to an APT design for the production of 3/8th of the New Production Reactor (NPR) program baseline tritium production goal. Some environmental impact information is included for a Phased APT which would produce lesser amounts of tritium. The general philosophy used in developing APT information for the PEIS was to generate bounding estimates. The information in this report includes the entire process from the production to the purification of tritium. Recycling and purification of tritium in the stockpile are not addressed in this report.

The report is organized into several sections, with each section addressing a different topic. A general description of the facilities involved and their interactions with other facilities is provided in Section 2. Section 3 contains design descriptions for the accelerator, the SILC target and tritium extraction for the SILC target, and the He-3 target and tritium extraction for the He-3 target. The resource needs for construction and operation are discussed in Sections 4 and 5, respectively. Section 6 provides information on the employment needs during construction and operation of the facility for both target concepts. Section 7 provides estimates of the waste effluents and emissions from the facilities. An analysis of radionuclide releases is presented in Section 8. A discussion of the Phased APT approach for meeting a range of tritium production goals is contained in Section 9, and the references are contained in Section 10. 
Intentionally Left Blank 


\subsection{OVERVIEW OF APT FACILITIES}

The APT Facility consists of the proton accelerator, the target area, the tritium-extraction area, and the support facilities. This facility would occupy approximately 70 ha $(173 \mathrm{acres})$ of land. The proposed layout of the facility is shown in Figure 2-1.

\subsection{Accelerator ${ }^{*}$}

The accelerator portion of the facility consists of the linear accelerator, the beam transport and switchyard, and the beam stop. Each of these is discussed in the following sections.

\subsubsection{Linear Accelerator}

The accelerator design is an extrapolation of existing proton linear accelerators similar to the Los Alamos Meson Physics Facility (LAMPF). Its physical length is about $1200 \mathrm{~m}$ (3940 ft), and it will use primarily $700 \mathrm{MHz}$ radio frequency (RF) power (generated by 1-MW klystrons) and some 350 $\mathrm{MHz}$ RF power to deliver a $200-\mathrm{mA}$ beam of $1.0-\mathrm{GeV}$ protons to one of two target/blanket assemblies located in separate target stations. The accelerator is housed within a concrete tunnel that is buried under 12 to $15 \mathrm{~m}$ ( 39 to $49 \mathrm{ft}$ ) of earth for radiation shielding. The tunnel is sealed during operation. During shutdown conditions, the air in the tunnel is exhausted to the atmosphere through a delay line and a stack.

\subsubsection{Beam Transport and Switchyard}

At the end of the accelerator, the beam is directed to one of two target/blanket assemblies in the target area by a beam transport and switchyard system. This system consists of bending and focusing magnets and evacuated pipes through which the beam travels. The system also provides the correct expanded beam size and shape at the target and switches the beam between target/blanket assemblies as required. Before the beam is directed onto the target, the beam is sent through a third transport channel to a full-power beam stop for tuning the accelerator prior to target operation.

\subsubsection{Beam Stop}

The beam stop is a device that stops the proton beam during accelerator tune-up, or any time it is necessary to divert the beam from the tritium-producing target area without shutting off the accelerator. The beam stop will accommodate the full $200 \mathrm{MW}$ for an unlimited time. The beam stop is designed to passively radiate the deposited power to an actively cooled structure.

- Section 2.1 is based on Los Alamos National Laboratory, "Accelerator Topical Report," LA-12668-MS, Vol. 1, September 1993. 


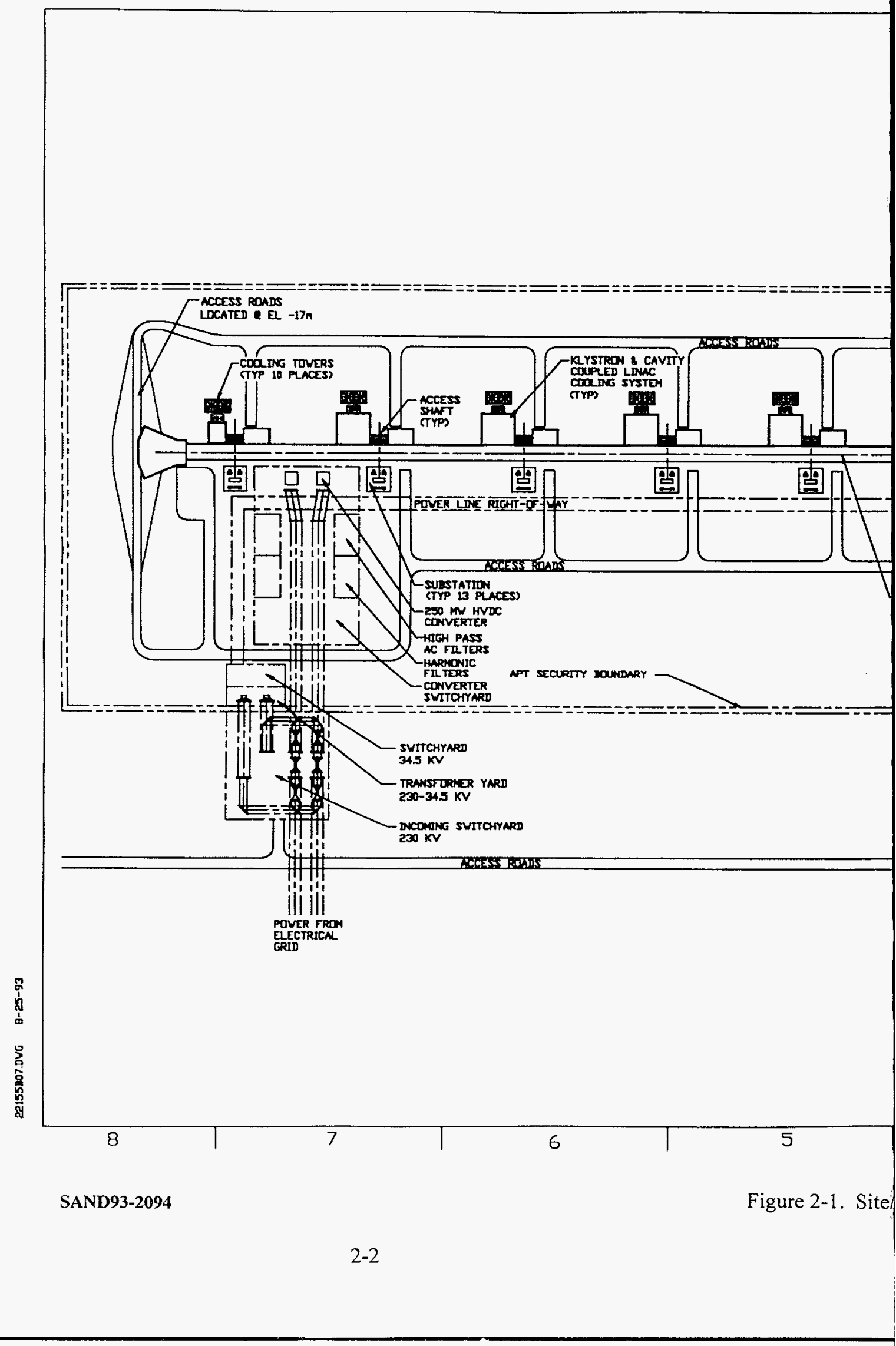




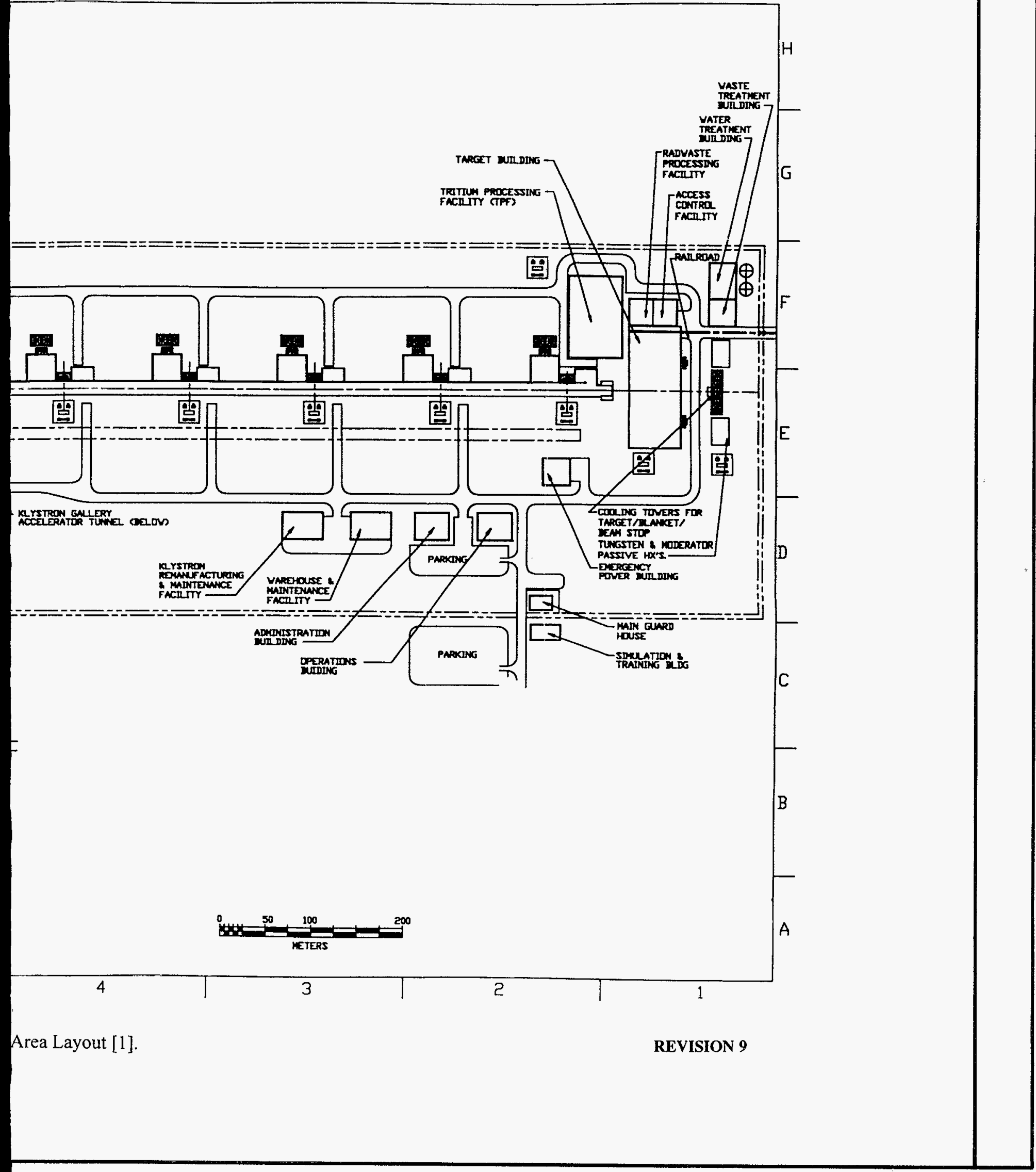




\subsection{Target Area}

The design of the target area depends on the choice of target assembly. The SILC target and He-3 target are two concepts presently being reviewed and are briefly described below. Under both concepts, the target chambers will be located in a subterranean structure to place the targets at the same elevation as the accelerator beam line. A confinement system will envelop not only the target area but also those spaces housing the primary loop components (i.e., heat exchangers, pumps) in the heat-removal systems associated with the target/blanket assemblies as well as the compartments in which spent target handling, disassembly, and preparation for transport are conducted. This confinement system will include the requisite isolation, atmospheric cleanup, and heat-removal features; that portion of the confinement system enveloping the operating target and primary loop components will be capable of limiting the leakage rate to no more than 5 volume percent per day.

\subsubsection{SILC Target}

The SILC target area will contain a target system consisting of heavy water $\left(\mathrm{D}_{2} \mathrm{O}\right)$ cooled, leadspallation targets and $\mathrm{H}_{2} \mathrm{O}$-cooled $\mathrm{LiAl}$ targets separated from the accelerator by a beam-entrance window. The concept consists of two identical target assemblies, each with two one-year operating cycles, allowing continuous production capability of one while the second is being serviced [2]. At the end of one year the LiAl blanket will be removed, and at the end of the second one-year cycle the lead-spallation target will be removed.

High-energy protons will induce spallation in the lead rods, thereby generating neutrons. $\mathrm{D}_{2} \mathrm{O}$ coolant will remove the heat of spallation. The $\mathrm{Li}-6$ isotope within the $\mathrm{H}_{2} \mathrm{O}$-cooled LiAl target rods will capture the thermal neutrons that were moderated in the $\mathrm{H}_{2} \mathrm{O}$ and produce tritium by the following reaction:

$$
{ }^{6} \mathrm{Li}_{3}+{ }^{1} \mathrm{n}_{0} \rightarrow{ }^{3} \mathrm{H}_{1}+{ }^{4} \mathrm{He}_{2}
$$

The target-processing facility will contain facilities to receive and store fresh lead and fresh LiAl targets. It will include (a) equipment to perform quality control tests for fresh targets and (b) retargeting equipment to transport the targets to the target chamber.

A water pool will provide cooling and radiation shielding for the spent-lead targets and LiAl targets. Underwater remote equipment will be used for dismantling spent targets and packaging them in special shipping bundles. Spent-lead targets will be reprocessed or sent to existing mixed-waste management facilities for final disposal.

\subsubsection{He-3 Target}

In the He-3 target design, the two target chambers will each house a target/blanket assembly consisting of a $\mathrm{D}_{2} \mathrm{O}$-cooled Inconel beam-entrance window followed by a neutron-producing target of tungsten. That target will be cooled by circulating $\mathrm{D}_{2} \mathrm{O}$ and be surrounded by a second isolated region containing $\mathrm{D}_{2} \mathrm{O}$ moderator with circulating $\mathrm{He}-3$ contained in tubes. The assembly will have 
lead in a surrounding annular region to provide neutron multiplication and moderation. The target is expected to be irradiated for 600 days ( 2.2 years at a $75 \%$ capacity) [3].

He-3 produces tritium through the following reaction:

$$
{ }^{3} \mathrm{He}_{2}+{ }^{1} \mathrm{n}_{0}>{ }^{3} \mathrm{H}_{1}+{ }^{1} \mathrm{H}_{1} .
$$

About half of the tritium is produced in the blanket region of the system; the remainder is produced in a separate $\mathrm{He}-3$ volume in the spallation target. The purpose of the second He-3 region is to reduce neutron leakage along the direction of the incident proton beam and to preferentially absorb thermal neutrons that would otherwise be lost to capture in tungsten and other structural materials. Tritium will be continuously removed from both regions by taking a sidestream of the circulating $\mathrm{He}-3$ gas into a processing area.

An area will be required for cooling and radiation shielding for spent tungsten removed from the target cavity. Remote-handling apparatus will be necessary to load packaged targets into shipping casks and to place the loaded casks onto truck or rail shippers. Spent tungsten targets will go to existing waste management facilities for final disposal. The estimated volume of this material will be small, typically on the order of a few cubic meters per year of operation.

\subsection{Tritium Extraction}

The tritium-extraction system depends on the choice of target assembly. The He-3 system processes tritium on a continuous basis while tritium is extracted from the LiAl plates in batches. These systems are discussed below.

\subsubsection{SILC Tritium Extraction}

For the SILC design, the production targets will be processed at a facility similar to the Savannah River Tritium Processing Facility. The aluminum-clad LiAl bars are heated to melting in a crucible in a vacuum furnace to release tritium, helium, and impurity gases. After extraction, the crucible with the spent melt is removed from the furnace and is sealed, encased in a secondary container, and transferred to a storage facility. The extracted gas mixture is processed through a uranium bed to ensure conversion of any tritiated water to a mixture of elemental hydrogen isotopes. After collection and accountability, the hydrogen isotopes are separated from $\mathrm{He}-3, \mathrm{He}-4$, and impurity gases by adsorption in a palladium/kieselguhr purifier or permeation through a heated palladiumsilver alloy diffuser. The waste gas is processed through catalytic reactors and zeolite to remove tritium as water before the gas is released to the atmosphere. Tritium is separated from other purified hydrogen isotopes by the thermal-cycling absorption process or cryogenic distillation. The purified tritium is stored in metal hydride beds for shipment. All process equipment will be installed inside gloveboxes filled with a nitrogen atmosphere to provide secondary confinement for any tritium leakage from the process. 


\subsubsection{He-3 Target Tritium Extraction}

For the He-3 design, tritium-extraction and purification requires an area of a few hundred square meters (few thousand square feet) with tritium containment similar to that in use at the Los Alamos Tritium System Test Assembly (TSTA) facility. A small sidestream will be taken off the gas circulating through the $\mathrm{D}_{2} \mathrm{O}$ blanket, and hydrogen and tritium will be extracted using a palladium membrane diffuser. The He-3 is then recirculated to the target area. The extracted hydrogen and tritium are separated by cryogenic distillation with the product purity being greater than $99.0 \mathrm{~mole} \%$ $\mathrm{T}_{2}$. The tritium would be stored in a solid matrix using hydrogen-getter bed technology. All process and waste systems are housed in enclosures designed to contain and allow recovery of tritium leaks, and a gaseous waste system will recover residual tritium before releasing the waste to the atmosphere. Packaging facilities will prepare the tritium gas for shipment to end-users.

\subsection{Support Facilities}

The APT facility includes several support facilities. These include the secondary cooling facilities, electric substations, emergency power building, administration building, simulator and training building, operations building, maintenance facilities, waste-treatment facility, radioactive wasteprocessing building, water-treatment facility, and the access-control facility.

\subsubsection{Secondary Cooling Facilities}

These facilities will include cooling towers (or possibly cooling ponds, not shown in the site layout diagram) and air-blast heat exchangers for rejecting APT waste heat to the atmosphere. The major heat sources include RF-power losses in the accelerator structure, heat produced in power supplies and klystrons, heat deposited in the target/blanket assemblies by the proton beam, decay heat from the irradiated targets, and heat produced in tritium extraction and target-processing facilities.

\subsubsection{Electric Substations}

The electric load of the operating APT will be approximately 550 MWe for a facility capable of producing 3/8th goal tritium annually. The electric substations will receive $550 \mathrm{MWe}$ electric power from the commercial supply grid, convert it to the required voltages for various functions, and distribute it to the accelerator, target/blanket related systems, processing systems, and other on-site facilities. Use of off-peak power to reduce electrical operating costs may be a feasible option for the system.

\subsubsection{Emergency Power Building}

This facility houses diesel generators or gas turbines that will be used to provide short-term emergency power to support safety-related loads in the event of temporary failure of the off-site power supply. 


\subsubsection{Administration and Simulator and Training Buildings}

These facilities will house administrative, technical support [including Environment, Safety, and Health (ES\&H)], and clerical staff, as well as provide for operator training, including simulator facilities. They include staff offices, a cafeteria, medical facilities, data processing, and a records center.

\subsubsection{Operations Building}

This facility will provide for operational control and monitoring of the accelerator target/blanket assemblies, and associated support and safety systems. It also will serve as the center for site safeguards and security and house the safety-related batteries providing an uninterruptible source of power for controls and instrumentation.

\subsubsection{Maintenance Facilities}

These facilities will provide shop and service areas for maintaining all accelerator, target/blanket, and processing system components, including klystron refurbishment and contaminated equipment maintenance. They also will provide warehousing and materials handling for consumable goods and spare parts for these systems.

\subsubsection{Waste-Treatment Facility}

This facility will receive and treat all site-generated sanitary sewage for release to the environment in accordance with a National Pollutant Discharge Elimination System (NPDES) permit.

\subsubsection{Radioactive Waste-Processing Building}

This facility will receive all solid, liquid, and gaseous radioactive waste, including fluids collected via the floor drains in potentially contaminated areas, for holdup, treatment, and packaging in preparation for either release or disposal at an appropriate permanent disposal facility.

\subsubsection{Water-Treatment Facility}

This facility will supply treated water of the required quality for the various plant cooling systems: deionized water for the accelerator and klystrons, filtered water for cooling-tower makeup, and filtered and treated water for domestic use. The fire-protection system will tap off of the facility water supply upstream of the water-treatment facility.

\subsubsection{Access-Control Facility}

This facility will provide the personnel monitoring and access control that is required for managing access to restricted radiological areas. 


\subsection{Site Interface}

As part of the weapons complex, APT will receive and supply various materials. These interfaces are discussed below for both target concepts.

\subsubsection{SILC Target}

The APT facility with a SILC target will receive LiAl plates and lead target rods from the tritium target and spallation target fabrication facilities. After irradiation, the tritium will be extracted from the LiAl rods and the tritium will be transferred to the end user. The inputs and outputs of each process are shown in Figure 2-2.

\subsubsection{He-3 Target}

An APT facility with a He-3 target will receive tungsten targets from the spallation target fabrication facility. The tritium is continuously extracted from the $\mathrm{He}-3$ and is transferred to the end user. The inputs and outputs of each process are shown in Figure 2-3. 


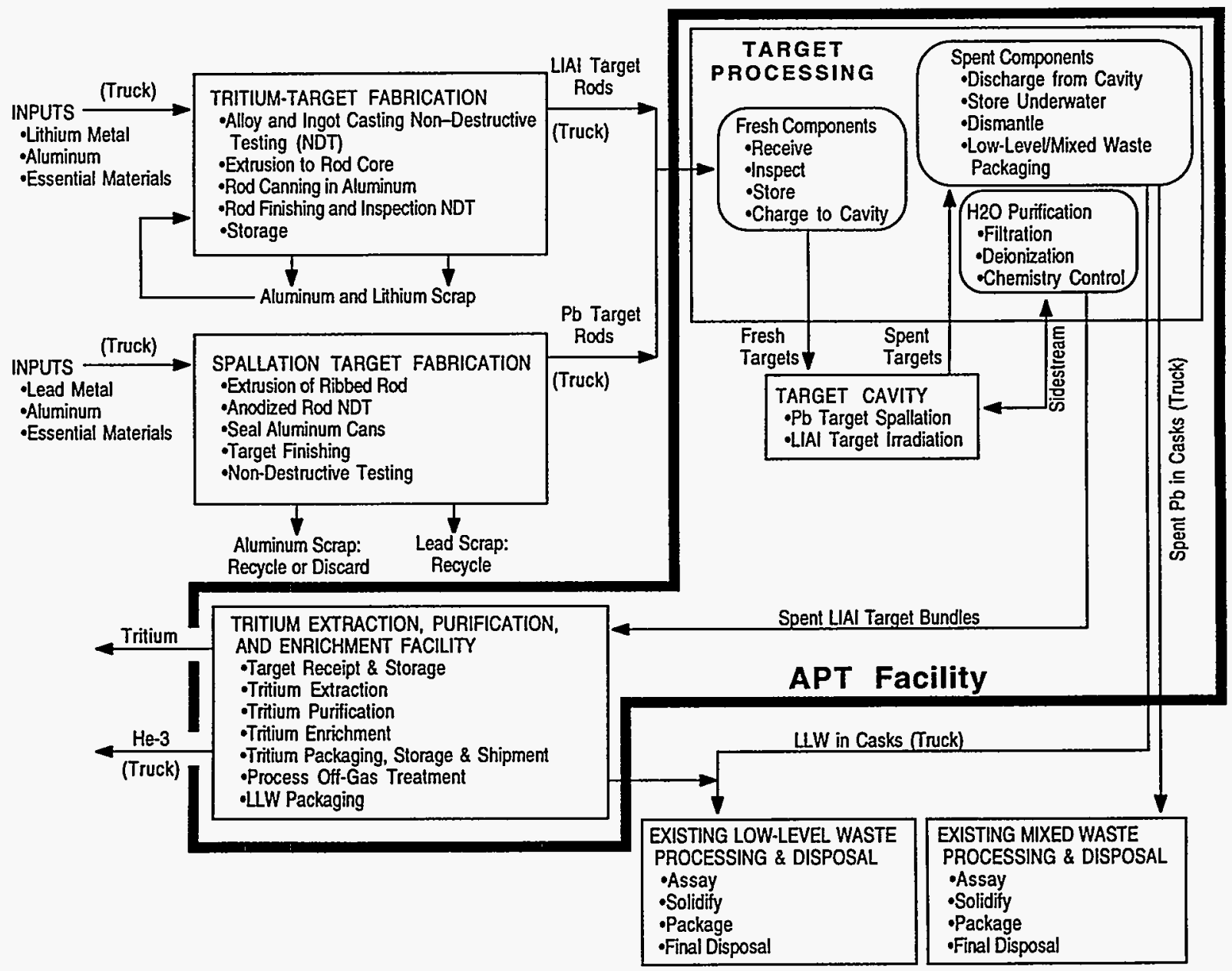

Figure 2-2. Site Interface Diagram for the SILC Target [1]. 


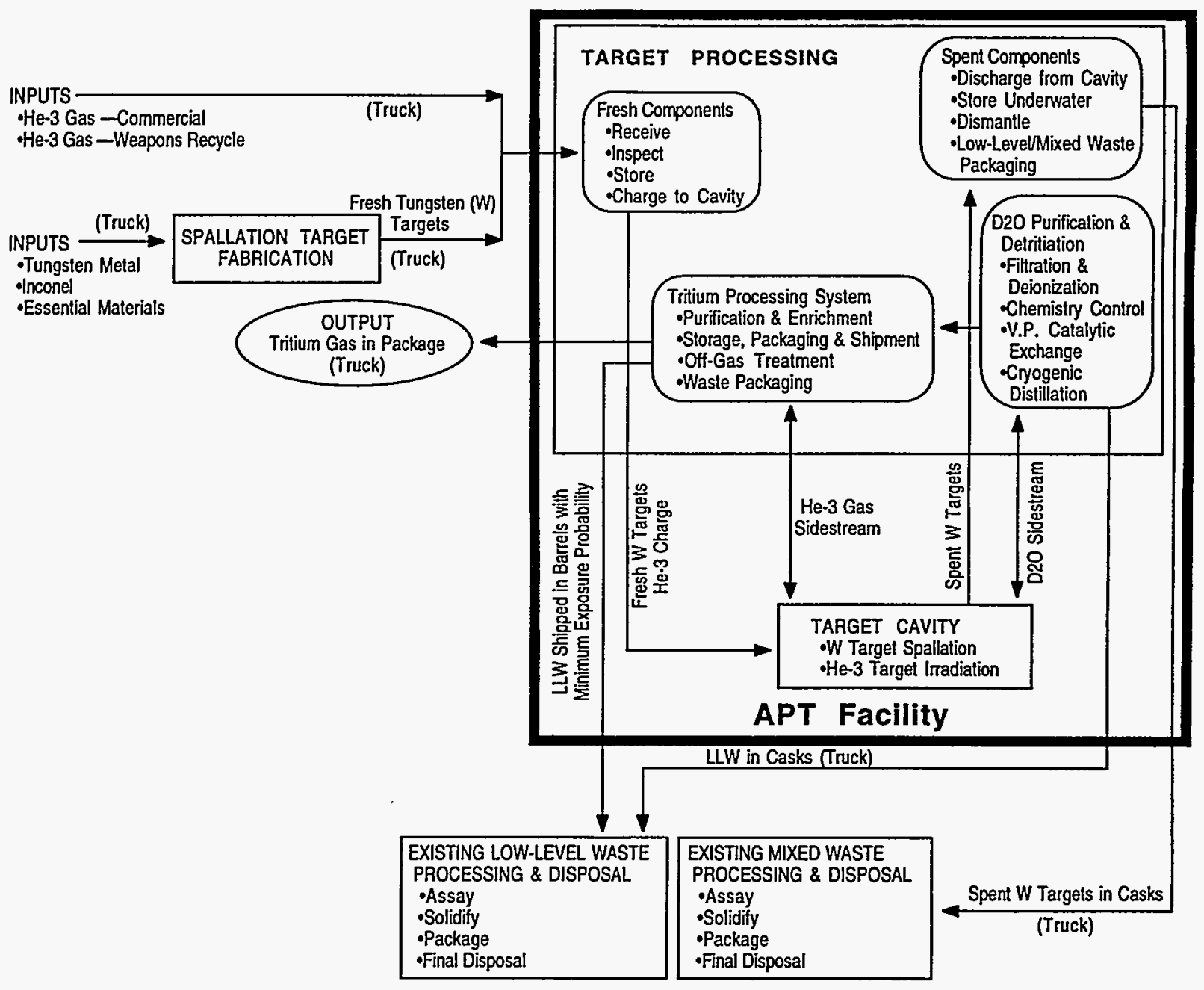

Figure 2-3. Site Interface Diagram for the He-3 Target [1]. 
Intentionally Left Blank 


\subsection{DESIGN DESCRIPTIONS}

This section provides the design information for the accelerator, the two targets, and the tritiumextraction systems for the two targets. Details regarding the design of the support facilities are not provided.

\subsection{Accelerator ${ }^{*}$}

The APT accelerator is made up of different types of accelerating structures that provide efficient energy gain to the beam over specific velocity ranges. The overall length of the system is about $1200 \mathrm{~m}(3940 \mathrm{ft})$, with an average accelerating gradient of approximately $1 \mathrm{MV} / \mathrm{m}(0.30 \mathrm{MV} / \mathrm{ft})$. A continuous stream of protons is generated in an ion source (plasma chamber) and injected at an energy of $75 \mathrm{keV}$ into Radio-Frequency Quadrupole (RFQ) linac, where it is formed into bunches at the frequency of the RF power system ( $350 \mathrm{MHz}$ ) and accelerated to $7 \mathrm{MeV}$. These bunches are then further accelerated to $20 \mathrm{MeV}$ in a Drift-Tube Linac (DTL), and combined longitudinally with a second bunch train at that energy (funneling). The combined proton beam is accelerated to 100 $\mathrm{MeV}$ in a Bridge-Coupled Drift-Tube Linac (BCDTL) and then to full energy $(1000 \mathrm{MeV})$ in a series of Coupled-Cavity Linac (CCL) modules. The latter structures (which are powered by $700-\mathrm{MHz}$ $\mathrm{RF}$ power tubes) make up the bulk of the accelerator. The average current in the CCL, for a $3 / 8$ goal production system, is $200 \mathrm{~mA}$, and the average beam power is $200 \mathrm{MW}$. Since the beam power and current are large compared with existing linear accelerators, there is a significant potential for damaging energy deposition in accelerating structures and beam transport lines if the beam is misdirected or misfocused for short periods of time. There is also a significant potential for activation of accelerating structures and beam lines if even a small fraction of the beam is lost on a continuous basis.

\subsubsection{Protection Systems}

Distributed throughout the accelerator and beam lines are multiple redundant sensors and diagnostics, all acting within very short (tens of microseconds) time scales, that determine if the beam is out of acceptable limits in terms of position, energy, size, intensity distribution, steering angle, local loss rate, etc. These detectors are integrated into several kinds of machine-protection systems that prevent damage and activation buildup. Secondary information is provided on accelerator vacuum, coolant flow and temperature, integrated beam losses along the linac, amplitude and phase of the RF power stations, energizing currents in focusing magnets, etc. to confirm the correct operation of the beam-manipulation elements of the accelerator and transport systems. Malfunctions or out-of-tolerance values for any of these devices will terminate or limit operation until the situation is corrected.

Monitoring and control of the accelerator and beam lines would be similar to methods standard at all large accelerator facilities - through a central computer communicating with data-collection and manipulation nodes distributed throughout the system. The control system interfaces with the

\footnotetext{
- Section 3.1 is based on Los Alamos National Laboratory, "Accelerator Topical Report," LA-12668-MS, Vol. 1, September 1993.
} 
operations staff through multiple color display screens, touch panels, assignable control knobs, and similar devices. Operations are highly automated, with control of even very large and multiple accelerator systems normally being accomplished by an on-station crew of four to six well-trained operators. Operation on a 24-hours-a-day basis for months at a time with only brief interruptions for service and maintenance is the norm at such installations. Specialized service personnel are available at any time for emergency repairs of equipment, but most service is performed during scheduled maintenance intervals, which typically would involve two eight-hour shifts every two weeks.

\subsubsection{Safety Management}

The APT accelerator and beam transport will use safety and machine-protection systems and administrative procedures similar to those that have become standard at large research accelerator facilities worldwide. These systems include:

Key lockout and tagout procedures for servicing energized equipment.

Key permit access to beam tunnels; hardwired interlock with accelerator run permit.

Sweeps, alarms, and scram switches for ensuring personnel clearance from beam areas.

Fast protect systems for rapid shutdown or termination of beam.

Activation protection systems for limiting or terminating beam operation when preset beam loss budgets are exceeded.

Personnel safety systems that prevent beam entry to locked-out areas, by means of triply redundant device interference.

Operator training and administrative procedures.

Using administratively independent personnel who are not under the control of operations staff to control access to the accelerator and beam channels.

\subsection{SILC Target ${ }^{*}$}

The full accelerator proton current passes through a beam expander and expansion chamber, and then through a thin window, composed of aluminum and cooling water. The beam, which at this point is spread over roughly $2 \mathrm{~m}^{2}\left(21 \mathrm{ft}^{2}\right)$, impacts on the face of the neutron source target. This source region is composed of 33 aluminum pressure tubes, which contain aluminum-clad lead pins cooled by $\mathrm{D}_{2} \mathrm{O}$. Most of the pressure tubes are about $30 \mathrm{~cm}$ (12 in.) in diameter, with an aluminum

\footnotetext{
- Section 3.2 is based on G. Van Tuyle, Project Manager, "Preliminary Topical Report for Revision-1 of a Preconceptual Design for the Spallation-Induced Lithium Conversion (SILC) Target for the Accelerator Production of Tritium (APT)," ATD/APT94-0008, Rev. 0, June 24, 1994.
} 
thickness of about $1 \mathrm{~cm}(0.4 \mathrm{in}$.). Each pressure tube contains a few hundred 1-cm- (0.4-in.-) diameter lead pins.

The LiAl blanket surrounds the neutron source, and captures nearly all neutrons created in the source. The LiAl plates are clad with aluminum and are cooled and moderated with light water. There is very little activation in the blanket region; thus the decay heat is very limited. The absence of significant decay heat in the blanket is important, since the tritium produced in the blanket is likely to be retained if the temperatures do not increase significantly during an accident.

To minimize the waste stream (especially lead), it is preferable to operate one target as long as possible. When target reload does become necessary, the beam is switched to the second target and the reload process can continue unrestricted for a few months, minimizing activation and exposure. Portions of the targets will be in modules, and some of the assembly and disassembly will be performed outside the target chamber.

The amount of lead in one target loading will suffice for several decades of operation. However, the aluminum cladding will likely force removal of the lead far more often, and we currently assume the lead is discarded at that time. Reprocessing and reuse of the lead is an option that requires evaluation. The present plan is to replace the LiAl after a one-year cycle and to replace the lead after two one-year cycles.

\subsubsection{Target Systems Design Description}

The SILC target system consists of the following elements: (a) Target Chamber, (b) Neutron Source, (c) Blanket Assemblies, and (d) Beam Expander Duct with integral window. These elements are discussed below. These target components are shown in exploded view in Figure 3-1.

The Target Chamber contains the target during operation and shutdown cooling prior to removal for tritium extraction and target component refurbishment/disposition. The chamber also contains the connections to the target cooling systems, shielding, and structural interfaces to the target components.

The Neutron Source is the neutron-generating portion of the target. The neutrons are generated via spallation reactions induced by the incident proton beam in an array of pressure tubes containing aluminum-clad lead rods cooled by heavy water.

The Blanket Assemblies and the Beam Expander Duct are the tritium-producing portions of the target. In the SILC design, there are two separate blanket assemblies: the U-Blanket and the LBlanket. Both blankets and the Expander Duct are based on the lithium-aluminum technology used at the Savannah River Site (SRS), and consist of aluminum-clad, lithium-aluminum plates cooled by light water.

The proton beam that ultimately impinges on the Source Array of the SILC Target is transported to the target chamber in a vacuum. The Beam Window is the terminus of the vacuum boundary. Protons enter the open end of the Expander Duct and exit through the Beam Window. 


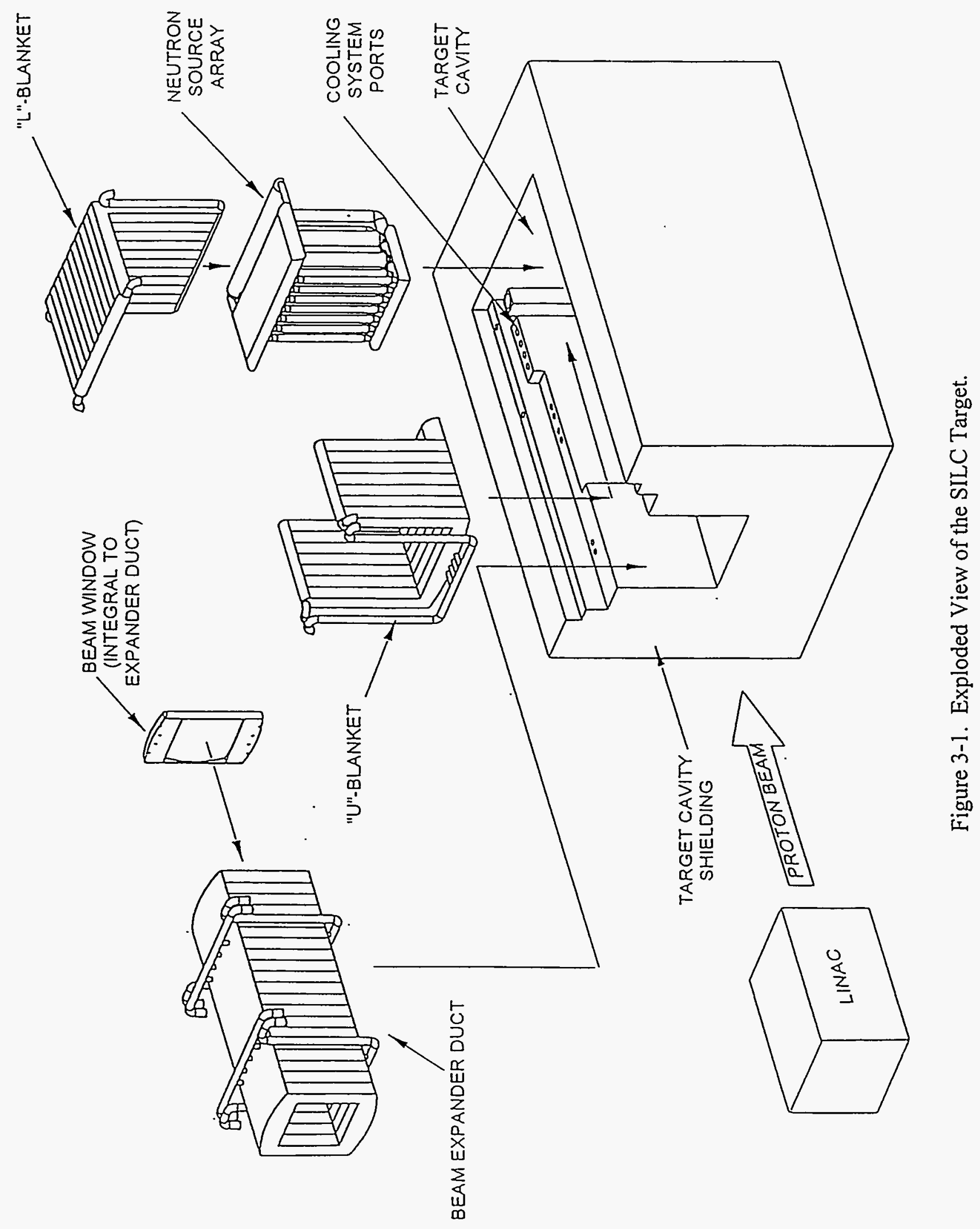


The above elements are configured as inseparable assemblies consisting of individually fabricated components joined to form an integral unit not normally capable of being disassembled for repair. This design approach minimizes material otherwise present in flanges, transfer tubes, etc. and contributes to overall system reliability by reducing seal connections.

\subsubsection{Source Array}

The Source Array of the SILC target consists of aluminum-clad lead rods with integrally extruded helical ribs to maintain uniform rod spacing when the rods are grouped into bundles. The three equally spaced ribs are integrally extruded with the clad material. Each rod is retained at the inlet end of the pressure tube by swaging of the inlet end fitting to a perforated capture plate. The other end of the rod is unrestrained, which allows the rods to expand freely in operation. These bundles are housed in aluminum pressure tubes of varying sizes that maintain the rod bundle arrangement and serve as a pressure boundary for the flow of the $\mathrm{D}_{2} \mathrm{O}$ coolant. The pressure tubes containing the rod bundles are arranged vertically in rows and joined top and bottom by coolant cross headers. The cross headers are in turn connected to two inlet and two outlet pipes. These pipes connect to the two loops of the cooling system. Coolant enters the pressure tubes in the array from the bottom and flows upward through the heated rod bundle, exiting at the top. Flow to the individual pressure tubes is controlled by an orifice at the inlet of each tube. In order to enhance the neutronic and thermalhydraulic performance of the Source Array, the number of source rods and their basic diameter (diameter over the cladding) varies from row to row. Table 3-1 presents basic rod bundle parameters on a row-by-row basis.

Table 3-1. Parameters for SILC Target Neutron Source Array.

\begin{tabular}{||c|c|c|c|c|c|c||}
\hline \hline ROW & $\begin{array}{c}\text { NUMBER OF } \\
\text { PRESSURE } \\
\text { TUBES }\end{array}$ & $\begin{array}{c}\text { PRESSURE } \\
\text { TUBE O.D. } \\
(\mathrm{mm})\end{array}$ & $\begin{array}{c}\text { NUMBER } \\
\text { OF RODS/ } \\
\text { TUBE }\end{array}$ & $\begin{array}{c}\text { BASIC } \\
\text { ROD DIA. } \\
(\mathrm{mm})\end{array}$ & $\begin{array}{c}\text { CORE } \\
\text { DIA. } \\
(\mathrm{mm})\end{array}$ & $\begin{array}{c}\text { ROD } \\
\text { PITCH } \\
(\mathrm{mm})\end{array}$ \\
\hline \hline 1 & 7 & 150.0 & 121 & 10.75 & 9.75 & 12 \\
\hline 2 & 6 & 219.5 & 265 & 10.75 & 9.75 & 12 \\
\hline 3 & 7 & 299.8 & 511 & 11.25 & 10.25 & 12 \\
\hline 4 & 6 & 299.8 & 511 & 11.50 & 10.50 & 12 \\
\hline 5 & 7 & 299.8 & 511 & 11.50 & 10.50 & 12 \\
\hline
\end{tabular}

\subsubsection{Blanket Assemblies}

The SILC target design, in addition to the Source Array, includes two Blanket Assemblies: the UBlanket and the L-Blanket. Figure 3-1 shows the relationship of the blanket assemblies to the other SILC target components. The blanket arrays consist of aluminum clad plates. Whereas the core material in the Source Array rods is elemental lead, the blanket plates have a solid core of $\mathrm{LiAl}$ alloy ( $\sim 3$ weight percent lithium max.) with Li- 6 enrichments in the range of 50 to 90 atom percent. These 
baseline parameters are governed by considerations of manufacturing, tritium retention, and tritium extraction. Blanket plates are housed in aluminum and the plates form narrow coolant passages. The coolant used in these passages is low temperature/low pressure light water to minimize the heavy-water inventory (and tritium production in the coolant) and to thermalize the neutron spectrum more efficiently to maximize the Li-6(n, )-tritium reaction. Manifolds are located at the top and bottom of the blanket assemblies. Coolant enters at the bottom and flows generally upward through the array. It is important to note that in this current target configuration it is virtually impossible for the proton beam to strike lithium-aluminum-containing plates.

\subsection{U-Blanket}

The U-Blanket consists of LiAl plates clad in commercially pure aluminum to envelop the sides and bottom of the Source Array. This configuration maximizes the absorption of neutrons streaming from the Source Array, and also supports the natural circulation cooling mode in the event of a lossof-pump accident or other events where forced-flow cooling is not available to the blanket.

\subsection{L-Blanket}

The L-Blanket consists of LiAl plates fabricated into an " $\mathrm{L}$ " shape to complete the encapsulation of the Source Array in blanket material. (Refer to Figure 3-1 for the relationship of the L-Blanket to the Source Array.) In this position, it serves to absorb neutrons streaming from the back and top of the Source Array to increase tritium production.

\subsubsection{Beam Expander Duct}

The Beam Expander Duct forms the vacuum boundary required for beam transport to the SILC target. The assembly consists of aluminum clad LiAl alloy plates fabricated into a hollow rectangular structure. (Refer to Figure 3-1 for the relationship of the Beam Expander Duct to the other components in the target chamber.) A significant fraction of the tritium production in the SILC target takes place in the Expander Duct LiAl plates.

\subsubsection{Coolant Systems Design Description}

The heat-removal systems for the SILC target consist of four sets of systems broadly defined as the source-cooling systems, the blanket-cooling systems, the window-cooling systems, and the target cavity flood system.

\subsubsection{Source Cooling Systems}

The source cooling systems (SCS) consist of systems that remove and transport the energy generated by the lead source to the ultimate heat sink. There are five systems: the source primary-cooling system (SPCS), the source secondary-cooling system (SSCS), the source circulating-water system (SCWS), the source residual primary-cooling system (SRPCS), and the source residual secondarycooling system (SRSCS). All of the systems contain two loops. The main cooling systems contain two $50 \%$ loops for normal operation where both trains are required to function. The loss of any one 
loop in the normally operating cooling systems will trip the accelerator. All of the residual heatremoval systems use two $100 \%$ loops, including the passive cooling capability included in the SPCS and the SSCS through a natural draft water-to-air heat exchanger; thus each of the residual heatremoval trains is redundant.

The SPCS provides forced circulation of the source coolant, $\mathrm{D}_{2} \mathrm{O}$, to remove the energy generated within the source assembly array. This energy is transferred to the SSCS under all conditions when $A C$ power is available, except when the system is depressurized. The SPCS contains $49 \mathrm{~m}^{3}(1730$ $\mathrm{ft}^{3}$ ) of $\mathrm{D}_{2} \mathrm{O}$. When the system is depressurized the beam must be shut down and the cooling transferred to either the passive system or the SPCS that is the active backup system. The passivecooling function is provided at the decay heat level through the natural circulation of the SPCS. Again the energy is transported to the SSCS, which is also naturally circulating, and then to the natural draft water-to-air heat exchanger. All component parts in contact with the source coolant are fabricated from highly corrosion-resistant materials designed to ensure a 40 -year minimum life for the SPCS when operated at the temperature, pressure, and water chemistry conditions expected in the SPCS.

The SPCS consists of two loops with each loop connected in parallel to the source inlet headers at the top and bottom of each row of source assemblies. Each loop removes approximately $50 \%$ of the generated energy, about $82 \mathrm{MW}$, and contains one pump, one heat exchanger, connecting piping, one pressurizer, one accumulator, and the associated instrumentation to meet the required single failure and redundancy criteria. The source coolant pumps are vertical canned motor units designed to circulate about $0.41 \mathrm{~m}^{3} / \mathrm{s}(6500 \mathrm{gpm})$ each. These pumps are expected to have an internally mounted inertial unit to extend the flow coastdown of the system to at least $45 \mathrm{~s}$, allowing the system to coast down to natural circulation in the event of a loss-of-offsite power or a station blackout. The two SPCS heat exchangers are horizontal, two-pass, straight tube and shell design with the source coolant, $\mathrm{D}_{2} \mathrm{O}$, on the tube side. The pressurizer is gas charged and the surge line serves as a return line for one loop of the source residual primary cooling system. The function of the pressurizer is to maintain the SPCS and the SRPCS in a subcooled state providing the required net positive suction head (NPSH) for the circulating pumps and to provide makeup in the event of a SPCS LOCA. Two code safety valves will be used on the pressurizer. The pressurizer is designed to not inject any of the charge gas into the system in the event of a LOCA or leak. One accumulator is provided to supply additional makeup in the event of a LOCA or leak. The accumulator contains a parallel, redundant set of check and stop valves in the surge line. It is also gas-charged and designed for operation such that the gas will not be injected into the source primary cooling system should a LOCA or leak occur. The surge line for the accumulator downstream of the check valves serves as the return line for the second loop of the SRPCS.

The SSCS provides forced circulation of light water, $\mathrm{H}_{2} \mathrm{O}$, to remove the energy generated within the source assembly array from the SPCS heat exchanger and deliver this energy to the source circulating water system under all conditions when $\mathrm{AC}$ power is available. A passive cooling function is also provided at the decay heat level through the SPCS. The energy is transported through natural circulation to the atmosphere by a natural draft water-to-air heat exchanger. The SSCS consists of two independent loops, each serving one heat exchanger for the SPCS and discharging the energy to the SCWS through the heat exchanger. 
The primary function of the SRPCS is to remove energy from the lead source assemblies when the beam is shut down and to cool down the source for replacement when the SPCS is not available for cooling by either normal operation or natural circulation. The SRPCS contains two loops, each capable of providing $100 \%$ of the cooling of about $1 \mathrm{MW}$ for the lead source following an accident. The loop contains $0.77 \mathrm{~m}^{3}\left(27 \mathrm{ft}^{3}\right)$ of $\mathrm{D}_{2} \mathrm{O}$. The loop is designed to be operable when the SPCS is depressurized because it is capable of cooling the lead source following a LOCA; thus the pump and heat exchanger are located low relative to the SPCS. Isolation valves are provided to isolate a loop should a break occur in that loop.

\subsubsection{Blanket Cooling Systems}

The blanket-cooling systems (BCS) are made up of those systems that remove and transport the energy deposited in the blanket assembly to the ultimate heat sink. These systems are the blanket primary-cooling system (BPCS), the blanket secondary-cooling system (BSCS), the blanket circulating-water system (BCWS), the blanket residual primary-cooling system (BRPCS), and the blanket residual secondary-cooling system (BRSCS). All of the systems contain two loops. The main cooling systems contain two $50 \%$ loops for normal operation where both loops are required to function. The loss of any one loop in the BPCS, BSCS, or BCWS will trip the accelerator. All of the residual heat-cooling systems include two $100 \%$ loops including the passive cooling capability of the BPCS and the BSCS to the natural draft water-to-air heat exchanger; thus the decay heat removal trains are redundant.

The BPCS provides forced circulation of the blanket coolant, $\mathrm{H}_{2} \mathrm{O}$, to remove the energy generated within the blanket assembly array. This energy is transferred to the BSCS under all conditions when $\mathrm{AC}$ power is available, except when the system is depressurized. The BPCS contains $17.7 \mathrm{~m}^{3}(625$ $\mathrm{ft}^{3}$ ) of $\mathrm{H}_{2} \mathrm{O}$. When the system is depressurized, the beam must be shut down and cooling transferred to either the passive system or the BRPCS. The blanket passive cooling function is provided at the decay heat level through the natural circulation of the blanket primary and secondary cooling system. Again the energy is transported to the BSCS, which is also naturally circulating through to the natural draft water-to-air heat exchanger. All component parts in contact with the blanket coolant are fabricated from highly corrosion-resistant materials designed to ensure a 40-year minimum life for the BPCS when operated at the expected temperature, pressure, and water chemistry conditions.

The BPCS consists of two loops with each loop connected in parallel to the blanket inlet headers at the top and bottom of each row of the blanket assemblies. Each loop removes approximately 50\% of the energy, about $13 \mathrm{MW}$, and contains one pump, one heat exchanger, connecting piping, one pressurizer, one accumulator, and the associated instrumentation to meet the required single failure and redundancy criteria. The blanket coolant pumps are vertical units designed to circulate about $0.28 \mathrm{~m}^{3} / \mathrm{s}(4500 \mathrm{gpm})$ each. These pumps are expected to have a flywheel unit attached to the motor shaft to extend the flow coastdown of the system to at least $45 \mathrm{~s}$, allowing the system to coast down to natural circulation in the event of a station blackout. The two BPCS heat exchangers are horizontal, two-pass, straight tube and shell design with the blanket coolant, $\mathrm{H}_{2} \mathrm{O}$, on the tube side. The pressurizer is gas-charged and the surge line serves as a return line for one loop of the BRPCS. The function of the pressurizer is to maintain the BPCS and the BRPCS in a subcooled state, providing the required NPSH for the circulating pumps and to provide makeup in the event of a 
BPCS LOCA. Two code safety valves will be used on the pressurizer. The pressurizer is designed to not inject any of the charge gas into the system in the event of a LOCA. One accumulator is provided to supply additional makeup in the event of a LOCA. The accumulator contains a parallel redundant set of check-and-stop valves in the surge line. It is also gas-charged and designed for operation such that the gas will not be injected into the blanket primary cooling system should a LOCA occur. The surge line for the accumulator downstream of the check valves serves as the return line for the second loop of the BRPCS.

The BSCS provides forced circulation of light water, $\mathrm{H}_{2} \mathrm{O}$, to remove the energy generated within the blanket assembly array from the BPCS heat exchanger and deliver this energy to the blanket circulating water system under all conditions when $\mathrm{AC}$ power is available. The passive cooling function is provided at the decay heat level through the BPCS. The energy is transported through natural circulation to the atmosphere by a natural draft water-to-air heat exchanger. All component parts are designed to ensure a 40-year minimum life for the BSCS when operated at the temperature, pressure, and water chemistry conditions expected in the BSCS. The BSCS uses two independent loops, each serving one BPCS heat exchanger and discharging the energy to the BCWS through one secondary heat exchanger.

The primary function of the BRPSC is to remove energy from the LiAl assemblies when the beam is shut down, in order to cool down the system for replacement or repairing when the blanket primary system is not available for cooling by either normal operation or natural circulation. The BRPCS contains $0.71 \mathrm{~m}^{3}\left(25 \mathrm{ft}^{3}\right)$ of $\mathrm{H}_{2} \mathrm{O}$. The BRPCS contains two loops, each capable of providing $100 \%$ of the cooling of the lithium-aluminum target assemblies following an accident, about $200 \mathrm{~kW}$ of cooling. The loop is designed to be operable when the BPCS is depressurized, as it is capable of cooling the LiAl assemblies following a LOCA.

\subsubsection{Window and Expander Cooling Systems}

The window-cooling systems (WCS) are made up of those systems that remove and transport the energy deposited in the accelerator window assembly to the ultimate heat sink. It is composed of the following three systems: the window primary-cooling system (WPCS), the window secondarycooling system (WSCS), and the window circulating-water system (WCWS). All of the systems contain two loops. Each loop provides $50 \%$ of the window cooling and one of the loops provides additional cooling for the expander tube assembly. Both systems are required to function (i.e., the loss of either loop in the cooling trains will result in an accelerator trip). Since the residual decay heat is very low, the passive cooling capability provided by the WPCS and the WSCS to their surroundings was considered to be adequate for residual decay heat cooling.

\subsubsection{Target-Cavity Flood System}

The target-cavity flood system (TCFS) is designed to support the cooling of the target in the event of a LOCA in the SPCS or BPCS. The system ensures that a break in any primary-cooling system inside the cavity will not result in loss of cooling for the systems. The system is sized to flood the target cavity in about $90 \mathrm{~s}$ following a signal for a LOCA when both trains of the system are open. The storage tank contains $24 \mathrm{~m}^{3}\left(848 \mathrm{ft}^{3}\right)$ of water. For redundancy, a third pipe train may be added 
between the tank and the cavity. The storage tank contains enough water to cover all of the headers

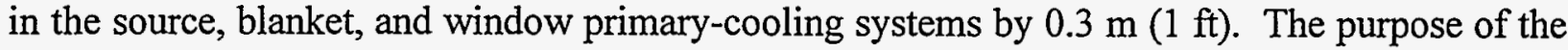
system is to cover any break that could result in the loss of passive or active cooling in any of the systems. To accommodate cleanup of the cavity, a drain pump is provided that can return the water to the storage tank. In conjunction with this forced return, a heat exchanger has been included that has the capability to remove about $1 \mathrm{MW}$ of energy, which is more than adequate for removal of the decay heat. The use of this pump and heat exchanger could serve as a backup for all of the decayheat-removal systems. The valves associated with each train are considered to be passive by today's standards as each valve has an associated source of energy for opening the valve, should that be required. Each train of the system may use a different motive source; for example, DC battery, pneumatic, or hydraulic. A $0.15-\mathrm{m}$ - (6-in.-) loop seal is used in the vent line that returns the displaced air to the tank in the event that the system is used. This seal is easily broken by the dumping head and the resulting gas flow. Its main purpose is to prevent radioactive gases in the vicinity of the target from being transported to the tank during normal power operation. The system components are considered to be safety-related; however, none of the components are a pressureretaining part of any primary cooling system boundary.

\subsubsection{Target Safety Systems Description}

There is very little decay heat in the LiAl blanket. Cooling is necessary if and only if the beam is on and there is externally driven heat production in the target. At the present stage of design, it is assumed that no achievable neutronic anisotropy can produce unacceptable heat loadings if normal cooling is operational. It is also assumed that the LiAl blanket must be protected from the proton beam. These assumptions mean that with the beam on the production blanket is presumed safe if (1) the beam is reasonably normal, (2) the lead target is not geometrically disturbed, and (3) the blanket is cooled with normal cooling; with the beam off, the blanket is safe independent of cooling. The following conditions would damage the blanket unacceptably, and would be presumed to lead to an in-confinement release: loss-of-blanket cooling, LOCA or loss-of-forced flow with concurrent failure to shut off the beam, or beam impingement on the LiAl blankets, regardless of cooling status. This means that the key elements of LiAl blanket protection are beam shutoff, invoked for loss-ofcooling or beam upsets, and normal cooling, which is essential only if the beam is on.

There may be significant decay heat in the lead target. Considerable normal cooling is necessary with the beam on, and auxiliary cooling is necessary with the beam off. The beam must meet isotropy requirements (peaking factor requirements) or unacceptable local heating will result regardless of cooling (beam must be tripped promptly if anisotropy occurs). Therefore, the lead target is safe if and only if the beam is off and at least one loop of cooling is operative (natural or forced circulation in one primary loop and its corresponding secondary loop), or the beam is on, within the control envelope, and normal cooling is operative. The present concept calls for mitigating a target LOCA by flooding the entire target cavity to a level above the break. Such an event would require replacement of the target in any case.

The beam is required to trip promptly if either the lead target or the LiAl blankets or Expander Duct suffers loss of cooling, either due to a LOCA or active system failures. The beam is required to trip promptly if beam parameters depart from acceptable values (e.g., focus, missteer). Abnormal 
radiation levels would be considered one indication of these. The beam is required to trip promptly on evidence of geometric disruption of either target or the window, or on evidence of abnormal confinement conditions. The beam will also be interlocked to many doors and other barriers for personnel protection, and may be interlocked to confinement status. These permissives are part of the scope of accelerator and confinement design.

\subsection{SILC Tritium Extraction*}

The overall process for extracting and purifying tritium for the SILC target consists of 13 process areas. These processes are described in this section.

\subsubsection{LiAI Plate Receiving and Spent-Melt Handling}

The LiAl plate receiving and spent-melt handling area is adjacent to the extraction furnace. The LiAl plates are received in bundles that are sized to fit the crucible. The bundles are placed in drying pits where they are dried with filtered, dry air that is then exhausted to the stack. After drying, the bundle is placed in a crucible that is then sealed and leak checked. The crucible is then placed in the furnace for extraction. Following extraction, the crucible containing the spent melt is removed from the furnace and placed in a secondary container for disposal.

\subsubsection{Extraction Furnace}

The vacuum extraction furnace system provides the heating capability required to release tritium, other hydrogen isotopes, and helium from the irradiated LiAl plates. A loaded crucible is placed in the retort of the extraction furnace. Following retort and crucible evacuation to the process stripper stack tank, a pressure rise rate is taken to confirm the integrity of the extraction system before beginning an extraction. The furnace is heated at a controlled rate to maintain an acceptable furnace pressure. The evolved gas is collected and analyzed to account for the tritium and helium from the rods. When the gas evolution has decreased, argon is added and the temperature is increased to melt the LiAl plates. After melting temperature has been maintained for an adequate time, the temperature is reduced, the crucible is evacuated, and a final pressure rise rate is taken to verify that the residual gas generation rate is acceptable before terminating the extraction.

\subsubsection{Gas Accountability}

The gas accountability system pumps the extraction gases from the crucible. The extraction gas is pumped through two uranium bed decomposers to convert water to element hydrogen isotopes. The uranium beds are heated to promote the reaction and prevent hydriding of the uranium. The gas is then collected in either one or two extraction tanks. These tanks are sized so that each can hold the gas from one extraction run without exceeding the maximum allowable operating pressure. Once

\footnotetext{
- Section 3.3 is based on G. Van Tuyle, Project Manager, "Preliminary Topical Report for Revision-1 of a Preconceptual Design for the Spallation-Induced Lithium Conversion (SILC) Target for the Accelerator Production of Tritium (APT)," ATD/APT94-0008, Rev. 0, June 24, 1994.
} 
the extraction gas has reached equilibrium, the tank is sampled and the amount of tritium and the composition of the extraction gas is determined.

\subsubsection{Inert-Separation System}

The inert-separation system separates hydrogen isotopes from other gases. The system normally receives feed from the accountability tanks. However, the system can also receive feed from product evacuation, load/unload stations, zeolite bed recovery, and the process-stripper systems. The products of this process are pure hydrogen isotopes and nearly tritium-free inert gas, which can be sent to the process-stripper system for release through the stack.

The inert-separation system consists of a flow-through, palladium/kieselguhr bed, feed-pump systems, two-stage palladium/silver diffuser, storage hydride beds, and draw-off pumping systems necessary to move the gas.

The flow-through bed provides for the bulk separation of hydrogen and nonhydrogen gases. The hydrogen is absorbed by the palladium; the nonhydrogen gas passes through and is fed into the downstream diffuser. The hydrogen isotopes diffuse through the heated diffuser tubes into the shell. All other gases remain in the tube and are collected in the by-product storage tanks. The nonhydrogen gas is sent through the process-stripper system that further reduces the tritium level and then, if the tritium level is acceptable, released through the stack.

The hydrogen isotopes absorbed in the bed are desorbed from the palladium by heating and stored in metal hydride beds. The hydrogen isotopes removed from the diffuser are also stored in metal hydride beds.

\subsubsection{Product Evacuation}

The product evacuation system is used to collect and store hydrogen isotopes from all sources within the extraction and purification facility. Four lanthanum-nickel-aluminum hydride storage beds are used to receive and store hydrogen isotopes of various compositions. The hydrogen isotopes are fed to the thermal-cycling-absorption process or the cryogenic distillation.

\subsubsection{Thermal Cycling Absorption Process}

Two options are being considered for separating hydrogen isotopes. The first is the thermal cycling absorption process (TCAP) system. The extracted gas, after the inert separation process, is separated by TCAP into a high-purity tritium product and a nearly tritium-free raffinate. The raffinate is released through the stack if the tritium level is confirmed to meet environmental requirements.

The TCAP is a semicontinuous gas chromatographic process. It consists of a palladium/kieselguhrpacked column, a kieselguhr-packed plug flow reverser (PFR), control volumes for feed, product, and raffinate, and storage beds for feed, product, and raffinate. The palladium/kieselguhr column is alternately heated and cooled during operation. The isotope mixture to be separated flows between the palladium/kieselguhr column and the PFR as a result of the alternate heating and 
cooling. Small amounts of feed, product, and raffinate are introduced to the midpoint of the column, and withdrawn from the bottom and top of the column, respectively.

\subsubsection{Cryogenic-Distillation System}

The second option for separating hydrogen isotopes is the cryogenic-distillation system. While the TCAP is a new process, cryogenic distillation is a conventional process and is particularly wellsuited for recovering low levels of tritium from protium and deuterium streams.

The system consists of a pumping system, storage tanks, a distillation column, recalculation system, and hydride beds. Feed for the cryogenic system is pumped from either zeolite bed recovery or from product storage.

The distillation column is made up of a packed column, a helium-cooled condenser at the top of the column and a helium-cooled and electrically heated reboiler at the bottom. The unit is insulated and enclosed in an evacuated copper vessel that is cooled with liquid nitrogen. The copper vessel is insulated and enclosed in an evacuated steel vacuum jacket. The gas enters the column either by pumping (hydride pump) or by being drawn into the condenser due to the lower temperature and pressure in the reboiler (cryopumping). As the batch progresses, heat is added to the reboiler vaporizing the mixture. At the completion of the batch, the gases are drawn off of the still by controlling the temperatures at the respective boiling points of the desired gases. The gases are then stored in tanks or hydride storage beds.

\subsubsection{Load/Unload Station}

This system is capable of loading and unloading all current types of shipping containers and portable hydride beds. A product will be analyzed before loading and after unloading.

\subsubsection{Glovebox-Stripper System}

There will be two glovebox-stripper systems: primary and secondary. The primary gloveboxstripper system continuously recycles the glovebox atmosphere from all the gloveboxes to equipment that will remove hydrogen isotopes, oxygen, and water vapor. The purpose of the system is to control the concentrations of tritium in the glovebox atmosphere to as low a level as possible.

The secondary glovebox-stripper system is the same design as the primary system and is normally in a standby operating condition. It will process gas from gloveboxes when a tritium release has occurred and serves as a spare primary system.

\subsubsection{Purge-Stripper System}

The purge-stripper system performs the final tritium stripping from the glovebox gas before the gas is released from the stack. It has two functions: to receive gases from the primary stripper system for the purpose of controlling the pressure and oxygen level in the gloveboxes, and to remove gases from the air locks of the gloveboxes when the air locks are used. 
This system consists of three beds filled with palladium deposited on zeolite and two sets of mechanical pumps. The three beds are connected in series but only two are on-line at any given time. The other bed is either in standby or is being regenerated. The palladium catalyzes the oxidation of tritium and the zeolite absorbs the water.

\subsubsection{Process-Stripper System}

The process stripper removes tritium from process waste streams by oxidizing elemental and other forms of hydrogen isotopes and absorbing the oxides on molecular sieves before exhausting the effluent gas to the atmosphere. Process waste gases and the by-product from the purification operation are accumulated in tanks. These gases are sent through the process-stripper system to the stack.

\subsubsection{Zeolite Bed Recovery System}

The zeolite bed recovery system reduces water desorbed from the zeolite beds of the primary, secondary, process, and purge-stripper systems to elemental hydrogen. When a zeolite bed becomes saturated, it is isolated and valved into a recovery loop. Flow is established through the zeolite bed being desorbed to the recovery systems. Heat is applied at a controlled rate that drives the water from the zeolite bed. The vapor-laden carrier gas is then processed through a uranium bed to crack the waters. The gas flows through a moisture meter and flow meter, through the pumping system and back to the zeolite bed. Circulation is maintained until all of the water has been driven from the zeolite bed and has been cracked by the uranium bed.

\subsubsection{Exhaust Stack System}

Exhaust from the heating, ventilation, and air conditioning (HVAC) system, the purge and process strippers, and the stackable discharge from hydrogen separation systems will exit the facility through an exhaust plenum to a stack.

\subsection{He-3 Target ${ }^{*}$}

The proton beam from the APT accelerator is directed towards one of two separate target/blanket modules. One module is in operation while the other is in maintenance or standby. Each module has separate cooling loops for their respective targets and moderators and, except for sharing the He$3 /$ tritium-separation equipment, operate independently.

The target/blanket is comprised of a centrally located tungsten neutron source, a surrounding lead neutron multiplier, and a surrounding heavy-water moderator. He-3 gas is circulated through the neutron source assembly (NSA) and the moderator. A schematic of the target module is shown in Figure 3-2. The proton beam enters the tungsten neutron source from the side in the horizontal plane.

\footnotetext{
- Section 3.4 is based on Los Alamos National Laboratory, "APT ${ }^{3} \mathrm{He}$ Target/Blanket Topical Report," LA-CP-
} 94-27, Revision 1, Vol. 1, March, 1994. 


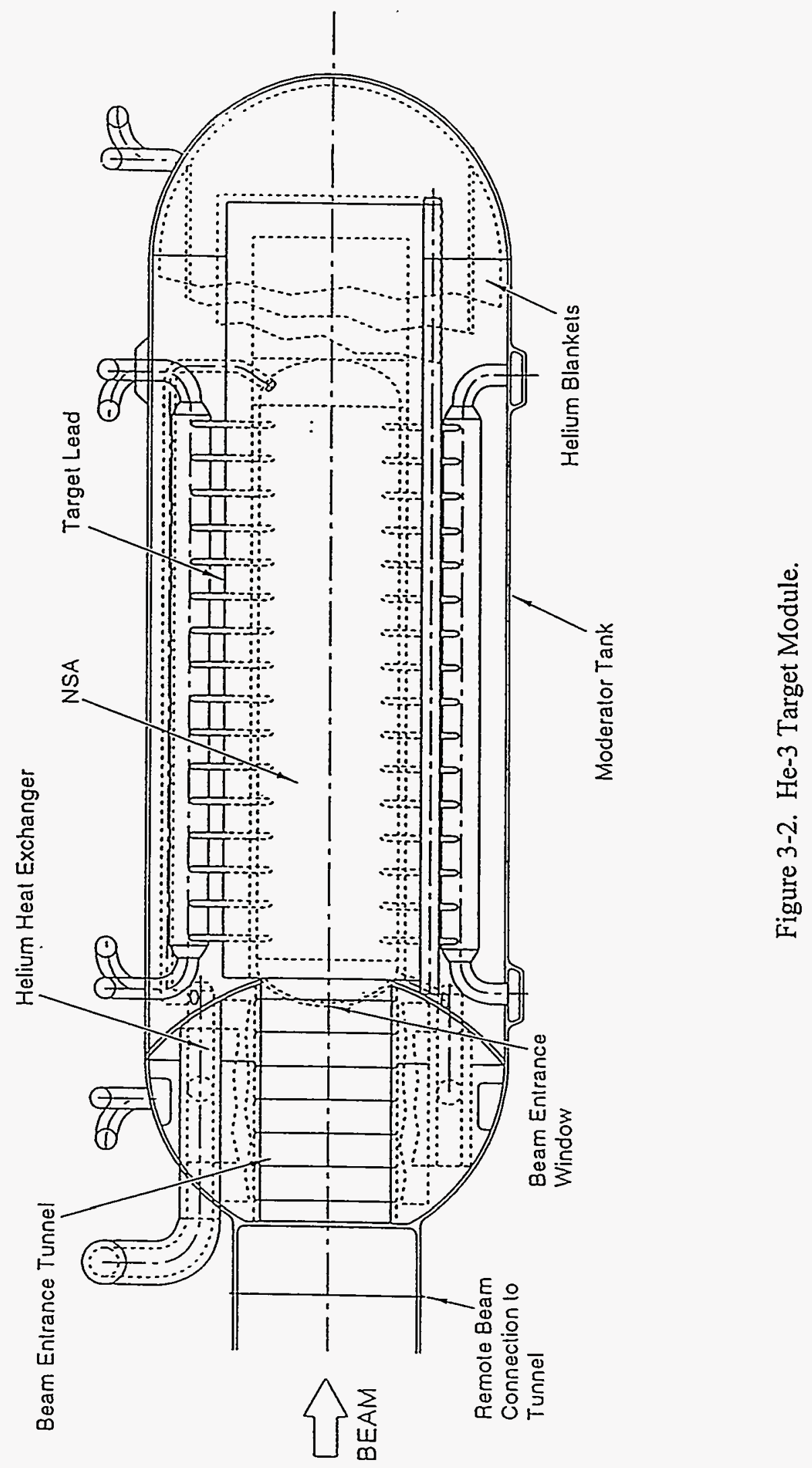


The neutron source, lead, moderator, and other structures are contained in a tank. He-3 is circulated in the heavy-water blanket where the production of tritium takes place through neutron capture. The tungsten neutron source is made of solid rods that are cooled with heavy water. Lead is used as a neutron multiplier. The preconceptual design of the target lead has focused on an unclad, stackedplate concept. The proton beam that strikes the tungsten neutron source is shaped into an approximately rectangular spatial pattern with a nearly flat intensity profile. The beam spot size is $42 \times 91 \mathrm{~cm}(16.5 \times 35.8 \mathrm{in}$. $)$. The He-3 is circulated through the blanket in aluminum tubes, and a sidestream is continually removed for separation, keeping the tritium content at a low level.

To meet the system availability requirement of $75 \%$ or greater, the design criteria evolved to the use of two target/blanket modules. At any given time, one module will be in production and one will be in retargeting or standby, thereby increasing the potential availability. The mechanical design of the target module provides for rapid retargeting, which can occur shortly after beam shutdown. Retargeting can be rapidly performed by a complete changeout of an entire target module structure. More complex operations such as assembly, disassembly, and target lead recovery and reuse can be performed off-line. The design allows readily operable remote retargeting connections with negligible irradiation effects for high integrity and reduced exposure. The design also allows recovery and reuse of most of the target lead for mixed waste minimization.

The target module is designed as a separate assembly that easily can be removed and replaced during a routine maintenance period. Based on existing proton irradiation experience, the Inconel structures that house the tungsten neutron source should provide 600 days of service at the expected proton fluxes. The target/blanket assembly consists of several components: tungsten rod bundles, a helium vessel, lead, He-3 blanket pipes, and a moderator tank. There are a total of 88 tungsten rod bundles arranged in alternating rows of five bundles in one row and six bundles in the next for a total of 16 rows. Rod bundle dimensions are based on a nominal rod diameter of $0.3175 \mathrm{~cm}(0.125 \mathrm{in}$.) and a nominal wire diameter of $0.1016 \mathrm{~cm}$ ( $0.040 \mathrm{in}$.). Rod and wire sizes were varied by position in the rows with smaller rods used in the higher power density front end rows where the beam strikes first and larger rods used in the lower power density back end rows. The Inconel helium vessel that provides the helium environment for the rod bundles is $118 \mathrm{~cm}$ (46.46 in.) in diameter by $4.5 \mathrm{~m} \mathrm{(177}$ in.) long with a 0.318 -cm- (0.125-in.-) thick wall. A $30-\mathrm{cm}-(11.8$-in.-) thick lead cover is located outside of the helium vessel.

Surrounding the lead is a thin annulus of $\mathrm{He}-3$ contained in aluminum tubing, a $\mathrm{D}_{2} \mathrm{O}$ moderator, another annulus of $\mathrm{He}-3$, a second $\mathrm{D}_{2} \mathrm{O}$ moderator, and a third annulus of He-3. Neutrons are moderated to near thermal energies in the $\mathrm{D}_{2} \mathrm{O}$. Tritium is produced through neutron capture in He-3 that is circulated and processed continually.

The moderator tank is a large vessel holding $\mathrm{D}_{2} \mathrm{O}$ in which the neutron source operates. A safety strategy has also been adopted for using the moderator tank and primary coolant piping outside of the moderator tank as a highly reliable radionuclide retention boundary that will meet the requirements for an American Society of Mechanical Engineers (ASME) Section III, Class I pressure boundary. 
The window provides the pressure boundary between the vacuum of the accelerator and the 2.1-MPa (300-psia) helium gas. The window is a double-walled Inconel 718 structure, and is cooled by $\mathrm{D}_{2} \mathrm{O}$ flowing between the walls. The tungsten window and moderator tank have the same cooling system that is described below.

\subsubsection{Target/Blanket Heat-Removal Systems}

The target/blanket heat-removal systems consist of three separate and independent heat-transport systems that are used to remove the thermal energy. These systems are the tungsten heat-transport systems (THTS), the moderator-tank heat-transport systems (MTHTS), and the He-3 heat-transport systems (HHTS). Together, these individual systems remove the thermal energy deposited in various components under normal operations and provide cooling capability for anticipated operational occurrences (AOOs), design basis events (DBEs), and selected beyond design basis events (BDBEs) for the APT target/blanket system. The target/blanket heat-removal systems are based on the "defense-in-depth" principle and utilize both active and passive cooling systems with redundancy to provide assurance that important safety functions are achieved.

The total beam power entering the window that separates the accelerator from the target module is $200 \mathrm{MW}$. Of the $200 \mathrm{MW}$ total, $148.8 \mathrm{MW}$ are deposited in the tungsten rod bundles, axial and radial lead regions, He-3, $\mathrm{D}_{2} \mathrm{O}$ moderator and coolant, Zircaloy- 4 in the backstop, and various structural components. The remaining beam power consists of $3.5 \mathrm{MW}$ that leak out of the moderator tank to the surrounding structures and shielding, $2.7 \mathrm{MW}$ to neutrinos, and $45.0 \mathrm{MW}$ that are used in the nuclear separation process (binding energy). Table 3-2 shows a further breakdown of how the 200-MW-beam is deposited in various regions.

Table 3-2. Beam Energy Deposition Summary for the He-3 Target.

\begin{tabular}{|c|c|}
\hline REGION & MW \\
\hline \hline Tungsten Rod Bundles & 76.7 \\
\hline Lead & 37.4 \\
\hline Heavy Water & 6.0 \\
\hline He-3 & 4.4 \\
\hline Zircaloy-4 in Backstop & 15.5 \\
\hline Structures Inside Tank & 8.8 \\
\hline Structures Outside Tank & 3.5 \\
\hline Neutrinos & 2.7 \\
\hline Nuclear Separation Process (Binding Energy) & 45.0 \\
\hline TOTAL ENERGY & 200.0 \\
\hline \hline
\end{tabular}




\subsubsection{Tungsten Heat-Transport System}

The tungsten rod bundle dimensions are based on a nominal rod diameter of $0.318 \mathrm{~cm}(1 / 8 \mathrm{th}$ in.) that are wrapped with a nominal $0.102-\mathrm{cm}-(0.04-$ in.-) diameter wire to provide proper spacing in the bundle. In the bundle design, the wire wraps around each rod four times and is continuously attached to the rod over its 96-cm (37.8-in.) length. The rods are arranged into an 88-rod bundle with a hexagonal pitch determined by the wire wrap. The rod bundle is contained in an Inconel duct that is $0.076 \mathrm{~cm}(0.030 \mathrm{in}$.) thick.

The THTS design includes three coolant systems that are connected in series. These are the tungsten primary-coolant system (TPCS) or primary-coolant system, the tungsten secondary-coolant system (TSCS), and the tungsten circulating-water system (TCWS). The TSCS provides an intermediate barrier between the TPCS and the environment to reduce the probability of radionuclide leakage from the plant to the environment.

The TPCS consists of two independent heat-transfer loops connected to the inlet and outlet plenums of the tungsten rod bundles. Each loop is designed to remove $50 \%$ of the steady-state heat load, but only one loop in natural circulation is required to remove the decay heat. Each loop contains one hot leg primary coolant pump, one horizontal heat exchanger, and associated piping. The hot leg pump location maintains a higher pressure on the primary side of the heat exchanger and prevents secondary-coolant system light water leakage into the $\mathrm{D}_{2} \mathrm{O}$ primary-coolant system from heat exchanger tube failures. A gas-charged pressurizer is connected to one TPCS loop to provide (a) for pressure and $\mathrm{D}_{2} \mathrm{O}$ volume control and (b) for tungsten target flooding in the event of a LOCA. An accumulator is connected to the other TPCS loop to maintain the tungsten target in a flooded condition in the event of a LOCA. Each of the primary pumps is equipped with a flywheel on its motor that is capable of providing coastdown flow for approximately $45 \mathrm{~s}$ and a smooth transition to natural circulation flow if pumping power is lost. Natural circulation is provided in the TPCS by the thermal center elevation difference between the primary heat exchangers and the tungsten rod bundles.

The TSCS consists of two independent heat-transfer loops that circulate light water though the primary heat exchangers and reject the heat to the TCWS via the secondary heat exchangers. Each loop is designed to remove $50 \%$ of the steady-state heat load, but only one loop in natural circulation is required to remove the decay heat. Each loop contains a secondary coolant pump, a heat exchanger, a surge tank, and associated piping. Each of the pumps is equipped with a flywheel on its motor that is capable of providing coastdown flow for approximately $45 \mathrm{~s}$ and a smooth transition to natural circulation flow if pumping power is lost. Natural circulation is provided by the thermal center elevation difference between the secondary heat exchangers and the primary loop heat exchangers.

The secondary-coolant system is designed to remove the rod bundle decay heat during a Station Blackout event with or without a LOCA. Cooling of the primary loop is accomplished by maintaining secondary flow through the primary heat exchangers by natural circulation in conjunction with natural circulation flow in the secondary loop. The secondary loop water is cooled by air-cooled heat exchangers with naturally induced air flow. 
The TCWS removes the heat from the secondary-coolant system during normal operations and transfers it to the cooling tower system. The TCWS serves no safety function.

The tungsten primary residual heat-removal system (TPRHRS) actively removes decay heat from the target rod bundles and the primary target coolant system when the TPCS or TSCS is unavailable or ineffective for providing heat-removal capability. The TPRHRS contains two loops, each capable of providing $100 \%$ of the cooling of the tungsten target following an accident. The TPRHRS is powered by onsite $\mathrm{AC}$ power and only one fluid loop is required to perform the range of design basis decay-heat-removal functions. Two independent fluid loops are provided to prevent the complete loss of TPRHRS function assuming a single failure and loss of function in one loop. The residual heat-removal system takes suction from the tungsten-rod-bundle outlet plenum and recirculates cooler coolant to the rod-bundle inlet plenum. The TPRHRS transfers rod-bundle decay heat to the tungsten secondary residual heat-removal system (TSRHRS) via the TPRHRS heat exchangers. The TSRHRS transfers the decay heat to the environment via an air blast water-to-air heat exchanger.

If the TPRHRS is, or becomes, unavailable during an accident condition, backup passive decay heat removal by natural circulation occurs in the TPCS, the TSCS, and the water-to-air-cooled heat exchangers. The design for passive decay heat removal by natural circulation is provided by establishing sufficient thermal center elevation differences between the rod bundles, the primary heat exchangers, the secondary heat exchangers, and the water-to-air heat exchangers. The natural circulation coolant systems are also designed with low system pressure drops. No operator action, valve motion, or active system responses are required to accomplish the transition to natural circulation decay heat removal.

The heavy-water-accumulator system (HWAS) is a passive system that provides the initial makeup of rod-bundle cooling water following a LOCA. The pressurizer also responds in conjunction with the HWAS to provide initial makeup water.

The HWAS consists of one tank that connects directly to the rod-bundle inlet plenum via the TPCS cold-leg line. The tank contains heavy water with a gas overpressure approximately $103 \mathrm{kPa}(15 \mathrm{psi})$ below the normal operating pressure of the rod-bundle inlet plenum. Parallel check valves are provided in the discharge path to prevent system failure in case of a single check valve failure. A single, normally open, motor-operated valve is used for isolation during outages.

In the event of TPCS depressurization, the heavy water in the accumulator is forced into the rodbundles by the expansion of the gas in the accumulator tank and maintains adequate cooling until the TPRHRS is activated or natural circulation decay-heat removal is established. The tank is sized such that the initial gas volume expands before the tank empties, thus precluding noncondensible gas injection into the TPCS. The discharge lines to the inlet plenum are sized to permit low inertial acceleration pressure drop and low frictional pressure drop. The HWAS is passive in that no operator action is required and no electrical power is necessary to perform its safety function. 


\subsubsection{Moderator Tank Heat-Transport System}

The Moderator Tank Heat Transport Systems (MTHTS) are made up of those systems that (1) remove the heat generated within the moderator tank, including the window, the target lead, the moderator, the proton beam backstop region, the He-3 blanket tubes, the He-3 in the NSA, and the moderator tank structural components and (2) transfer it to the environment, which is the ultimate heat sink. The following five systems are included: the Moderator Primary Coolant System (MPCS), the Moderator Secondary Coolant System (MSCS), the Moderator Circulating Water System (MCWS), the Moderator Primary Residual Heat Removal System (MPRHRS), and the Moderator Secondary Residual Heat Removal System (MSRHRS): All of the systems contain two loops. The main cooling systems contain two $50 \%$ loops for normal operation where both loops are required to function while the accelerator is operating. The loss of any one loop in the MPCS, the MSCS, or the MCWS will result in an accelerator trip. The MPRHRS contains two $100 \%$ capacity primary coolant loops for actively removing residual heat from the moderator tank. Each of the MPRHRS coolant loops is capable of removing the total residual heat if the other loop is not available. The MPCS and the MSCS also provide a passive cooling capability for removing moderator tank residual heat through a natural draft water-to-air heat exchanger located in the MSCS. Each primary loop and its associated secondary loop can passively remove the total residual heat load. Thus the active and passive residual heat removal trains are fully redundant.

\subsubsection{He-3 Heat-Transport System}

The He-3 Heat Transport Systems (HHTS) consist of those components that remove the energy generated in the He-3 in the neutron source assembly and blankets and transport it to the moderator in the moderator tank. It also contains the lines that (1) let down the He-3 containing the produced tritium to the Tritium Extraction Facility and (2) compress and return the He-3 from the Tritium Extraction Facility to the neutron source assembly and blankets. It is composed of the following two systems: NSA Coolant System (NCS) and Blanket Coolant System (BCS). All of the systems consist of one loop. The NCS and BCS transfer the He-3 thermal energy to the MTHTS which transports the energy to the environment, which is the ultimate heat sink.

\subsubsection{Plant Protection and Inherent Safety Features}

There are many passive and active systems that are independent, and operate on different physical parameters. These systems can mitigate potential accidents, protect the plant, and prevent radioactive releases to the environment. Below is a list of inherent safety features and important engineered systems:

There is no fissile material; a nuclear chain reaction is not possible.

The target/blanket system has a small radioactive inventory and heat source compared with a nuclear reactor.

The tungsten target and moderator are cooled with independent heat-transport loops providing containment of spallation products in the event of a target LOCA. 
The cooling systems for the tungsten and moderator easily can remove decay heat through natural circulation without any pumped flow. Also, the window easily can be cooled with radiation heat transfer alone during a LOCA.

Sensors continually monitor cooling loop pressure, temperature, pressurizer level, etc. There are several independent signals, any one of which can rapidly shut off the proton beam. The accelerator beam also can be shut off very quickly (less than $1 \mathrm{~ms}$, given a trip signal). The protection system features should put initiating events "with failure to trip beam" in the residual risk category.

A heavy-water accumulator is connected to the cooling loop with passively activated check valves that allow water flow into the target flow loops in the event of large pipe breaks.

The entire target assembly sits in a tank of heavy-water moderator that in itself is a large heat sink, and will help cool the target rods in the event of large coolant conduit failure.

All of the coolant loops are at low pressure (less than $1.72 \mathrm{MPa}(250 \mathrm{psi})$ ) and at low specific energy so that the confinement system will not be subjected to any significant pressure increase in the event of large pipe breaks.

The tungsten is a high-temperature material that melts at $3410 \mathrm{C}(6170 \mathrm{~F})$. The Inconel structure that houses the tungsten rod-bundles, and the Inconel window material is also a high-temperature, high-strength alloy.

The decay heat after 600 days of operation, immediately following beam trip, is about $0.9 \%$ of full power. This reduces to about $0.34 \%$ after one day, and $0.015 \%$ after one year.

\subsection{He-3 Target Tritium Extraction ${ }^{*}$}

The extraction and purification of tritium produced in the He-3 target is discussed in this section. All of the tritium extraction and purification processes are contained in a Process Building that will satisfy DOE-mandated seismic, tornado, and safety requirements for facilities handling radioactive materials.

\subsubsection{Target Extraction}

The target-extraction system processes a He-3 sidestream using a palladium membrane diffuser to recover hydrogen isotopes of greater than 99.9 mole \% purity. This stream may be sent directly to the isotope-separation system to yield protium, deuterium, and tritium products.

- Section 3.5 is based on Los Alamos National Laboratory, "APT Tritium Extraction Facility Technical Report," LA-UR-93-3113, September 1993. 


\subsubsection{Isotope Separation}

The isotope-separation system is a cryogenic distillation system that can process hydrogen isotopes recovered in the target-extraction system to produce $\mathrm{T}_{2}, \mathrm{D}_{2}$, and $\mathrm{H}_{2}$ products. Product purity should be greater than 99.0 mole $\% \mathrm{~T}_{2}$. An essentially tritium-free $\mathrm{H}_{2}$ stream is sent to the gaseous waste system for final cleanup. The isotope-separation system is also capable of processing small recycle streams for the gaseous-waste systems that contain low concentrations of $T_{2}$.

\subsubsection{Tritium Storage}

The tritium-storage system uses hydrogen-getter bed technology to store product tritium in a solid matrix. The maximum $T_{2}$ inventory in any single bed is limited to $120 \mathrm{~g}(0.26 \mathrm{lb})$. The tritium storage beds may also be used to strip hydrogen isotopes from the $\mathrm{He}-3$ before transfer to storage.

\subsubsection{Tritium Loadout}

Product tritium will be shipped from the APT facility in Department of Transportation approved shipping containers. Regenerable getter beds may be used for product shipment to further reduce the risk of tritium release during potential shipping accidents.

\subsubsection{Gaseous Waste}

The gaseous-waste system processes the tritium-processing waste and atmosphere from secondary containments to recover residual tritium. The gaseous-waste system oxidizes hydrogen isotopes and their compounds to produce water that is then recovered by molecular sieve dryers. The output of the gaseous-waste system may be released through the stack with no significant environmental impact.

\subsubsection{Process Containment}

All process and waste systems are housed in enclosures designed to contain and allow recovery of tritium leaks. These enclosures are maintained under negative pressure to prevent leakage of contaminated gases to the Process Building. The enclosure atmosphere is discharged to the gaseouswaste system to recover tritium.

\subsubsection{Room Detritiation}

The room detritiation systems provide the capability to clean up the Process Building atmosphere in the event of an accidental release of tritium to the Process Building.

\subsubsection{He-3 Load-in and Storage}

The He-3 load-in system will receive and unload He-3 for use in the APT Target/Blanket facility. He-3 will be shipped to the APT complex as bottled gas. Tankage will be provided to store He-3 feed makeup. Capacity will also be provided to accommodate the target/blanket-system inventory 
during normal shutdown for maintenance or to collect the inventory in the event of an emergency shutdown.

\subsubsection{Monitoring and Control}

Process systems are monitored and controlled by local computers dedicated to subsystem operations. All systems will fail to a safe status in the event of loss-of-control. A central computer has supervisory capability over local computers and the capability to independently monitor and control the critical safety functions of each processing system. The central computer system will also monitor facility support systems.

\subsubsection{Analytical Laboratory}

A laboratory will be provided for routine analysis of process samples and potentially contaminated materials. Capability for real time, online analysis of process streams will also be included. 
Intentionally Left Blank 


\subsection{RESOURCE NEEDS DURING CONSTRUCTION}

Several resources are needed during the construction of an APT facility such as materials, energy, and personnel. This section describes the derivation of estimated requirements for construction. Section 4.1 addresses the resources necessary to construct the accelerator. Sections 4.2 and 4.3 address the resource needs for the SILC target and tritium extraction for that target, respectively. The resource needs for the He-3 target and its tritium extraction appear in Sections 4.4 and 4.5. Section 4.6 deals with the needs for the balance-of-plant that include all requirements except for those specifically for the targets, the accelerator, and the tritium-extraction systems.

\subsection{Construction Resource Needs for the Accelerator}

The estimates for the construction needs for the accelerator (Table 4-1) were made based on existing accelerators [4]. The primary resources needed for construction include carbon steel and stainless steel, copper, klystrons, ion pumps, and waveguides. The quantities of carbon, stainless steel, and copper are only for the accelerator and are not included in the tabulation for the balance-of-plant. The number of klystrons required consists of $3781-\mathrm{MW}$ units and six 100-kW units.

Table 4-1. Construction Resource Needs for the Accelerator.

\begin{tabular}{|c|c|}
\hline RESOURCE & QUANTITY \\
\hline \hline Carbon Steel & $400 \mathrm{Mg}(882,000 \mathrm{lb})$ \\
\hline Stainless Steel & $130 \mathrm{Mg}(286,600 \mathrm{lb})$ \\
\hline Copper & $860 \mathrm{Mg}(1,896,000 \mathrm{lb})$ \\
\hline Klystrons & 384 Units \\
\hline Ion Pumps & 460 Units \\
\hline Waveguide & $10,000 \mathrm{~m}(32,800 \mathrm{ft})$ \\
\hline
\end{tabular}

\subsection{Construction Resource Needs for the SILC Target}

The construction resource needs for the SILC target were estimated based on current design information [2]. The quantities shown in Table 4-2 are for the initial construction and filling with $\mathrm{D}_{2} \mathrm{O}$ of two SILC targets. Data do not include the quantities needed for heat exchangers, pumps, valves in the primary cooling loops, and coolant piping. These are included in the balance-of-plant resource needs (see Section 4-6). 
Table 4-2. Construction Resource Needs for the SILC Target.

\begin{tabular}{|c|c|}
\hline \hline RESOURCE & QUANTITY \\
\hline \hline Aluminum in target & $80 \mathrm{Mg}(177,000 \mathrm{lb})$ \\
\hline Aluminum-structural & $15 \mathrm{Mg}(33,500 \mathrm{lb})$ \\
\hline Lithium & $2.3 \mathrm{Mg}(5070 \mathrm{lb})$ \\
\hline Lead & $44 \mathrm{Mg}(97,000 \mathrm{lb})$ \\
\hline $\mathrm{D}_{2} \mathrm{O}$ & $66 \mathrm{Mg}(145,000 \mathrm{lb})$ \\
\hline
\end{tabular}

\subsection{Construction Resource Needs for the SILC Tritium-Extraction System}

The construction needs for the SILC target tritium-extraction system were estimated by adding the material needed for construction of the furnace and associated equipment to the material needed for construction of the He-3 tritium-extraction system [5]. The requirements are tabulated in Table 4-3.

Table 4-3. Construction Resource Needs for the SILC Target Tritium-Extraction System.

\begin{tabular}{|c|c|}
\hline RESOURCE & QUANTITY \\
\hline \hline Carbon Steel & $20 \mathrm{Mg}(44,100 \mathrm{lb})$ \\
\hline Stainless Steel & $<28 \mathrm{Mg}(<61,700 \mathrm{lb})$ \\
\hline Copper & $<2 \mathrm{Mg}(<4410 \mathrm{lb})$ \\
\hline
\end{tabular}

\subsection{Construction Resource Needs for the He-3 Target}

The construction resource needs for the He- 3 target were estimated by calculating the masses for the components and materials inside the moderator tank boundary (including the moderator tank) of the solid materials and the heavy water for two APT target modules. The components considered include the rod bundles, the inlet and exit tubes, the target helium chamber, the inlet and exit plena, the inlet and exit piping, the moderator tank wall, the window, the beam tube, helium tubes in the moderator tank and for the target chamber, the helium heat exchanger and piping, the backstop, the support structure, the radial lead, and the piping associated with radial lead and backstop [6]. The estimated values for lead, stainless steel, aluminum, Inconel, tungsten, and $\mathrm{D}_{2} \mathrm{O}$ are shown in Table 4-4. The values in Table 4-4 do not include the quantities needed for heat exchangers, pumps, valves in the primary cooling loops, and the coolant piping. These are included in the balance-of-plant construction resource needs in Section 4.6. The expected lifetime of most of the lead blanket is 40 years, but $13,550 \mathrm{~kg}(29,950 \mathrm{lb})$ will be replaced after each 2.2-year-target cycle. The amount of $\mathrm{D}_{2} \mathrm{O}$ shown is for both the moderator and the primary loop, and it is assumed to be shared between targets. In addition, the He-3 mass in the He-3 target chamber, in the tubes in the moderator tank, in the aluminum structure in the backstop, in the He-3 heat exchanger, and in the pipes supplying 
and removing $\mathrm{He}-3$ for cooling from the target chamber was estimated. The assumption was made that all of the $\mathrm{He}-3$ is at $400 \mathrm{~K}$. The $\mathrm{He}-3$ in the moderator tank and the backstop aluminum contain $\mathrm{He}-3$ at $689.5 \mathrm{kPa}$ (100 psia), while the target chamber, heat exchanger, and connecting pipes contain $\mathrm{He}-3$ at an average pressure of $2068 \mathrm{kPa}$ (300 psia). [6] The masses of $\mathrm{He}-3$ and $\mathrm{D}_{2} \mathrm{O}$ for initially filling one target is shown in Table 4-4.

Table 4-4. Construction Resource Needs for the He-3 Target.

\begin{tabular}{|c|c|}
\hline RESOURCE & QUANTITY \\
\hline \hline METALS (for two targets) & \\
\hline Lead & $141.6 \mathrm{Mg}\left(3.12 \times 10^{5} \mathrm{lb}\right)$ \\
\hline Stainless Steel & $33.2 \mathrm{Mg}\left(7.33 \times 10^{4} \mathrm{lb}\right)$ \\
\hline Aluminum & $11.0 \mathrm{Mg}\left(2.42 \times 10^{4} \mathrm{lb}\right)$ \\
\hline Inconel & $9.9 \mathrm{Mg}\left(2.19 \times 10^{4} \mathrm{lb}\right)$ \\
\hline Tungsten & $3.0 \mathrm{Mg}\left(6.51 \times 10^{3} \mathrm{lb}\right)$ \\
\hline Zircaloy-4 & $8.7 \mathrm{Mg}\left(1.91 \times 10^{4} \mathrm{lb}\right)$ \\
\hline LIQUIDS (for one target) & \\
\hline $\mathrm{D}_{2} \mathrm{O}$ & $86.2 \mathrm{Mg}\left(1.90 \times 10^{5} \mathrm{lb}\right)$ \\
\hline He-3 & $14.2 \mathrm{~kg}(31.3 \mathrm{lb})$ \\
\hline
\end{tabular}

\subsection{Construction Resource Needs for the He-3 Tritium-Extraction System}

The construction needs for the He-3 Tritium-Extraction System are based on the Tritium Systems Test Assembly located at Los Alamos National Laboratory (LANL) [7]. The size of the two facilities will be similar and therefore the resource needs for construction of the APT He-3 TritiumExtraction System are assumed to be approximately the same. The construction needs for this system are shown in Table 4-5.

Table 4-5. Construction Resource Needs for the He-3 Tritium-Extraction System.

\begin{tabular}{|c|c|}
\hline RESOURCE & QUANTITY \\
\hline \hline Carbon Steel & $20 \mathrm{Mg}(44,100 \mathrm{lb})$ \\
\hline Stainless Steel & $<10 \mathrm{Mg}(<22,000 \mathrm{lb})$ \\
\hline Copper & $<2 \mathrm{Mg}(<4410 \mathrm{lb})$ \\
\hline
\end{tabular}




\subsection{Construction Needs for the Balance-of-Plant}

This section describes the basis for the balance-of-plant resource needs during construction. A summary of the values is shown in Table 4-6 [8].

The dominant uses of water during construction are for concrete mixing and the satisfaction of personal needs. Based upon the $210,000 \mathrm{~m}^{3}\left(7,410,000 \mathrm{ft}^{3}\right)$ of estimated concrete required, the total concrete water usage is estimated to be approximately $36,435 \mathrm{~m}^{3}\left(1,290,000 \mathrm{ft}^{3}\right)$. Based upon the estimated 726,000 person-days of construction labor, the total amount of water used for personal needs is estimated to be $68,790 \mathrm{~m}^{3}\left(2,430,000 \mathrm{ft}^{3}\right)$. An additional $50 \%$ is estimated for other uses, resulting in approximately $157,840 \mathrm{~m}^{3}\left(5,570,000 \mathrm{ft}^{3}\right)$ of total use over five years.

The maximum electrical load during construction is expected to be the dewatering pumps. The maximum dewatering capability to be employed before using some water containment or in-leakage barrier technique is 20 dewatering pumps with a capacity of $0.094 \mathrm{~m}^{3} / \mathrm{s}(90,000 \mathrm{gph})$ each. It is assumed that dewatering will only be used during the first year of construction. In addition to this pumping power requirement, it is assumed that a comparable amount of electrical energy will be consumed for other purposes each year during the five years of construction. These assumptions result in an estimate of $40 \times 10^{3} \mathrm{MWh}$ of electrical energy consumed during construction.

The estimation of fuel usage during construction was made on the basis of the following assumptions: (a) rolling 4 - 10 construction schedule, (b) twenty pieces of construction equipment, each fitted with a $500 \mathrm{HP}$ diesel, which consume an average of $1.05 \times 10^{-5} \mathrm{~m}^{3} / \mathrm{s}(10 \mathrm{gph})$ of fuel for two years, and (c) three cranes consuming $5.26 \times 10^{-6} \mathrm{~m}^{3} / \mathrm{s}(5 \mathrm{gph})$ over the subsequent two years. An additional $33 \%$ was included to account for vehicles, portable generators, and contingencies, to yield an estimate of $8000 \mathrm{~m}^{3}\left(2.11 \times 10^{6} \mathrm{gal}\right)$ of fuel.

The volume of concrete required for the accelerator tunnel and target areas was estimated to be $70 \times 10^{3} \mathrm{~m}^{3}\left(2.47 \times 10^{6} \mathrm{ft}^{3}\right)$ based upon preliminary layout sketches developed from available design information and interface requirements. An additional $140 \times 10^{3} \mathrm{~m}^{3}\left(4.94 \times 10^{6} \mathrm{ft}^{3}\right)$ was added to account for the other buildings (assumed to be structural steel with metal siding and reinforced concrete foundations) and structures as well as to provide for contingencies.

The estimated quantities of carbon steel required include the amounts needed for reinforcing steel, structural steel, steel siding, piping, cooling towers, pumps, electrical, and HVAC systems. A $30 \%$ contingency was added, giving a total estimate of $55 \times 10^{3} \mathrm{Mg}\left(1.21 \times 10^{8} \mathrm{lb}\right)$.

A similar estimate was made for the stainless steel required for the electrical and cooling systems. A $50 \%$ contingency was added, resulting in a total estimate of $310 \mathrm{Mg}\left(6.83 \times 10^{5} \mathrm{lb}\right)$. 
Table 4-6. Construction Resource Needs for the Balance-of Plant.

\begin{tabular}{|c|c||}
\hline RESOURCE & QUANTITY \\
\hline Water & $157,840 \mathrm{~m}^{3}\left(5.57 \times 10^{6} \mathrm{ft}^{3}\right)$ \\
\hline Electrical Energy & $40 \times 10^{3} \mathrm{MWh}$ \\
\hline Fuel & $8000 \mathrm{~m}^{3}\left(2.11 \times 10^{6} \mathrm{gal}\right)$ \\
\hline Concrete & $210,000 \mathrm{~m}^{3}\left(7.41 \times 10^{6} \mathrm{ft}^{3}\right)$ \\
\hline Carbon Steel & $55,000 \mathrm{Mg}\left(1.21 \times 10^{8} \mathrm{lb}\right)$ \\
\hline Stainless Steel & $310 \mathrm{Mg}\left(6.83 \times 10^{5} \mathrm{lb}\right)$ \\
\hline Copper & $5100 \mathrm{Mg}\left(1.12 \times 10^{7} \mathrm{lb}\right)$ \\
\hline Aluminum & $50 \mathrm{Mg}\left(1.10 \times 10^{5} \mathrm{lb}\right)$ \\
\hline Chemicals & $250 \mathrm{~m}^{3}\left(8830 \mathrm{ft}^{3}\right)$ \\
\hline Land Disturbance & $70 \mathrm{ha}^{(173 \mathrm{acres})}$ \\
\hline Total Effort & $6380 \mathrm{worker}^{\mathrm{years}}$ \\
\hline Peak Work Force & $2650 \mathrm{workers}$ \\
\hline Construction Duration & 5 years \\
\hline Wastewater & $6000 \mathrm{~m}^{3}\left(219,000 \mathrm{ft}^{3}\right)$ \\
\hline Nonhazardous Solid & $21,000 \mathrm{~m}^{3}\left(741,000 \mathrm{ft}^{3}\right)$ \\
\hline Hazardous Waste & $50 \mathrm{~m}^{3}\left(1,760 \mathrm{ft}^{3}\right)$ \\
\hline Construction Dewatering & $60 \times 10^{6} \mathrm{~m}^{3}\left(2.12 \times 10^{9} \mathrm{ft}^{3}\right)$ \\
\hline & \\
\hline & \\
\hline
\end{tabular}

The amounts of copper and aluminum were estimated for the buildings and electrical and cooling systems. A 20\% contingency is embodied in the weights of such items as wire and cable while other items, such as transformers, reflect manufacturers' data with no additional contingency. The resulting estimate was $5100 \mathrm{Mg}\left(1.12 \times 10^{7} \mathrm{lb}\right)$ of copper and $50 \mathrm{Mg}\left(1.10 \times 10^{5} \mathrm{lb}\right)$ of aluminum.

The use of chemicals during construction is generally limited to the chemical flush of cooling systems. This is usually done using a tanker truck carrying three $18.9-\mathrm{m}^{3}$ (5000-gal) tanks, one each for $\mathrm{Na}_{3} \mathrm{PO}_{4}$, phosphoric acid, and demineralized water. They are generally recycled and filtered; however, it was assumed that the contents of such a truck were depleted each month during a sixmonth system-commissioning period. This results in the usage of approximately $250 \mathrm{~m}^{3}\left(8,830 \mathrm{ft}^{3}\right)$ of chemicals.

The amount of land disturbance was taken directly from the preliminary site layout. The site length is set primarily by the accelerator and its width by the target building and tritium- processing 
facilities. Since the target building and tritium-extraction buildings exist at only one end, there is sufficient unencumbered space within the APT security boundary that additional construction laydown space is not required.

In the absence of a specified construction duration, a span of five years was assumed as reasonable and typical for a facility of the APT's size and complexity. On the basis of this assumption and the material quantities to be installed, a time-dependent site personnel loading was estimated. This resulted in a total required construction effort of 6380 worker-years with a peak work force of 2650 workers.

Construction waste includes wastewater, nonhazardous solids, hazardous waste, and construction dewatering. The amount of waste water produced was estimated by multiplying the highest ratio of waste water to water use for the heavy water reactor (HWR), the modular high-temperature gas reactor (MHTGR), and the light water reactor (LWR) by the construction water needs. This resulted in a waste water volume of $1200 \mathrm{~m}^{3} / \mathrm{yr}\left(42,400 \mathrm{ft}^{3} / \mathrm{yr}\right)$ or for five years of construction, $6000 \mathrm{~m}^{3}$ $\left(212,000 \mathrm{ft}^{3}\right)$.

The amount of nonhazardous solid waste is generally dominated by the volume of waste concrete, which is usually less than $10 \%$ of the total concrete volume. This results in a nonhazardous solid waste-generation rate of $4,200 \mathrm{~m}^{3} / \mathrm{yr}\left(148,000 \mathrm{ft}^{3} / \mathrm{yr}\right)$. For the expected five years of construction, this results in a total of $21,000 \mathrm{~m}^{3}\left(740,000 \mathrm{ft}^{3}\right)$.

The amount of hazardous waste was estimated in the same way as the wastewater resulting in a hazardous waste generation rate of $10 \mathrm{~m}^{3} / \mathrm{yr}\left(353 \mathrm{ft}^{3} / \mathrm{yr}\right)$. The total expected hazardous waste during construction is $50 \mathrm{~m}^{3}\left(1760 \mathrm{ft}^{3}\right)$.

The amount of dewatering is based on information used to estimate the electrical energy required during construction. Only 20 dewatering pumps with a capacity of $0.094 \mathrm{~m}^{3} / \mathrm{s}(90,000 \mathrm{gph})$ each will be used. Assuming that ingress of water at a wet site if the inflow is less than this capacity and that dewatering will be required for no more than the year estimated to be required to construct the embedded structures, the total dewatering volume is $60 \times 10^{6} \mathrm{~m}^{3}\left(2.12 \times 10^{9} \mathrm{ft}^{3}\right)$. 


\subsection{RESOURCE NEEDS DURING OPERATIONS}

This section describes the derivation of estimated personnel, energy, and material requirements for operation. Section 5.1 addresses the resources necessary to operate the accelerator. Sections 5.2 and 5.3 address the resource needs for the SILC target and tritium extraction for that target, respectively. The resource needs for the He-3 target and its tritium extraction are given in Sections 5.4 and 5.5, respectively. Section 5.6 addresses the needs and requirements for the balance-of-plant except for those specifically for the targets, the accelerator, and the tritium-extraction systems.

\subsection{Operational Resource Needs for the Accelerator}

The estimates for the operational needs for the accelerator are based on existing accelerators [4]. The primary resources needed for operation of the accelerator are klystrons and ion pumps. The estimated number of refurbishments per year for the klystrons and ion pumps are shown in Table 51.

Table 5-1. Annual Operational Resource Needs for the Accelerator.

\begin{tabular}{|c|c|}
\hline $\begin{array}{c}\text { RESOURCE } \\
\text { (Special Equipment) }\end{array}$ & QUANTITY \\
\hline Klystrons & 25 units \\
\hline Ion Pumps & 20 units \\
\hline
\end{tabular}

\subsection{Operational Resource Needs for the SILC Target}

The operational resource needs for the SILC target were estimated from current design information [2]. In general, the resources needed are aluminum, lithium, lead, and $\mathrm{D}_{2} \mathrm{O}$. Table 5-2 contains a summary of the annual resource needs for operating the SILC target. A few of the entries in the table are not required for this target and were included to show the completeness of the evaluation.

Table 5-2. Annual Operational Resource Needs for the SILC Target.

\begin{tabular}{|c|c|}
\hline RESOURCE & QUANTITY \\
\hline \hline METALS & \\
\hline Aluminum in target & $40 \mathrm{Mg}\left(8.80 \times 10^{4} \mathrm{lb}\right)$ \\
\hline Aluminum-structural & $5.8 \mathrm{Mg}\left(1.28 \times 10^{4} \mathrm{lb}\right)$ \\
\hline Lithium & $1.1 \mathrm{Mg}(2400 \mathrm{lb})$ \\
\hline
\end{tabular}


Table 5-2. Annual Operational Resource Needs for the SILC Target (Continued).

\begin{tabular}{|c|c|}
\hline RESOURCE & QUANTITY \\
\hline \hline Stainless Steel & 0 \\
\hline Lead & $11 \mathrm{Mg}(24,250 \mathrm{lb})$ \\
\hline CHEMICALS & 0 \\
\hline Decontamination solutions & 0 \\
\hline Nitric Acid & \\
\hline WATER $\quad \mathrm{D}_{2} \mathrm{O}$ makeup & $0.6 \mathrm{~m}^{3}\left(21.2 \mathrm{ft}^{3}\right)$ \\
\hline
\end{tabular}

\subsection{Operational Needs for the SILC Tritium-Extraction System}

Some of the operational needs for the SILC target tritium-extraction system were estimated from the expected waste streams. Additional information was derived from the estimated usage for the Replacement Tritium Facility and the relative sizes of the two facilities [5]. The resource needs, on an annual basis, are shown in Table 5-3.

Table 5-3. Annual Operational Resource Needs for the SILC Tritium-Extraction System.

\begin{tabular}{|c|c|}
\hline RESOURCE & QUANTITY \\
\hline Uranium & $0.35 \mathrm{Mg}(772 \mathrm{lb})$ \\
\hline Nitrogen & $56 \mathrm{Mg}\left(1.23 \times 10^{5} \mathrm{lb}\right)$ \\
\hline Stainless Steel & $29 \mathrm{Mg}\left(6.40 \times 10^{4} \mathrm{lb}\right)$ \\
\hline
\end{tabular}

\subsection{Operational Resource Needs for the He-3 Target}

The operational resource needs for the He-3 target were estimated by using the values presented in Table 4-4 for the construction resource needs [6] and the 2.2-year expected lifetime of a target. Note that all of the target metals except for the major portion of the lead are not assumed to be reused. Of the total lead in one target, $13,550 \mathrm{~kg}(29,950 \mathrm{lb})$ is disposable at each retargeting operation and the rest is reused. The estimated annual resource needs for the He-3 target are shown in Table 5-4. The amount of He-3 required is equal to the production rate of tritium. A makeup rate of $1 \%$ was used to estimate the amount of heavy water required for operations. Some unused materials were included in the table for completeness. 
Table 5-4. Annual Operational Resource Needs for the He-3 Target.

\begin{tabular}{|c|c||}
\hline RESOURCE & QUANTITY \\
\hline \hline METALS & \\
\hline Inconel & $2.3 \mathrm{Mg}(4980 \mathrm{lb})$ \\
\hline Tungsten & $0.7 \mathrm{Mg}(1480 \mathrm{lb})$ \\
\hline Aluminum & $2.5 \mathrm{Mg}(5510 \mathrm{lb})$ \\
\hline Disposable Lead & $6.2 \mathrm{Mg}(13,600 \mathrm{lb})$ \\
\hline Stainless Steel & $7.6 \mathrm{Mg}(16,700 \mathrm{lb})$ \\
\hline Zircaloy-4 & $2.0 \mathrm{Mg}(4340 \mathrm{lb})$ \\
\hline CHEMICALS & 0.0 \\
\hline Decontamination Solutions & 0.0 \\
\hline Nitric Acid & $1.8 \mathrm{~m}^{3}\left(63.5 \mathrm{ft}^{3}\right)$ \\
\hline WATER & \\
\hline D & \\
\hline
\end{tabular}

\subsection{Operational Resource Needs for the He-3 Tritium-Extraction System}

The operational resource needs for the He-3 tritium-extraction system are based on the Tritium Systems Test Assembly located at LANL. The size of the two facilities will be similar and therefore the resource needs for operation of the APT He-3 tritium-extraction system are assumed to be approximately the same. The annual operational needs for this system are shown in Table 5-5.

Table 5-5. Annual Operational Resource Needs for the $\mathrm{He}-3$ Tritium-Extraction System.

\begin{tabular}{|c|c|}
\hline RESOURCE & QUANTITY \\
\hline \hline Aluminum & $10 \mathrm{Mg}\left(2.20 \times 10^{4} \mathrm{lb}\right)$ \\
\hline Aluminum Components & $0.1 \mathrm{Mg}(220 \mathrm{lb})$ \\
\hline Stainless Steel & $0.1 \mathrm{Mg}(220 \mathrm{lb})$ \\
\hline Lead & $25 \mathrm{~kg}(55.1 \mathrm{lb})$ \\
\hline Copper & $0.25 \mathrm{Mg}(551 \mathrm{lb})$ \\
\hline Liquid Nitrogen & $<1 \times 10^{6} \mathrm{~m}^{3}\left(<3.53 \times 10^{7} \mathrm{ft}^{3}\right)$ \\
\hline
\end{tabular}




\subsection{Operational Resource Needs for the Balance-of-Plant}

The operational resource needs for the balance-of-plant are discussed in this section. A summary of the resource needs is shown in Table 5-6 [8].

Table 5-6. Annual Operational Resource Needs for the Balance-of-Plant.

\begin{tabular}{|c|c|}
\hline RESOURCE & QUANTITY \\
\hline \hline Electrical Energy & $3,740,000 \mathrm{MW} \mathrm{h}$ \\
\hline Fuel & $50 \mathrm{~m}^{3}\left(1760 \mathrm{ft}^{3}\right)$ \\
\hline Steam & 0 \\
\hline CHEMICALS & $0.2 \mathrm{Mg}(441 \mathrm{lb})$ \\
\hline Sodium Hydroxide & $1250 \mathrm{Mg}\left(2.75 \times 10^{6} \mathrm{lb}\right)$ \\
\hline Sulfuric Acid & \\
\hline WATER $\quad$ & $4.5 \times 10^{6} \mathrm{~m}^{3}\left(1.2 \times 10^{9} \mathrm{gal}\right)$ \\
\hline $\mathrm{H}_{2} \mathrm{O}$ (Wet Site) & $5.7 \times 10^{5} \mathrm{~m}^{3}\left(1.5 \times 10^{8} \mathrm{gal}\right)$ \\
\hline $\mathrm{H}_{2} \mathrm{O}$ (Dry Site) & \\
\hline
\end{tabular}

The total power requirement for the APT when in full operation is estimated to be $550 \mathrm{MW}$. When the accelerator is not operating, the power requirement is estimated to be no more than $10 \%$ of this value. With a $75 \%$ availability, this results in $3,740,000 \mathrm{MW}$ h for each year.

The principal users of fuel during operations will be emergency diesel generators and motor vehicles. Based on Nuclear Regulatory Commission (NRC) Regulatory Guide 1.108, the annualized run time per diesel for testing was estimated at $28 \mathrm{~h}$. Including the annualized expected duration of actual operation results in approximately $30 \mathrm{~h} / \mathrm{yr}$ for each diesel. Based on typical fuel usage for a diesel generator and two generators, an estimate of $18 \mathrm{~m}^{3} / \mathrm{yr}\left(635 \mathrm{ft}^{3} / \mathrm{yr}\right)$ for diesel fuel usage was obtained. To estimate the vehicle usage, the number of vehicle trips per day was estimated at 42 round trips of a maximum of 3 miles. Assuming an average fuel consumption rate of $3.79 \times 10^{-4} \mathrm{~m}^{3} / \mathrm{mile}(0.10$ gallons/mile) yields a vehicle fuel usage of $17.5 \mathrm{~m}^{3} / \mathrm{yr}\left(618 \mathrm{ft}^{3} / \mathrm{yr}\right)$. Combining the diesel generator and the vehicle fuel usage with a $33 \%$ contingency factor results in an estimated fuel usage of $50 \mathrm{~m}^{3} / \mathrm{yr}\left(1760 \mathrm{ft}^{3} / \mathrm{yr}\right)$.

The APT concept does not include any steam production or utilization features. In addition, it was assumed that electric heating elements will be used in the HVAC systems, eliminating any need for steam for heating purposes.

The only chemicals of interest to be used in the balance-of-plant systems are sodium hydroxide and sulfuric acid. The amount of sulfuric acid used is overwhelmingly dominated by the quantity 
required to maintain the $\mathrm{pH}$ of the cooling tower circulating water. Based on the estimated cooling tower flow and makeup rates, the quantity of sulfuric acid to be consumed annually to maintain the requisite $\mathrm{pH}$ is estimated to be $930 \mathrm{Mg} / \mathrm{yr}\left(2.05 \times 10^{6} \mathrm{lb} / \mathrm{yr}\right)$. With a $33 \%$ contingency, the total quantity of sulfuric acid is expected to be no more than $1250 \mathrm{Mg} / \mathrm{yr}\left(2.75 \times 10^{6} \mathrm{lb} / \mathrm{yr}\right)$.

Sodium hydroxide is used only to adjust the alkalinity of the makeup water for the closed loop $\mathrm{H}_{2} \mathrm{O}$ cooling systems. At a usage rate of $60 \mathrm{~g} / \mathrm{m}^{3}(0.5 \mathrm{lb} / 1000 \mathrm{gal})$ per year and a total volume of approximately $833 \mathrm{~m}^{3}(220,000 \mathrm{gal})$ in the $\mathrm{H}_{2} \mathrm{O}$ cooling systems, sodium hydroxide use is not expected to exceed $50 \mathrm{~kg} / \mathrm{yr}(110 \mathrm{lb} / \mathrm{yr})$. However, to account for uncertainties in both the cooling system volumes and the makeup water quality, a 100\% contingency has been applied. Furthermore, a comparable quantity of other chemicals is assumed to also be used in conditioning the cooling water makeup. Therefore, the total annual use of sodium hydroxide or equivalents is estimated to be no greater than $0.2 \mathrm{Mg} / \mathrm{yr}(441 \mathrm{lb} / \mathrm{yr})$.

Cooling tower makeup and the satisfaction of personal needs are the dominant uses of water during operation. Based upon a maximum onsite population of 624 persons, an assumed average work year of 50 weeks, and an assumed water usage rate of $0.19 \mathrm{~m}^{3} /$ day (50 gal/day) per person, the personnelrelated water usage is estimated to be $30,000 \mathrm{~m}^{3} / \mathrm{yr}\left(1.1 \times 10^{6} \mathrm{ft}^{3} / \mathrm{yr}\right)$. The annual water usage is estimated to be $4.5 \times 10^{6} \mathrm{~m}^{3}\left(1.2 \times 10^{9} \mathrm{gal}\right)$ for a wet site at which evaporative cooling is used.

At a dry site, dry cooling systems will be used with the exception of cooling for the RF cavities which will be evaporative. The estimated water usage at a dry site is $5.7 \times 10^{5} \mathrm{~m}^{3}\left(1.5 \times 10^{8} \mathrm{gal}\right)$ [9].

The source of the water depends on the location of the facility. Surface water is readily available as a makeup water source and large surface streams are available to receive wastewater discharges at a wet site. In contrast, at a dry site, groundwater is the primary water source and large surface streams are not available to receive wastewater discharges. Annual water balances for a generic dry site and for a generic wet site are shown in Figures 5-1 and 5-2, respectively. The primary difference in water usage between the wet and dry sites is that the blowdown and the treated effluent from the wastewater treatment facility will be recycled for the dry site. The process systems include the target and the tritium extraction facilities. The ratio of blowdown to evaporation and drift is assumed to be 1 to 4 . At both types of sites rainfall is trapped, and if clean, it is released to natural drainage channels. 


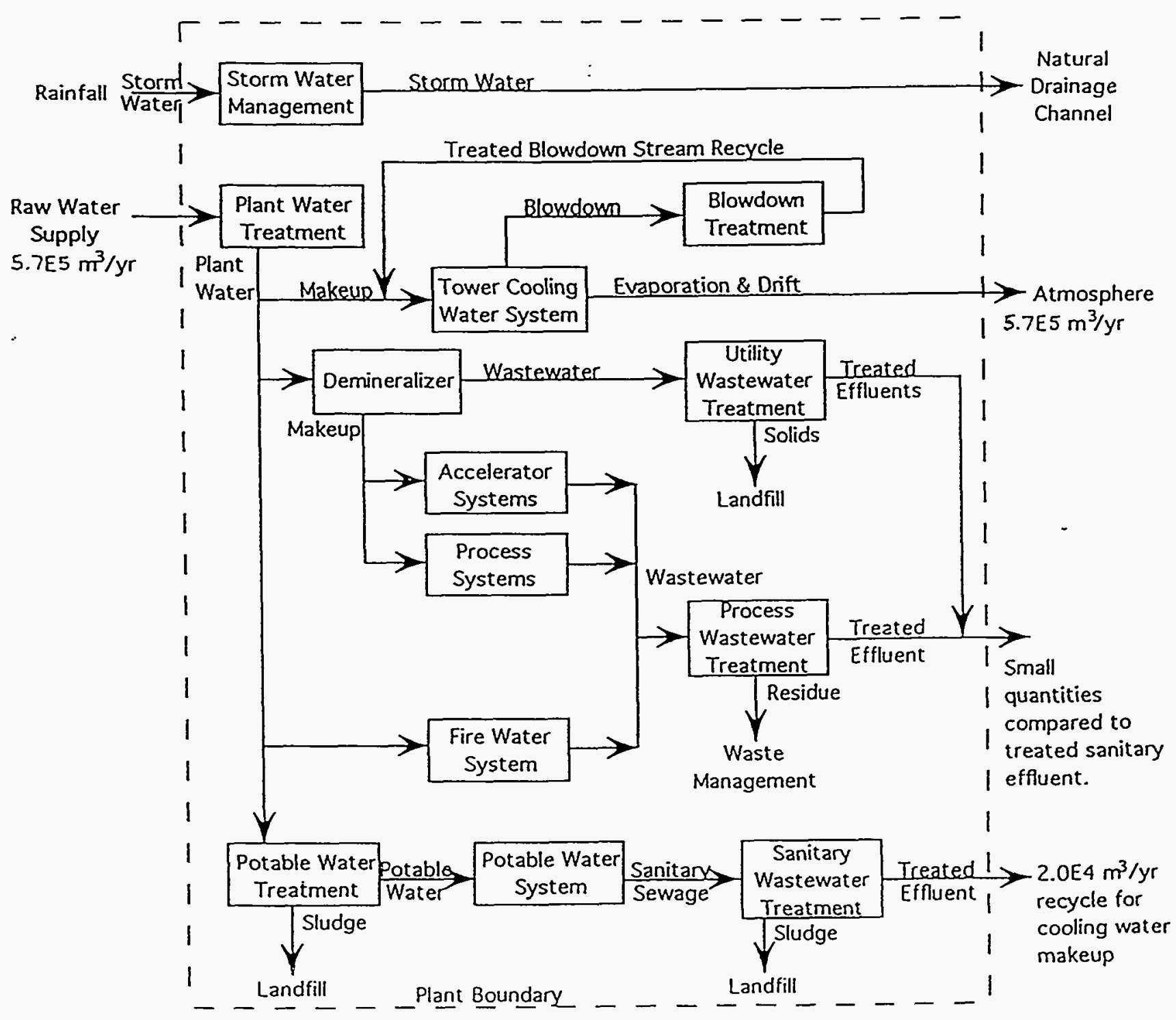

Figure 5-1. Annual Water Balance - Generic Dry Site 


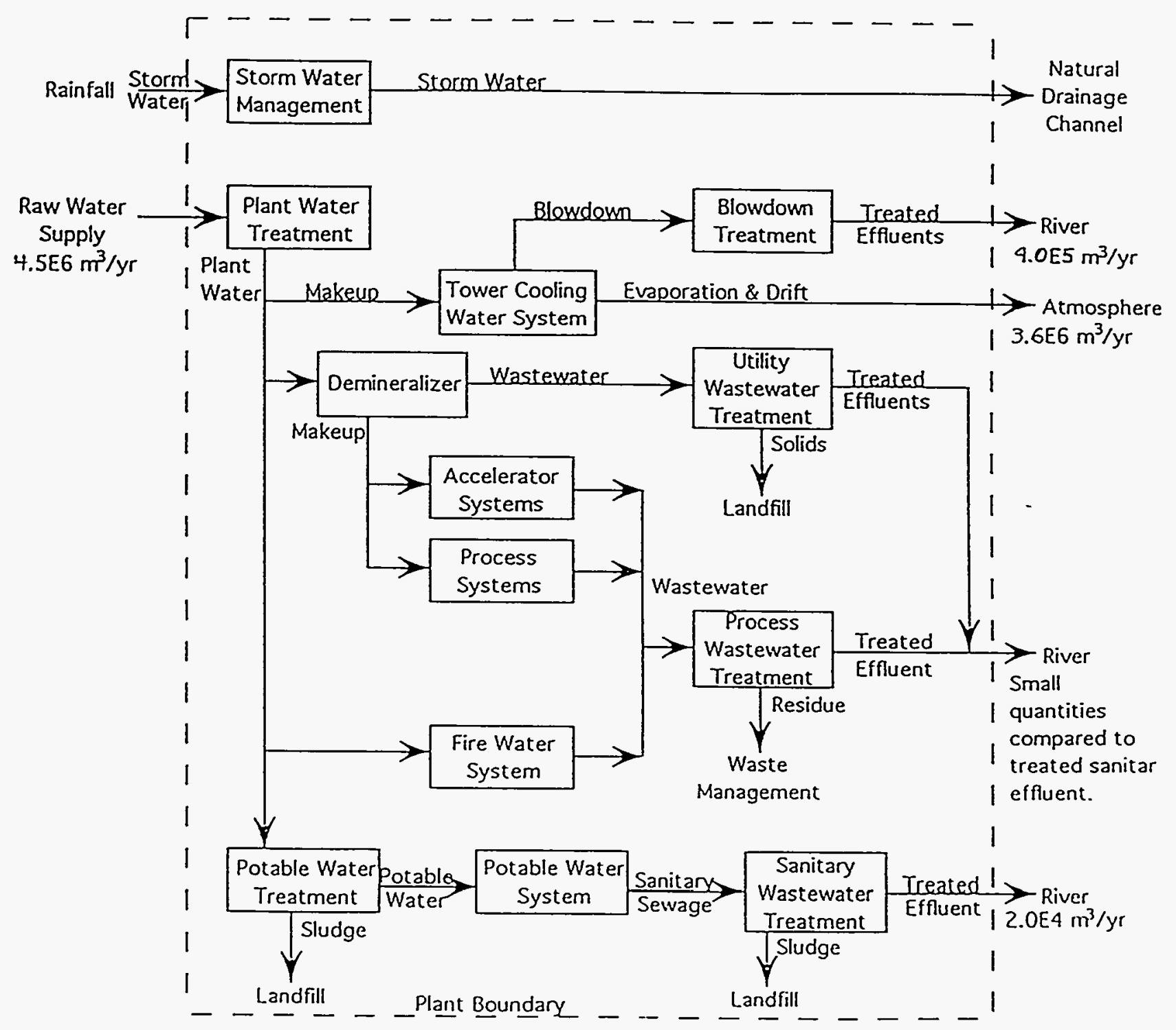

Figure 5-2. Annual Water Balance - Generic Wet Site 
Intentionally Left Blank 


\subsection{EMPLOYMENT}

One of the primary resources needed during construction and operation of the APT facility is personnel. Estimates of the personnel required for both target concepts during construction and operation of the facility are summarized in Table 6-1. Employment numbers are restricted to total onsite employment and direct engineering support. Experience with the Tritium Systems Test Assembly was the basis for the operational needs of the He-3 tritium-extraction system. The number of workers for the SILC target tritium-extraction system was estimated to be the same as for the He-3 tritium-extraction system. Due to the early stage of the design, employment profiles cannot be provided at this time.

Table 6-1. Employment Requirements for the APT.

\begin{tabular}{||c|c|c||}
\hline & $\begin{array}{c}\text { Accelerator/ } \\
\text { Target }\end{array}$ & $\begin{array}{c}\text { Tritium } \\
\text { Extraction }\end{array}$ \\
\hline \hline \multicolumn{3}{|c|}{ Construction and Preoperation } \\
\hline \hline $\begin{array}{c}\text { Total } \\
\text { (person-years) }\end{array}$ & 6130 & 250 \\
\hline Peak (persons) & 2650 & 110 \\
\hline \hline \multicolumn{2}{|c|}{ Annual Operation and Maintenance } \\
\hline \hline $\begin{array}{c}\text { Total } \\
\text { (persons/year) }\end{array}$ & 554 & 70 \\
\hline
\end{tabular}

Some of the workers will be exposed to radioactive materials. Table 6-2 contains estimates of the numbers of workers handling radiological materials by process area and the limits on doses. A 200 $\mathrm{mrem} / \mathrm{yr} /$ worker administrative limit is used at the LAMPF. This limit is the basis of the administrative limit for the accelerator and target operations. The estimated dose for the He-3 tritium extraction is based on experience at the TSTA at LANL and the estimated dose for the SILC tritium-extraction system is based on an experience with heavy water reactors that use the same type of process [10]. 
Table 6-2. Radiological Workers and Exposures.

\begin{tabular}{|c|c|c|c||}
\hline $\begin{array}{c}\text { NUMBER OF } \\
\text { WORKERS }\end{array}$ & PROCESS AREA & $\begin{array}{c}\text { ADMINISTRATIVE } \\
\text { LIMIT OR } \\
\text { ESTIMATED DOSE }\end{array}$ & DOE LIMIT \\
\hline \hline 188 & $\begin{array}{c}\text { Accelerator and Target } \\
\text { Operations }\end{array}$ & $<200 \mathrm{mrem} / \mathrm{yr} /$ worker & $5 \mathrm{rem} / \mathrm{yr} /$ worker \\
\hline 70 & $\begin{array}{c}\text { He-3 Tritium } \\
\text { Extraction }\end{array}$ & $<10 \mathrm{mrem} / \mathrm{yr} /$ worker & $5 \mathrm{rem} / \mathrm{yr} /$ worker \\
\hline 70 & $\begin{array}{c}\text { SILC Tritium } \\
\text { Extraction }\end{array}$ & $<45 \mathrm{mrem} / \mathrm{yr} /$ worker & $5 \mathrm{rem} / \mathrm{yr} /$ worker \\
\hline
\end{tabular}




\subsection{WASTE EFFLUENTS AND EMISSIONS (ANNUAL)}

The waste effluents from the APT facilities were estimated for both the SILC target design and the He-3 target design [11]. In general, the quantities were estimated by combining design information and experience with similar processes and components across the DOE complex. There will be no high-level or transuranic waste generated at APT. The amounts of solid and liquid sewage were estimated based on the number of personnel at the site. No significant chemical releases to the environment have been identified.

The estimates for waste from the accelerator are discussed in Section 7.1. The wastes from the SILC target and tritium extraction are described in Sections 7.2 and 7.3, respectively. In Sections 7.4 and 7.5 , the wastes from the He-3 target and tritium extraction are discussed.

\subsection{Waste Effluent for the Accelerator}

The estimated annual quantities of waste for the accelerator portion of the facility are shown in Table 7-1. The amount of low-level waste includes klystron and ion pump refurbishment and cooling system maintenance. Sources of mixed waste include solvents, solvent rags, and discarded batteries. Hazardous waste includes primarily solvents and solvent rags.

Table 7-1. Annual Waste Effluent From the Accelerator.

\begin{tabular}{||c|c|c||}
\hline WASTE & MASS & VOLUME \\
\hline \hline High-Level Waste & 0 & 0 \\
\hline Transuranic Waste (solid) & 0 & 0 \\
\hline Low-Level Waste (solid) & $590 \mathrm{~kg}(1300 \mathrm{lb})$ & $0.2 \mathrm{~m}^{3}\left(7.0 \mathrm{ft}^{3}\right)$ \\
\hline Mixed Waste (solid) & $430 \mathrm{~kg}(950 \mathrm{lb})$ & $0.4 \mathrm{~m}^{3}\left(14.1 \mathrm{ft}^{3}\right)$ \\
\hline Hazardous Waste (solid) & $340 \mathrm{~kg}(750 \mathrm{lb})$ & $0.3 \mathrm{~m}^{3}\left(10.5 \mathrm{ft}^{3}\right)$ \\
\hline
\end{tabular}

\subsection{Waste Effluent From the SILC Target}

The annual estimated quantities of waste for the SILC target and blanket portion of the facility are shown in Table 7-2. The estimated amount of low-level waste includes treatment residues from liquid low-level waste, spent resin and filters, piping and pressure tubes, the window, the wastehandling facility, the disassembly basin, and job control wastes. Sources of mixed waste include solvent rags, lead aluminum targets, discarded batteries, and paint. Nonhazardous solid waste includes office, cafeteria, and sewage waste and includes a factor of 3 for compaction for the office and cafeteria waste. The amount of sewage includes the estimates for the accelerator as well as the target operations. 
Table 7-2. Annual Waste Effluent From the SILC Target.

\begin{tabular}{||l|c|c||}
\hline \multicolumn{1}{|c|}{ WASTE } & MASS & VOLUME \\
\hline \hline High-Level Waste & 0 & 0 \\
\hline Transuranic Waste (solid) & 0 & 0 \\
\hline Low-Level Waste (solid) & $19,900 \mathrm{~kg}(43,700 \mathrm{lb})$ & $18.5 \mathrm{~m}^{3}\left(650 \mathrm{ft}^{3}\right)$ \\
\hline Mixed Waste (solid) & $11,800 \mathrm{~kg}(26,000 \mathrm{lb})$ & $2.4 \mathrm{~m}^{3}\left(85 \mathrm{ft}^{3}\right)$ \\
\hline Hazardous Waste (solid) & $340 \mathrm{~kg}(750 \mathrm{lb})$ & $0.3 \mathrm{~m}^{3}\left(10.6 \mathrm{ft}^{3}\right)$ \\
\hline Liquid Sewage & $2.63 \times 10^{7} \mathrm{~kg}\left(5.80 \times 10^{7} \mathrm{lb}\right)$ & $\begin{array}{c}2.63 \times 10^{4} \mathrm{~m}^{3} \\
\left(9.27 \times 10^{5} \mathrm{ft}^{3}\right)\end{array}$ \\
\hline Nonhazardous (solid) & $6.74 \times 10^{5} \mathrm{~kg}\left(1.49 \times 10^{5} \mathrm{lb}\right)$ & $840 \mathrm{~m}^{3}\left(2.97 \times 10^{4} \mathrm{ft}^{3}\right)$ \\
\hline
\end{tabular}

\subsection{Waste Effluent From the SILC Target Tritium-Extraction System}

The amount of annual waste that may be produced by the LiAl tritium extraction and purification processes is shown in Table 7-3. The sources of low-level waste that were considered in this estimate include job-control wastes, crucibles, spent LiAl melts, piping, valves, filters, and the waste-handling facility. Mixed wastes include contaminated batteries, aerosol cans, and spent solvents. The hazardous wastes include solvent rags and solvents. The nonhazardous solid waste includes office and cafeteria waste as well as sewage. The office and cafeteria waste includes a factor of 3 for compaction. The nonhazardous solid waste and sewage waste are only for the tritiumextraction facility.

Table 7-3. Annual Waste Effluent From the SILC Tritium-Extraction Facility.

\begin{tabular}{||l|c|c||}
\hline \multicolumn{1}{|c|}{ WASTE } & MASS & VOLUME \\
\hline \hline High-Level Waste & 0 & 0 \\
\hline Transuranic Waste (solid) & 0 & 0 \\
\hline Low-Level Waste (solid) & $328,000 \mathrm{~kg}(723,000 \mathrm{lb})$ & $397.0 \mathrm{~m}^{3}\left(14,000 \mathrm{ft}^{3}\right)$ \\
\hline Mixed Waste (solid) & $2500 \mathrm{~kg}(5,500 \mathrm{lb})$ & $2.4 \mathrm{~m}^{3}\left(85 . \mathrm{ft}^{3}\right)$ \\
\hline Hazardous Waste (solid) & $1400 \mathrm{~kg}(3100 \mathrm{lb})$ & $1.3 \mathrm{~m}^{3}\left(46.0 \mathrm{ft}^{3}\right)$ \\
\hline Liquid Sewage & $3.32 \times 10^{6} \mathrm{~kg}\left(7.32 \times 10^{6} \mathrm{lb}\right)$ & $3320 \mathrm{~m}^{3}\left(1.17 \times 10^{5} \mathrm{ft}^{3}\right)$ \\
\hline Nonhazardous (solid) & $8.60 \times 10^{4} \mathrm{~kg}\left(1.90 \times 10^{5} \mathrm{lb}\right)$ & $110 \mathrm{~m}^{3}\left(3800 \mathrm{ft}^{3}\right)$ \\
\hline
\end{tabular}




\subsection{Waste Effluent for the He-3 Target}

Similar estimates were made for the He-3 target concept and are shown for the target and blanket in Table 7-4. The estimate for the quantity of low-level waste includes treatment residues, spent resin and filters, cooling system maintenance, Inconel, tungsten, zircaloy, job control waste, and the waste handling facility. The estimate for mixed waste includes lead from the target blanket, discarded batteries, and paint. The solid nonhazardous waste includes sewage, office, and cafeteria waste. The office and cafeteria waste has been compacted by the factor of 3 . The estimated liquid sewage and nonhazardous waste includes that for accelerator operations.

Table 7-4. Annual Waste Effluent From the He-3 Target.

\begin{tabular}{||c|c|c||}
\hline \multicolumn{1}{|c|}{ WASTE } & MASS & VOLUME \\
\hline \hline High-Level Waste & 0 & 0 \\
\hline Transuranic Waste (solid) & 0 & 0 \\
\hline Low-Level Waste (solid) & $31,400 \mathrm{~kg}(69,200 \mathrm{lb})$ & $20.7 \mathrm{~m}^{3}\left(730 \mathrm{ft}^{3}\right)$ \\
\hline Mixed Waste (solid) & $10,800 \mathrm{~kg}(23,700 \mathrm{lb})$ & $2.0 \mathrm{~m}^{3}\left(68.5 \mathrm{ft}^{3}\right)$ \\
\hline Hazardous Waste (solid) & $340 \mathrm{~kg}(750 \mathrm{lb})$ & $0.3 \mathrm{~m}^{3}\left(10.7 \mathrm{ft}^{3}\right)$ \\
\hline Liquid Sewage & $2.63 \times 10^{7} \mathrm{~kg}\left(5.80 \times 10^{7} \mathrm{lb}\right)$ & $\begin{array}{c}2.63 \times 10^{4} \mathrm{~m}^{3} \\
\left(9.27 \times 10^{5} \mathrm{ft}^{3}\right)\end{array}$ \\
\hline Nonhazardous (solid) & $6.74 \times 10^{5} \mathrm{~kg}\left(1.49 \times 10^{6} \mathrm{lb}\right)$ & $840 \mathrm{~m}^{3}\left(2.97 \times 10^{4} \mathrm{ft}^{3}\right)$ \\
\hline
\end{tabular}

\subsection{Waste Effluent for the He-3 Target Tritium-Extraction System}

Estimates of the waste produced annually during He-3 tritium purification are shown in Table 7-5. The estimate of low-level waste includes job control wastes, piping, valves, filters, and the wastehandling facility. Mixed wastes include contaminated batteries, aerosol cans, and spent solvents. Hazardous wastes include solvent rags and other processing wastes. The nonhazardous solid and sewage waste are only for the tritium-extraction facility. The nonhazardous solid waste includes sewage, office, and cafeteria waste. The office and cafeteria waste have been compacted by a factor of 3 .

Table 7-5. Annual Waste Effluent for the He-3 Tritium-Extraction Facility.

\begin{tabular}{||c|c|c|}
\hline WASTE & MASS & VOLUME \\
\hline \hline High-Level Waste & 0 & 0 \\
\hline Transuranic Waste (solid) & 0 & 0 \\
\hline Low-Level Waste (solid) & $24,600 \mathrm{~kg}(54,000 \mathrm{lb})$ & $34.4 \mathrm{~m}^{3}\left(1210 \mathrm{ft}^{3}\right)$ \\
\hline Mixed Waste (solid) & $470 \mathrm{~kg}(1030 \mathrm{lb})$ & $0.4 \mathrm{~m}^{3}\left(15.4 \mathrm{ft}^{3}\right)$ \\
\hline
\end{tabular}


Table 7-5. Annual Waste Effluent for the He-3 Tritium-Extraction Facility (Continued).

\begin{tabular}{||c|c|c||}
\hline WASTE & MASS & VOLUME \\
\hline \hline Hazardous Waste (solid) & $360 \mathrm{~kg}(795 \mathrm{lb})$ & $0.3 \mathrm{~m}^{3}\left(10.7 \mathrm{ft}^{3}\right)$ \\
\hline Liquid Sewage & $3.32 \times 10^{6} \mathrm{~kg}\left(7.32 \times 10^{6} \mathrm{lb}\right)$ & $3320 \mathrm{~m}^{3}\left(1.17 \times 10^{5} \mathrm{ft}^{3}\right)$ \\
\hline Nonhazardous (solid) & $8.60 \times 10^{4} \mathrm{~kg}\left(1.90 \times 10^{5} \mathrm{lb}\right)$ & $110 \mathrm{~m}^{3}\left(3800 \mathrm{ft}^{3}\right)$ \\
\hline
\end{tabular}




\subsection{HAZARD ANALYSIS AND RADIOACTIVE RELEASES}

The assessment of radionuclide releases from the facility is described in this section. Section 8.1 contains the results of hazard analyses for the facility based on DOE Order 5480.23. A discussion of the normal operations that may lead to releases of radioactive materials is contained in Section 8.2. Sections 8.3 and 8.4 contain discussions of the Design Base Events (DBEs) and Beyond Design Base Events (BDBEs) for the facility, respectively.

\subsection{Hazard Classification}

DOE Standard, DOE-STD-1027-92, was used to determine the hazard classification for the accelerator, the two targets, and the two tritium-extraction systems. The results of this analysis are summarized in the following sections.

\subsubsection{Accelerator}

The overall hazard classification for the APT accelerator and beam transport system is judged to be at most a Category 3 hazard. A Category 3 hazard shows the potential for significant, but localized onsite consequences. It is likely that the accelerator is below a Category 3 hazard since radionuclides are located only in the beam stops and in the beam tube. The beam stops have been designed to absorb the full power of the beam, and therefore it is unlikely that radionuclides contained in a beam stop will be released by melting the beam stop. The beam tube contains activation products from normal beam loss. The amount of beam loss is monitored and maintained within specifications to prevent excessive activation of the beam tube.

The accelerator systems are completely enclosed and sealed off from the general public at all times, and during beam-on conditions access by operations and service personnel is permitted only in zones where radiation levels are very low. The accelerator and beam transport lines are contained in buried tunnels, shielded by sufficient thickness of concrete and earth to prevent significant radiation doses to plant workers even in the event of the maximum credible beam-loss accident. The main path for potential release of radioactive material to the environment and to the general public is from leakage or exhaust of air in the accelerator tunnel that has been activated by beam losses. In the APT design, radiation exposures due to such activated air releases would be kept to very low levels, one or more orders of magnitude below the existing DOE dose limits. In comparison with the target/blanket system, the overall radioactivity levels are extremely low. However, localized hazards exist that could affect the operation of the accelerator system itself, could result in loss of production (availability) or damage to equipment, or could result in limited threats to operating personnel.

\subsubsection{SILC Target}

The target/blanket for the SILC system is adjudged to be a Category 2 hazard [12]. A Category 2 hazard shows the potential for significant onsite consequences, but does not show the potential for significant offsite consequences. 
The determination of a Category 2 hazard classification is based on a comparison of the inventory of the target to threshold values for the radioactive isotopes contained in the target. The threshold values are calculated by limiting the dose that a person $300 \mathrm{~m}(984 \mathrm{ft}$ ) away would receive to $1 \mathrm{rem}$, given that they were exposed to only that radionuclide. The ratios of the threshold values to the inventory are summed and if the sum is greater than one, a hazard classification of at least 2 is assigned. In the case of the SILC target, the nuclides primarily responsible for the Category 2 assignment were Al-28, Hg-197, Na-24, $\mathrm{Hg}-203$, and F-18.

\subsubsection{SILC Target Tritium Extraction}

The only radionuclide in sufficient quantities for concern in the tritium-extraction system is tritium itself. The Category 2 threshold for tritium is $30 \mathrm{~g}(0.066 \mathrm{lb})$ [13]. The expected amount of tritium in one batch is greater than this value [5]. Therefore, the SILC target tritium-extraction system has been classified as a Category 2 hazard [12].

\subsubsection{He-3 Target}

The target/blanket for the He-3 system is adjudged to be a Category 2 hazard [12] using the same methodology as discussed in Section 8.1.2. A Category 2 hazard shows the potential for significant onsite consequences but does not show the potential for significant offsite consequences. The primary nuclides resulting in this classification are W-185, W-187, Na-24, $\mathrm{Hg}-203, \mathrm{Co}-58$, and Ta182.

\subsubsection{He-3 Target Tritium Extraction}

The tritium-extraction facility for the He-3 target is adjudged to be a Category 3 hazard [12]. As noted above, the threshold activity of tritium for a Category 2 classification is $30 \mathrm{~g}(0.066 \mathrm{lb})$ [13]. Only $15 \mathrm{~g}(0.033 \mathrm{lb})$ is expected to be contained in the He-3 blanket and in the tritium extraction facility. The basis for the hazard classification does not take into account tritium that may be stored at the facility since the tritium will be stored in a solid matrix and is not easily released.

\subsection{Normal Operations}

Normal operations may lead to very small radioactive releases to the environment. The following subsections include discussions on anticipated operational occurrences that may lead to release from the facility as well as estimated annual releases.

\subsubsection{Anticipated Operational Occurrences}

A number of potential events have been considered and categorized in terms of their likelihood of occurrence. Some example Anticipated Operational Occurrences (AOOs) are listed below for all of the systems. AOO-1 events are from normal operations and transients expected to occur regularly. AOO-2 and AOO-3 events are those which are expected to occur less often, but at least once during the facility's lifetime. 


\section{AOO-1}

Normal Operations

Startup

Shutdown

Normal release of activated air from accelerator tunnel during maintenance

Small releases of tritium into the secondary containment.

\section{Operational Transients}

Beam-trips

Normal loss-of-beam to accelerating structures

$\mathrm{RF}$ power station failure

Ion source failure

Power surge.

\section{AOO-2}

Loss of offsite power

Failure to maintain system vacuum

Maintenance in radiation fields

Conventional industrial accidents.

\section{AOO-3}

Target window leak

Secondary side failure or loss of heatsink

Accelerator focusing magnet failure

Accelerator cooling water flow failure

Release of activated accelerator primary cooling water

Small tritium leak/releases in tritium-extraction system

Small release of tritium from a storage/shipping container

Loss of a single-target-coolant-system pump

Loss of pressurizer pressure control.

\subsubsection{Anticipated Annual Releases}

Releases can be expected to occur due to the above AOOs. This section discusses the expected annual releases from the accelerator and the tritium extraction systems. No routine releases are expected from either target. 


\subsubsection{Anticipated Annual Releases From the Accelerator}

The amount of radioactivity released from the accelerator due to air leakage from the tunnel during normal beam operations and due to air exhaust from the tunnel following shutdown for maintenance was estimated based on experience at LAMPF [14]. The composition of activity release from the accelerator tunnel is shown in Table 8-1.

Table 8-1. Composition of Isotopes Released from the Accelerator Tunnel.

\begin{tabular}{|c|c|}
\hline Isotope & Activity Distribution (\%) \\
\hline \hline $\mathrm{C}-10$ & 0.8 \\
\hline $\mathrm{C}-11$ & 48.4 \\
\hline $\mathrm{N}-13$ & 18.6 \\
\hline $\mathrm{N}-16$ & 0.2 \\
\hline $\mathrm{O}-14$ & 1.1 \\
\hline $\mathrm{O}-15$ & 24.8 \\
\hline $\mathrm{Ar}-41$ & 6.1 \\
\hline
\end{tabular}

Conservative analyses for the release of radioactivity to the environment due to air leakage from the tunnel during normal beam operations yield a release of $87 \mathrm{Ci} / \mathrm{yr}$ at the surface.

Similar conservative analyses for the release of activated air to the environment following beam shutdown for maintenance result in a release of $83 \mathrm{Ci} / \mathrm{yr}$ with the same breakdown by isotope shown above. A holdup time of one hour will reduce the amount of radioactivity by a factor of 10 since the dominant activated air products are short-lived radionuclides.

\subsubsection{SILC Target Tritium Extraction}

The annual release of tritium from the SILC target tritium extraction and purification process has been estimated to be $5000 \mathrm{Ci}$ [15]. This estimate is based on the assumptions that the furnaces will have double containment and that all high hazard tritium activities will be contained in gloveboxes. Therefore, the annual release should be similar to the Replacement Tritium Facilities at Savannah River Site, which has a design based on a release of $5000 \mathrm{Ci} / \mathrm{yr}$.

\subsubsection{He-3 Target Tritium Extraction}

Releases of tritium to the environment during routine operations can occur due to inefficiencies in tritium removal or unavailability of the gaseous-waste-treatment system, small releases to the 
building that are not cleaned up with the atmospheric tritium-removal system, and small releases of tritium from the cooling-water system.

In analyzing the releases to the environment, certain design features must be considered. One of the requirements is that secondary containment will be used for all systems that handle significant (greater than $100 \mathrm{Ci}$ ) amounts of tritium under normal conditions. This is a different design basis than that used at the TSTA at LANL where the gaseous-waste-processing system is not secondarily contained. This requirement is consistent with current practices for new cleanup systems at DOE facilities. In addition, tertiary containment and cleanup will be provided by the building and an atmospheric tritium-removal system. This system will be provided for the area that contains the tritium-extraction system and will be operated as needed.

With these design requirements, the total tritium release to the environment is expected to be less than $250 \mathrm{Ci} /$ year. As a point of comparison, the design goal for TSTA is less than $200 \mathrm{Ci} /$ year. Actual releases have been less than $50 \mathrm{Ci} / \mathrm{year}$ with a total release of 200 curies in eight years of operation.

\subsection{Design Basis Events}

DBEs were investigated for the accelerator, both targets, and the tritium-extraction systems for both targets. The events presented here are those that represent the range of events that could occur.

\subsubsection{Accelerator}

One DBE for the accelerator was considered. Incorrect administrative procedures and controls for maintenance access to activated accelerator components could result in higher than permitted dose levels to service personnel on an infrequent basis. From LAMPF's operation, we estimate that, as an upper limit, one such incident could occur each year for the APT accelerator and beam-transport system. The consequences would be limited to the dose received by that individual. No lost production time or equipment replacement expense would be incurred.

\subsubsection{SILC Target System*}

Two levels of design basis are under consideration for the SILC target. One level of design basis is associated with the source-cooling systems. The design intent of the source-cooling systems is that any single break in the primary or secondary will be coolable by passive means, given credit for a timely beam-trip. Successful performance of this function will provide a path for continuous removal of decay heat from the target and from confinement, thereby preventing target overheating to the point of radioactive release. Another level of design basis is associated with the confinement. Failure of the target auxiliary cooling function should not occur, but for defense-in-depth reasons, the present intention is to engineer confinement to limit releases, even in the event of target overheating, for most or all scenarios in which beam-trip has not failed. If the beam-trip fails, or if

- Section 8.3.2 is based on Brookhaven National Laboratory document APT/GAG/081993/016, August 1993. 
an extremely unlikely sequence of failures leads both to target overheating and failure to contain releases, then the situation is beyond all design bases.

Three DBEs are discussed below:

Window failure

Large-break LOCA (LBLOCA): one active cooling system responding

Fire in radioactive system

Events 1 and 2 are DBEs for the cooling systems; they result in minimal or no release of radionuclides to the confinement. Event 3 has not been analyzed.

\subsubsection{Window Failure}

The evaluation of this event assumes that all plant protection safety systems function as designed. This event will not result in any release of radionuclides to the confinement.

\subsubsection{LBLOCA: One Active Cooling System Responding}

This accident assumes that all plant-protection safety systems function as designed. The worst single failure in an active system responding to the initiating event is assumed to occur. The source term for this event will consist of a small fraction of the circulating inventory of tritium released from the $\mathrm{D}_{2} \mathrm{O}$ coolant that is expelled into the confinement. The source term to the environment will be a small fraction of this and is expected to be determined by the confinement leakage rate.

\subsubsection{Fire in Radioactive Waste System}

The complete survey needed to determine the limiting radioactive waste system fire has not been completed. This is due, in part, to the fact that the design information needed to complete such a survey has not yet evolved. In all cases, applicable release criteria will be satisfied.

\subsubsection{SILC Target Tritium Extraction}

The DBEs for the SILC target tritium extraction and purification process are based on those analyzed for the new Tritium Extraction Facility that was designed to replace existing gas purification and extraction furnace facilities in Building 232-H at the Savannah River Site [16]. The largest design basis release of tritium to the environment was $1.2 \times 10^{6} \mathrm{Ci}$. This release could occur if a deflagration accident occurred because the operator failed to remove tritium from the equipment before opening a glovebox for maintenance and an ignition source was present. Several types of events could lead to tritium leaks, although most would only release the tritium to a cell or glovebox. A release of $5.0 \times 10^{4} \mathrm{Ci}$ is a reasonable upper bound on the amount that could be released to the environment.

Tritium release from storage containers was not considered due to uncertainties in the amount to be stored on site. 


\subsubsection{He-3 Target}

Four DBEs were chosen for analysis because they represent a range of potential releases to the environment: (a) a single helium-tube break, (b) a window failure, (c) a fire in the most critical radioactive waste area, and (d) a LBLOCA with active systems responding as designed and a single failure in the most critical active system responding to the initiator. Descriptions of these events are provided below.

\subsubsection{Single Helium-Tube Break*}

This radiological release to the confinement for this event is bounded by the BDBE entitled "Multiple Helium-Tube Break or Chamber Failure," documented in Section 8.4.4.2. The source term will be bounded by the bounding $\mathrm{BDBE}$ for this $\mathrm{DBE}$ (5500 $\mathrm{Ci}$ to the environment during the first 24 h).

\subsubsection{Window Failure ${ }^{*}$}

In the He-3 design, the mechanical interface between the accelerator beam transport tube and He-3 vessel of the target/blanket is a double-walled window made of Inconel 718. One window is attached to the He-3 vessel of the target/blanket assembly. The remaining window is attached to the accelerator beam transport tube. The MPCS provides for the forced circulation of cooling water $\left(\mathrm{D}_{2} \mathrm{O}\right)$ through the inner space between the two windows. Two scenarios must be considered: failure of the window attached to the $\mathrm{He}-3$ vessel and failure of the window attached to the accelerator beam transport tube. The windows will be designed so that the failure of one window does not lead to the subsequent failure of the remaining window.

Failure of the window attached to the He-3 vessel. The MPCS average coolant pressure is approximately $310 \mathrm{kPa}$ (45 psia) in the window. The He-3 vessel operating pressure is $2.1 \mathrm{MPa}$ (300 psia). Upon failure of the window, gas will flow from the He-3 vessel into the MPCS; the pressure in the MPCS will increase and the beam will be tripped. A small amount of tritium will accompany the flow of He-3 into the MPCS. However, the integrity of the MPCS pressure boundary will be retained and there will be no release of radioactivity to the confinement.

Failure of the window attached to the accelerator beam tube. The MPCS operating pressure is approximately $310 \mathrm{kPa}$ (45 psia) in the window. The accelerator beam-transport tube is evacuated. Upon failure of the window, cooling water will be ejected into the accelerator beam tube; all or a significant fraction of the cooling water will vaporize. The introduction of water vapor and possibly some water into the accelerator beam-transport tube will be rapidly detected by accelerator beamtransport-tube protection systems. Upon detection of water vapor in the accelerator beam-transport tube, the beam will be tripped. In addition, redundant fast-acting gate valves will close and isolate the accelerator beam-transport tube from the window region. A small amount of vapor will pass into the accelerator beam-transport tube before closure of the gate valves. However, the accelerator

- Sections 8.3.4.1 and 8.3.4.2 are based on Los Alamos National Laboratory, "APT ${ }^{3}$ He Target/Blanket Topical Report," Los Alamos National Laboratory report, LA-CP-94-27, Revision 1, Vol. 1, March 1994. 
beam-transport tube is a sealed system having pressure integrity that will be retained. Therefore, the activity released from the MPCS will remain in the accelerator beam-transport tube. It will be allowed to decay in place before cleanup activities are started. No activity will be released to the environment.

\subsubsection{Fire in Radioactive Waste System*}

The complete survey needed to determine the limiting radioactive waste system fire has not been completed. This is due, in part, to the fact that the design information needed to complete such a survey has not yet evolved. In all cases applicable release criteria will be satisfied.

\subsubsection{LBLOCA With One Active Residual Heat-Removal System*}

A double-ended guillotine cold-leg break near the pump discharge was simulated with the TRACPF1/MOD3 computer code for $180 \mathrm{~s}$. For this DBE, the plant protection and safety systems performed as designed. The analysis assumed the most limiting single failure was the loss of power to one residual heat-removal system pump.

The short-term ( 0 to $50 \mathrm{~s})$ transient results were very similar to the BDBE LOCA. At $60 \mathrm{~s}$, one of the two residual heat-removal systems was turned on to provide long-term rod-bundle cooling. At $180 \mathrm{~s}$, the rod-bundle temperatures had flattened out at approximately $340 \mathrm{~K}(152 \mathrm{~F})$ and would be expected to decrease in time as the decay heat decreased.

The source term to the confinement for this DBE is judged to be similar to and bounded by the source term for the LBLOCA (see Section 8.4.4.4).

\subsubsection{He-3 Target Tritium Extraction}

Only one DBE has been identified for the He-3 target tritium-extraction system. This event is a major tritium release into a glovebox followed by a failure of secondary containment. Significant releases of tritium (approximately $1000 \mathrm{Ci}$ ) to the secondary containment may occur at a frequency of less than one per year. If in addition to the release to the secondary containment a total failure of the secondary containment occurred, the tritium released into the building would be removed by the atmospheric cleanup system. Experience at TSTA suggests that this system will operate with a tritium recovery efficiency of at least $99.99 \%$. For a release of 100 grams into the building, the release to the environment would be less than $100 \mathrm{Ci}$.

Tritium release from storage containers was not considered due to uncertainties in the amount to be stored on site.

\footnotetext{
- Sections 8.3.4.3 and 8.3.4.4 are based on Los Alamos National Laboratory, "APT ${ }^{3}$ He Target/Blanket Topical Report," Los Alamos National Laboratory report, LA-CP-94-27, Revision 1, Vol. 1, March 1994.
} 


\subsection{Beyond Design Basis Events}

BDBEs are of extremely low probability because of the many different beam and target sensors that must fail. Any of these indicators would shut down the beam in a matter of microseconds and mitigate the accident.

\subsubsection{Accelerator}

The only accelerator and beam-transport system BDBE that has any significant probability involves misdirection or misfocusing of the beam that is not terminated rapidly by the fast protection system, leading to vacuum seal failure, outright breaching of the vacuum system envelope, or partial melting of critical accelerator structures. Such an accident would admit air to the accelerator, causing cavity arc-downs, tripping the RF stations off, and terminating the acceleration. Depending on the location of the damage and its severity, repair and replacement could take from several hours to a week. The major consequence would be lost production time. Lesser consequences would be the cost of replacement parts, and possibly elevated radiation doses to service personnel during the replacement activity.

With respect to personnel shielding, the maximum credible beam loss accident is defined (in accordance with LAMPF and Superconducting Super Collider definitions) as loss of the entire 200 $\mathrm{mA}$ beam at $1 \mathrm{GeV}$ for a period of $1 \mathrm{~h}$. The corollary assumption is that the beam loss is so distributed over a sufficient length of accelerator or beam-transport $(>100 \mathrm{~m})$ that the local power deposition in the vacuum wall is not great enough to cause melting or rupture of the envelope. If the vacuum is lost, beam operation would terminate immediately. The thickness of earth shielding over the APT linac and beam-transport tunnels has been sized to keep radiation doses well below maximum acceptable levels (100 mrem per accident for controlled areas and 10 mrem for open areas) even in such a worst-case scenario. This thickness is much greater than that needed for protection against normal operating beam losses.

\subsubsection{SILC Target ${ }^{*}$}

Six BDBEs for the SILC target are discussed below:

Single assembly flow blockage with delayed beam-trip.

Small-break LOCA (SBLOCA) with delayed beam-trip.

LBLOCA: total failure of active cooling systems, passive cooling systems are available.

LBLOCA: total failure of active cooling systems, passive cooling systems are available, confinement fails.

- Section 8.4.2 is based on Brookhaven National Laboratory document APT/GAG/081993/016, August 1993. 
LBLOCA: total failure of active cooling systems and nonmechanistic failure to establish natural circulation in the unbroken loop.

LBLOCA: total failure of active cooling systems and nonmechanistic failure to establish natural circulation in the unbroken loop, confinement fails.

The first two events involve delayed beam-trips that are beyond design basis by definition, since delay is relative to the timing assumed in the safety analysis. The third event is an internally initiated LOCA. The fifth event involves multiple failures and nonmechanistic evolutions leading to significant target damage, but is still within the proposed design basis of the confinement. The fourth and sixth event are the externally initiated counterparts of the third and fifth events.

\subsubsection{Single-Assembly Flow Blockage With Delayed Beam-Trip}

The single-assembly flow blockage with delayed beam-trip is a BDBE. The event scenario assumes a total blockage of a single lead source pressure tube. It is an objective of the SILC target design effort that the source pressure tubes will be designed to prevent total blockage. In the present design of the lead source assembly, approximately $20 \%$ of the cross-sectional area of the pressure tubes is open for coolant flow between the wire-wrapped source rods; however, this area is broken into hundreds of subchannels between the rods, making complete blockage of an entire pressure tube inlet essentially impossible. No mechanism for such a blockage has been identified. Such a condition would be discovered during installation inspection procedures. It is currently expected that not only will each source pressure tube have outlet temperature instrumentation, but also the entire source primary coolant system (SPCS) will be heavily instrumented with temperature, pressure, flow rate, and liquid level instrumentation. As a result, such a blockage event would be immediately identified as an off-normal condition. Pressure and temperature signals in and around the blocked pressure tube would immediately signal to trip the proton beam once they went out of range of operating limits set by technical specifications. Assuming that this is when the coolant temperature in the affected pressure tube reaches saturation, the beam would be tripped and the primary-coolant-system flow would be continued. At decay heat levels in the source rods, saturated boiling of the source coolant in the blocked pressure tube would continue with cold coolant reflooding into the pressure tube from the upper header to replenish the coolant lost by boiling. Since the heat flux at the top of the source rods would be less than the critical heat flux, reflooding of the pressure tube would occur. If deemed necessary, the source basin flood system could be actuated to flood the source basin, thus aiding in decay heat removal and ensuring that no target damage occurred. There would be no melting of the lead source material, no breach of the SPCS, and no release of activity to the confinement. Production could resume if the blockage were removed. Otherwise, operation of the tandem target system could be ordered in order to resume production.

\subsubsection{SBLOCA With Delayed Beam-Trip}

The SBLOCA with delayed beam-trip is a BDBE. A SBLOCA is assumed to occur in one source pressure tube inside the floodable source basin room. The SBLOCA proceeds undetected and the proton beam remains on target. Inventory of $\mathrm{D}_{2} \mathrm{O}$ is lost from the break location and accumulates in the source basin. As liquid inventory is lost, $\mathrm{D}_{2} \mathrm{O}$ is discharged into the SPCS by the 
pressurizer/accumulator system to make up the losses. While the accident continues undetected, the liquid levels in the pressurizer and accumulator would decrease and, simultaneously, the gas space pressures in the accumulator and pressurizer would decrease. At the same time, as $\mathrm{SPCS}_{2} \mathrm{O}$ is flowing out the break and accumulating in the source basin, some of the circulating inventory of tritium would also be released to the confinement. Eventually, the detection of airborne radiation in the confinement atmosphere by the confinement radiation instrumentation, the detection of decreasing levels of pressure and liquid inventory in the pressurizer and accumulator by instrumentation in the SPCS, or a combination of multiple signals would indicate that a break had occurred. The beam and the SPCS pumps would be tripped. The basin flood system would be actuated, filling the source target basin within $90 \mathrm{~s}$ and submerging the break location. Once the SPCS pumps have coasted down, the break flow would stop and the residual heat removal system (RHRS) would be actuated (if not already running) to remove decay heat from the source target. Both RHRS loops are sized for full decay-heat removal capacity to ensure success of cooling the source bundles. The two loops of the SPCS would remain full of $\mathrm{D}_{2} \mathrm{O}$ and the accident would be terminated with no damage to the lead-spallation target assembly. The source basin recirculationheat exchanger with a $1 \mathrm{MW}$ heat transfer capacity would also be available to assist in decay heat removal from the source pressure tubes. In the absence of any damage to the source rods due to overheating, the release of radioactivity from the SPCS to the confinement would be at most a fraction of the circulating inventory of tritium in the $\mathrm{D}_{2} \mathrm{O}$ coolant, a quantity that will be set by regulations. An upper bound can be set on this source term equal to the total inventory of tritium in the SPCS. In fact, the actual source term would be less than that amount; a more likely value would appear to be $50 \%$ of the circulating inventory of tritium, based upon capacities of the SPCS piping and the capacities of the pressurizer and accumulator. No release of spallation or fragmentation products from the neutron source is predicted for this accident, since there would be no melting or breach of the cladding on the spallation rods.

\subsubsection{LBLOCA: Total Failure of Active Cooling Systems, Passive Cooling Systems Available}

In this scenario, a large double-ended pipe break is assumed to occur in the cold leg outside the basin. This is immediately followed by a successful beam-trip, tripping of pumps, and activation of the TCFS. However, a break in this location cannot be covered by the basin flood system. This break location was chosen to be conservative. It is further assumed that all active-cooling systems fail. As the coolant leaks from the primary system, the accumulator and the pressurizer begin to discharge their water inventories. The heavy-water coolant leaks from both ends of the break. The water discharged from the pressurizer flows directly through one end of the break without going through the source. Part of the accumulator water discharged is circulated through the source pressure tubes during the pump coastdown period, and the remaining flow is discharged from the other side of the break in the cold leg via the bottom header of the source. Since the decay heat at this time is only about $1 \%$ of operating power, the spallation source rods would cool during this period. Assuming an exponential pump coastdown with a time constant of $10 \mathrm{~s}$, it was calculated that at the end of the pump coastdown period ( $45 \mathrm{~s}$ ) the source rods would have cooled to $62 \mathrm{C}$ (144 F). This temperature $\dot{\mathrm{s}}$ not sensitive to the assumed pump coastdown characteristics. By this time, the accumulator and the pressurizer will have discharged and the broken loop will have drained to the break location. However, due to the partial vacuum in the accumulator, the second loop would remain full of water. The source rods would begin to heat up after the pump coastdown flow has 
ended. After $90 \mathrm{~s}$, the source basin would be fully flooded and would thus present an additional heat sink for the decay heat in the source pressure tubes. As the source rods heat up, thus heating the $\mathrm{D}_{2} \mathrm{O}$ adjacent to the source, natural convection would be established in the unbroken primary coolant loop, thus providing a mechanism to remove the decay heat from the spallation source to the source secondary-cooling system. It is estimated that the source temperature would remain well below the saturation temperature for $\mathrm{D}_{2} \mathrm{O}$. Therefore, no damage to the lead source rods would result. It is noted that there would be ample time to establish natural convection (bulk flow through the pressure tubes) in the unbroken loop. For example, if the natural convection in the unbroken loop is neglected and the basin water is considered to be the only heat sink for the source pressure tubes, the average source temperature will have reached only $353 \mathrm{~K}(176 \mathrm{~F})$ after $12 \mathrm{~h}$. Natural convection through the unbroken loop would certainly be established within this time frame. The source term to the confinement for this accident would be the entire circulating inventory of tritium in the SPCS.

\subsubsection{LBLOCA: Total Failure of Active Cooling Systems, Passive Cooling Systems Available, Loss of Confinement}

This scenario is the same as that described in 8.4.2.3 with the exception of confinement failure due to the externally initiated nature of the accident. In this case the source term to the environment, not the confinement, would be the entire circulating inventory of tritium in the Source Primary Coolant System (SPCS).

The probability of this event is based on the assignment of a Performance Category of 3 [17] to the facility. This corresponds to an annual probability of exceedance of about $10^{-4} /$ year for damage beyond which hazardous material confinement is impaired. In addition to that, it is assumed that the conditional probability of a LBLOCA is 0.1 . This results in a probability of $10^{-5} /$ year for this accident scenario.

\subsubsection{LBLOCA: Total Failure of Active Cooling Systems Plus Nonmechanistic Failure to Establish Natural Circulation in the Unbroken Loop}

A more bounding source term may be estimated by continuing the scenario in Section 8.4.2.3 in time and by further assuming that all passive-cooling systems fail as well as all the active cooling systems. The only system that is assumed to function is the TCFS, a passive water dump tank whose function is to flood the target room in the event of a LOCA. This scenario is similar to the scenario in Section 8.4.2.3 except that it is postulated that natural circulation (bulk flow through the pressure tubes) in the unbroken loop is not established. The probability of this accident will place it into the residual risk category. However, it is proposed to be within the design basis of the confinement.

The source temperature history for this case is identical to that of the case above up to the end of the pump coastdown, which occurs $45 \mathrm{~s}$ after the instant of break in the cold leg. From 45 to $90 \mathrm{~s}$, the time at which the basin is completely flooded, it is assumed that the source heats up adiabatically. At $90 \mathrm{~s}$, the average temperature of the spallation source is calculated to be $338.5 \mathrm{~K}(150 \mathrm{~F})$.

After the basin has been flooded with cold water, the following mechanisms for the heat transfer from the source rods to the water in the basin are considered. The source rods transfer heat to the pressure 
tubes via conduction and natural convection (natural convection within each pressure tube, wherein the hot fluid from the central region rises upward and cold fluid along the walls of the cold pressure tube moves downward). The pressure tubes transfer energy to the basin water via natural convection on the basin side. Due to the high thermal conductivity of the aluminum pressure tubes, the thermal resistance of the pressure tubes is negligible.

Since the failure of all active systems is assumed, the water in the basin is assumed to heat up adiabatically due to heat transfer from the source pressure tubes. Transient heat transfer calculations show that the source reaches the saturation temperature of $374 \mathrm{~K}(214 \mathrm{~F})$ at 22.8 hours. Fromthis time onward, the heavy water within the source would boil off. At approximately $31 \mathrm{~h}$ into the accident, the water inventory from the unbroken loop drains as the upper header is uncovered. This $\mathrm{D}_{2} \mathrm{O}$ inventory (at $335 \mathrm{~K}$ ) would sweep through the source pressure tubes and the upper header rapidly, displacing the saturated water with the cold water from the unbroken loop. This would result in a rapid cool-down of the source pressure tubes, but only for a very short time. The source rods and water would reheat to saturation in less than 30 minutes.

Calculations show that at $37.2 \mathrm{~h}$, the basin water would have reached $373 \mathrm{~K}(212 \mathrm{~F})$. Therefore, from this time forward, heat would be transferred from the pressure tubes to the basin water via boiling heat transfer. At $43.6 \mathrm{~h}$ into the accident, the $\mathrm{D}_{2} \mathrm{O}$ inventory in the upper header of the source would have been boiled off and the source rods would begin to be uncovered. At $48.4 \mathrm{~h}$ the source would have boiled dry. Until this time, the temperature of the spallation source had not exceeded the $\mathrm{D}_{2} \mathrm{O}$ saturation temperature. From this time onward, the source rods heat up. At $50.4 \mathrm{~h}$ into the accident, while the average source temperature has only reached $492 \mathrm{~K}(426 \mathrm{~F})$, the centerline temperature in the pressure tubes has reached the melting point of lead $(600 \mathrm{~K}, 621 \mathrm{~F})$. At this time, lead in the central regions of the pressure tubes will begin to melt. When the average source temperature reaches 576 $\mathrm{K}(577 \mathrm{~F})$, heat transfer from the source rods to the pressure tbes would be equal to the decay heat, assuming that the source had operated continuously for one year prior to the accident. This occurs at 57.3 hours. Since the decay heat would be continuously decreasing with time, from this time onward the source rods would cool. By this time, $26.8 \%$ of the lead in the source rods would have melted, relocated to the bottom header, frozen, and quenched. Beyond this time the average source temperature would continuously decrease; the system would be coolable. It is noted that due to the design of the structures above the basin and the basin flood tank, all the steam produced from the boiling of basin water would be condensed and returned to the basin. Therefore, the basin would remain flooded. It is also noted that after three days, only $2854 \mathrm{~kg}(6290 \mathrm{lb})$ of water in the basin would have been boiled off. If the assumption were made that the water boiled off from the basin were not returned but just lost as steam, the decrease in the basin water level after three days would be approximately $15 \mathrm{~cm}$ (5.9 in).

As the lead in the source pressure tubes begins to melt (at $50.4 \mathrm{~h}$ ), it would relocate downward freely and freeze and quench in the inlet header that is full of water. None of the quenched debris from the previously molten lead from the damaged spallation rods is expected to be released from the piping of the primary cooling system; once the melt is quenched, it is assumed to remain in the inlet header in a coolable configuration. If any of the source pressure tubes were to fail due to contact with the melt at any time before $57 \mathrm{~h}$ (termination of melting), the basin water would flood into the break location, flood the source pressure tubes to the level of the basin water, and quench the overheated rods. This 
would immediately terminate the melting process and there would be no further release of radionuclides to the confinement. Provisions are being considered to preserve this possibility in the design of the SILC target for managing accidents. The availability of such an option (i.e., the ability to flood the spallation source with basin water before damage to the source rods) could preclude target damage during any accident with beam-off as long as the basin flood system was available.

During the melting period, the lead is calculated to heat only to its melting point of $600 \mathrm{~K}(621 \mathrm{~F})$. The molten lead from the damaged spallation rods would remain molten only as long as it took to fall under gravity into the water in the inlet header. This would be on the order of $1 \mathrm{~s}$ (calculated to be $0.65 \mathrm{~s}$ for a $2-\mathrm{m}(6.56-\mathrm{ft})$ fall). There is more than $2000 \mathrm{~kg}(4410 \mathrm{lb})$ of $\mathrm{D}_{2} \mathrm{O}$ in the lower header, an order of magnitude more water in the lower header to freeze and quench the lead debris than would be necessary. The melting of the spallation source would continue for $7 \mathrm{~h}$ (until $57.3 \mathrm{~h}$ into the accident), at which time the heat losses would exceed the decay heat (which is continuously decreasing); thus, from $57.3 \mathrm{~h}$ on, the source temperature would continue to decrease and melting would be arrested. The peak average temperature of the spallation source was calculated to be just $576 \mathrm{~K}(577 \mathrm{~F})$. Over this period of $7 \mathrm{~h}$ of melting, it is calculated that $27 \%$ of the lead would have been melted $(6600 \mathrm{~kg}$ $\left(1.45 \times 10^{4} \mathrm{lb}\right)$ of lead) and that it would have required the vaporization of $162.5 \mathrm{~kg}(358 \mathrm{lb})$ of water to freeze and quench this mass of debris in the inlet header. Since the cross-sectional area for upflow in all the source pressure tubes is $0.36 \mathrm{~m}^{2}\left(3.87 \mathrm{ft}^{2}\right)$, this results in an average steam velocity through all the spallation source pressure tubes of approximately $3 \mathrm{~cm} / \mathrm{s}(1.2 \mathrm{in} / \mathrm{s})$.

The driving force for the volatilization and transport of radionuclides from the molten lead would be minimal at best. Since the lead relocation process (free fall) will limit the time during which the lead will be molten to the order of seconds, rate-limiting processes such as mass diffusion in the molten lead will play a dominant role in limiting the vaporization release of radionuclides such as mercury and must be considered. Those radionuclides that would be released from the melt would be carried upwards through the densely packed pressure tubes by the steam flow from the lower header of 3 $\mathrm{cm} / \mathrm{s}(1.2 \mathrm{in} / \mathrm{s})$, through the upper header and the SPCS piping, through the pump and heat exchanger, and finally out the break location and into the confinement air space.

Release fractions for different spallation and fragmentation products that have built up in the lead spallation target have been calculated at Sandia National Laboratories (SNL) [18]. These release fractions were then integrated over time and applied to the inventory of radionuclides in the lead spallation target that was calculated by LANL with the CINDER90 code. The inventory that was the basis for these calculations is that predicted to occur after a one-year proton irradiation at $1.0 \mathrm{GeV}$ and 200 $\mathrm{mA}$. The short half-lives of the releasable radionuclides makes this appropriate for use following two one-year cycles. Using this information, an aerosol decontamination factor during transport through the confinement of 2 , and a $5 \mathrm{vol} . \% /$ day leak rate from the confinement, the release to the atmosphere over the first $30 \mathrm{~h}$ of release due to the accident was calculated. The decontamination factor specified above applies only to the release of spallation and fragmentation products. The release of the maximum circulating inventory of tritium in the SPCS $\left(6.0 \times 10^{4} \mathrm{Ci}\right)$ to the confinement was assumed. This inventory is based on a maximum concentration in the heavy water of $2.0 \mathrm{Ci} / \mathrm{L}$. Based on these analyses, a bounding source term to the environment was developed and is shown in Table 8-2. 
Several conservatisms are include in the source term in Table 8-2. For example, the release fractions were applied to the entire target, not just the melted portion. In addition, experimental data suggest that the release of mercury is much lower than that shown here [2].

Although detailed analyses have not been completed at this time, the estimated frequency is based on the following. Estimates of Loss of Coolant Accidents (LOCAs) for nuclear power plants are $5 \times 10^{-4} /$ year for a Pressurized Water Reactor (PWR) for a leak rate of greater than $50 \mathrm{gpm}$ and $7 \times 10^{-4} /$ year for a Boiling Water Reactor (BWR) for a leak rate of greater than $5000 \mathrm{gpm}$ [19]. These values are for leaks, whereas the high consequence accident begins with an instantaneous double-ended guillotine break. We therefore think that this probability is conservative. In addition to the LOCA in one of the coolant loops, active and passive cooling must fail in the second coolant loop and both of the residual heat removal systems must fail. The natural circulation in the second, independent, coolant loop could be inhibited by void formation in the piping or by failure of the piping. Similar failures would have to occur in the two independent residual heat removal systems. It is assumed here that the conditional probability each of these failures is 0.1 . The combination of these independent failures, using the largest frequency, results in an estimated frequency of $7 \times 10^{-7} /$ year.

\subsubsection{LBLOCA: Total Failure of Active Cooling Systems Plus Nonmechanistic Failure to Establish Natural Circulation in the Unbroken Loop and Loss of Confinement}

This scenario is an externally initiated version of the scenario described in Section 8.4.2.5. The loss of systems is the same with the exception of the confinement which is assumed to fail in this scenario. The postulated source term to the environment is shown in Table 8-3 for this scenario.

The probability of this event is also based on the assignment of a Performance Category of 3 [17] for the facility. This results in a probability of $10^{-4} /$ year for damage due to a seismic event. In addition to that, it is assumed that the conditional probability of a LBLOCA is 0.1 . In order for the passive and active systems to fail to cool the target at decay heat levels, the unbroken loop of the SPCS and both active cooling systems of the Source Residual Primary Cooling System (SRPCS) must fail. The assignment of a probability of 0.1 to each of these failures results in a total probability of $10^{-8} / y e a r$ for this scenario.

\subsubsection{SILC Target Tritium Extraction}

A BDBE could potentially release more tritium than the events discussed in Section 8.3.3. A reasonable upper limit of the release would be approximately an order of magnitude higher due to some massive failure of confinement [16].

\subsubsection{He-3 Target}

Six BDBEs that demonstrate a range of events are documented below. They are (a) a single-assembly flow blockage with delayed trip, (b) multiple helium-tube-break or chamber failure, (c) a LBLOCA with total failure of all active cooling systems, (d) a LBLOCA with total failure of all active cooling systems and loss of confinement, (e) LBLOCA with total failure of the ECS and loss of the ultimate 
heat sink, and (f) LBLOCA with total failure of the ECS and loss of the ultimate heat sink and loss of confinement.

\subsubsection{Single-Assembly Flow Blockage With Delayed Beam-Trip*}

The single-assembly flow blockage with delayed beam-trip is a BDBE. The event scenario assumes a total blockage of a single tungsten rod-bundle. It should be noted that the tungsten rod-bundles will be designed to preclude total blockage. Normally, an increase in fluid temperature would be detected by the redundant tungsten rod-bundle outlet's coolant-temperature sensors. All the sensors in the blocked bundle are assumed to fail and thus the beam is not tripped. The heavy water coolant in the blocked tungsten rod-bundle rapidly heats to saturation and evaporates. In the absence of coolant and with the beam still on, the tungsten rods will heat in a near-adiabatic environment. Some beam energy will also be deposited in the hexagonal duct of the tungsten rod-bundle. The duct is made of Inconel 718. Although the temperature of the Inconel duct will begin to rise, it will be at a slower rate than the tungsten rods because the energy deposition is smaller and a heat sink exists on the outside of the duct where $\mathrm{He}-3$ is circulating. As the temperature of the tungsten rods increases, radiative heat transfer to the Inconel duct will increase, the temperature of the Inconel duct will rise, and the duct will eventually fail. Once the Inconel duct fails, one or more detectors in the He-3 system will indicate that acceptable limits have been exceeded and the beam will be tripped. Although it is possible to perform analyses to identify and evaluate the Inconel duct failure mechanism, the subsequent trip mechanisms, and the conditions of the tungsten rod-bundle at the time of duct failure, the bounding release of activity into the TPCS and the circulating system for $\mathrm{He}-3$ was determined. As an upper bound, the total activity inventory of a single tungsten rod-bundle is assumed to be released. The activity in a single bundle available for release under this scenario is $1.633 \times 10^{6} \mathrm{Ci}$. The fractions of the total activity that will enter the TPCS and the circulating system for He-3, respectively, have not been determined. However, since both the TPCS and circulating system for He-3 are primary structural boundaries, there will be no release of radioactivity to the confinement.

Subsequent failures have also been considered. The He-3 pressure boundary will be protected against overpressurization by the tungsten coolant in two ways. First, the design pressure for the He-3 pressure boundary will be chosen to prevent failure from a TPCS leak. Second, a pressure relief valve will be provided to further protect the $\mathrm{He}-3$ pressure boundary. Any fluid released through the pressure relief valve will be released to a container so that there will be no release to the environment. The possibility that the heatup of the Inconel could, either before or shortly after beam-trip, lead to failure of the penetration at the chamber/moderator tank interface was considered. A scoping calculation was performed to determine the magnitude of conduction axially in the duct. This calculation showed that axial conduction is significantly less than radiation heat transfer from the surface of the tungsten rods to the Inconel duct. Therefore, we conclude that failure of the duct at the penetration will not occur. We note, however, that should this postulated failure occur, the activity would be released to the moderator tank. The activity would still be contained within a primary pressure boundary and there should be no release to the confinement.

- Section 8.4.4.1 is based on Los Alamos National Laboratory, "APT ${ }^{3}$ He Target/Blanket Topical Report," Los Alamos National Laboratory report, LA-CP-94-27, Revision 1, Vol. 1, March 1994. 
Table 8-2. BDBE Environmental Source Term for the SILC Target With No Confinement Failure.

\begin{tabular}{|c|c|}
\hline Isotope & $\begin{array}{c}\text { Released } \\
\text { Activity }(\mathrm{Ci})\end{array}$ \\
\hline $\mathrm{H}-3$ & 1900 \\
\hline $\begin{array}{c}\mathrm{Hg}-197 \\
\mathrm{~F}-18 \\
\mathrm{Kr}-83 \mathrm{~m} \\
\end{array}$ & $\begin{array}{l}1065 \\
1039 \\
1039 \\
\end{array}$ \\
\hline $\begin{array}{c}\mathrm{Hg}-195 \\
\mathrm{Kr}-79 \\
\mathrm{Xe}-125 \\
\mathrm{Xe}-127 \\
\end{array}$ & $\begin{array}{l}518 \\
477 \\
465 \\
320 \\
\end{array}$ \\
\hline $\begin{array}{c}\mathrm{Kr}-88 \\
\mathrm{Kr}-85 \mathrm{~m} \\
\mathrm{Br}-83 \\
\mathrm{Kr}-87 \\
\end{array}$ & $\begin{array}{l}259 \\
258 \\
243 \\
221 \\
\end{array}$ \\
\hline $\begin{array}{c}\mathrm{Hg}-193 \\
\mathrm{Br}-82 \\
\mathrm{Br}-76 \\
\mathrm{Hg}-203 \\
\end{array}$ & $\begin{array}{l}211 \\
193 \\
177 \\
136 \\
\end{array}$ \\
\hline $\begin{array}{c}\mathrm{Hg}-192 \\
\mathrm{I}-125 \\
\mathrm{I}-123 \\
\mathrm{I}-126 \\
\end{array}$ & $\begin{array}{c}115 \\
113 \\
101 \\
84 \\
\end{array}$ \\
\hline $\begin{array}{c}\mathrm{Br}-84 \\
\mathrm{Br}-77 \\
\mathrm{Xe}-122 \\
\mathrm{I}-121 \\
\end{array}$ & $\begin{array}{l}83 \\
79 \\
77 \\
76 \\
\end{array}$ \\
\hline $\begin{array}{l}\mathrm{I}-124 \\
\mathrm{I}-120 \\
\mathrm{I}-130 \\
\mathrm{I}-128 \\
\end{array}$ & $\begin{array}{l}64 \\
55 \\
54 \\
45 \\
\end{array}$ \\
\hline $\begin{array}{c}\mathrm{Hg}-197 \mathrm{~m} \\
\mathrm{I}-122 \\
\mathrm{I}-131 \\
\mathrm{Hg}-195 \mathrm{~m} \\
\end{array}$ & $\begin{array}{l}40 \\
38 \\
27 \\
20 \\
\end{array}$ \\
\hline $\begin{array}{c}\mathrm{Hg}-190 \\
\mathrm{I}-133 \\
\mathrm{I}-135\end{array}$ & $\begin{array}{l}14 \\
13 \\
12 \\
\end{array}$ \\
\hline
\end{tabular}


Table 8-3. BDBE Environmental Source for the SILC Target With Confinement Failure.

\begin{tabular}{|c|c|}
\hline Isotope & Released Activity (Ci) \\
\hline $\mathrm{H}-3$ & 61000 \\
\hline $\begin{array}{c}\mathrm{Hg}-197 \\
\mathrm{~F}-18 \\
\mathrm{Kr}-83 \mathrm{~m}\end{array}$ & $\begin{array}{l}68000 \\
66000 \\
33000\end{array}$ \\
\hline $\begin{array}{c}\mathrm{Hg}-195 \\
\mathrm{Br}-83 \\
\mathrm{Kr}-79 \\
\mathrm{Xe}-127\end{array}$ & $\begin{array}{l}33000 \\
16000 \\
15000 \\
10000\end{array}$ \\
\hline $\begin{array}{c}\mathrm{Xe}-125 \\
\mathrm{Hg}-193 \\
\mathrm{Br}-82 \\
\mathrm{Br}-76\end{array}$ & $\begin{array}{l}15000 \\
13000 \\
12000 \\
11000\end{array}$ \\
\hline $\begin{array}{c}\mathrm{Hg}-20 \\
\mathrm{Kr}-88 \\
\mathrm{Kr}-85 \mathrm{~m} \\
\mathrm{Hg}-192\end{array}$ & $\begin{array}{l}8600 \\
8200 \\
8200 \\
7300\end{array}$ \\
\hline $\begin{array}{l}\mathrm{I}-125 \\
\mathrm{Kr}-87 \\
\mathrm{I}-123 \\
\mathrm{Br}-84\end{array}$ & $\begin{array}{l}7200 \\
7000 \\
6400 \\
5300\end{array}$ \\
\hline $\begin{array}{c}\mathrm{Br}-77 \\
\mathrm{I}-126 \\
\mathrm{Xe}-122 \\
\mathrm{I}-121\end{array}$ & $\begin{array}{l}5000 \\
5400 \\
2400 \\
4900\end{array}$ \\
\hline $\begin{array}{l}\mathrm{I}-124 \\
\mathrm{I}-120 \\
\mathrm{I}-130 \\
\mathrm{I}-128 \\
\end{array}$ & $\begin{array}{l}4100 \\
3500 \\
3500 \\
2900\end{array}$ \\
\hline $\begin{array}{c}\mathrm{Hg}-197 \mathrm{~m} \\
\mathrm{I}-122 \\
\mathrm{I}-131 \\
\mathrm{Hg}-195 \mathrm{~m}\end{array}$ & $\begin{array}{l}2500 \\
2500 \\
1700 \\
1300\end{array}$ \\
\hline $\begin{array}{c}\mathrm{Hg}-190 \\
\mathrm{I}-133 \\
\mathrm{I}-135\end{array}$ & $\begin{array}{l}910 \\
820 \\
760\end{array}$ \\
\hline
\end{tabular}




\subsubsection{Multiple Helium-Tube Break or Chamber Failure*}

Release of the total He-3 inventory to the confinement building is assumed if multiple He-3 tubes break or the chamber fails. Release of the associated radionuclide inventory in the circulating He- 3 is also assumed. The total release to the confinement will be $1.1 \times 10^{5} \mathrm{Ci}$. The average $\mathrm{He}-3$ temperature in the chamber and moderator tank pipes is $400 \mathrm{~K}$ (261 F). Confinement cleanup and processing systems are assumed to be inactive. Therefore, the release to the environment is at the design leak rate (estimated to be $5 \mathrm{vol} . \% / d a y)$ for the confinement building. It is estimated that for this event the tritium release to the environment will be less than $5500 \mathrm{Ci}$ during the first $24 \mathrm{~h}$. Other physical mechanisms that are likely to mitigate the tritium release from the confinement were not considered in this analysis.

\subsubsection{LBLOCA With Total Failure of Active Emergency Cooling System (ECS)*}

LBLOCA simulations have been performed with the TRAC-PF1/MOD3 computer code at several stages in the evolution of the design specifications for the TPCS. Only the most recent [20], which incorporate preliminary specifications for most of the components, will be discussed here. These simulations give a longer time for the TPCS to drain and a larger volume of liquid spilled because the volume of liquid in the TPCS is significantly larger than that earlier estimated.

Double-ended guillotine hot-leg and cold-leg breaks have been run to $1000 \mathrm{~s}$. For this DBE, the plantprotection systems were assumed to function and trip the beam at $0.2 \mathrm{~s}$, but the two active residual heat removal systems were assumed to fail. The hottest structure temperature, $432.0 \mathrm{~K}(318 \mathrm{~F})$ occurred in the cold-leg break case at the time of beam-trip. This temperature is $5.8 \mathrm{~K}(10.4 \mathrm{~F})$ higher than the corresponding steady state value. For both cases, from the time of beam-trip until the pressurizer and accumulator emptied at approximately $250 \mathrm{~s}$, the temperatures in the system were dominated by the temperature of the pressurizer and accumulator fluid entering the system. Following the emptying of the pressurizer and accumulator, fluid in the TPCS heated up to a condition that would support natural circulation. The simulation verified that the intact loop stayed liquid-filled, as it was designed to do, except for the initial 30 to $40 \mathrm{~s}$ of the transient. After the end of pressurizer and accumulator discharge, natural circulation was established in the intact loop and the maximum fluid temperatures stayed in the 340 to $365 \mathrm{~K}$ (152 to $197 \mathrm{~F}$ ) range with a slow decrease over time corresponding to the change in decay heat.

At $1000 \mathrm{~s}$, TRAC shows a total integrated break flow of approximately $27,000 \mathrm{~kg}\left(5.95 \times 10^{+} \mathrm{lb}\right)$ of liquid with a mass weighted average temperature of $316 \mathrm{~K}(108 \mathrm{~F})$. The initial $5 \mathrm{~s}$ of break flow in the hot-leg break case was at the saturation temperature with a rapid decrease in temperature after $5 \mathrm{~s}$. The cold-leg break simulation showed only subcooled flow. The mass of liquid lost from the break in both cases is greater than the mass of liquid circulating in the TPCS $(12,300 \mathrm{~kg})$. This 12,300 $\mathrm{kg}\left(2.71 \times 10^{4} \mathrm{lb}\right)$ does not include the mass of liquid in the pressurizer and accumulator and associated piping. During a LBLOCA all the liquid circulating in the TPCS could be expelled through the break plus a significant portion of the liquid from the pressurizer and accumulator. Therefore, the assumption is made that all of the circulating inventory at the start of the LBLOCA is lost instantaneously out

* Sections 8.4.4.2 and 8.4.4.3 are based on Los Alamos National Laboratory, "APT ${ }^{3}$ He Target/Blanket Topical Report," Los Alamos National Laboratory report, LA-CP-94-27, Revision 1, Vol. 1, March 1994. 
of the break to the confinement. The release to the confinement is $2.2 \times 10^{5} \mathrm{Ci}$ from the target spallation products and $1.9 \times 10^{4} \mathrm{Ci}$ of tritium, resident in the heavy-water coolant. Release to the environment during the first 24 hours would be a factor of approximately 40 lower.

\subsubsection{LBLOCA With Total Failure of Active Emergency Cooling System (ECS) and Loss of Confinement}

This scenario, which is externally initiated, results in the same plant state as that described in 8.4.4.3 with the exception of the confinement failure. The source term to the confinement was estimated at $2.2 \times 10^{5} \mathrm{Ci}$ from the target spallation products and $1.9 \times 10^{4} \mathrm{Ci}$ of tritium, resident in the heavy water coolant. With the failure of the confinement, more of the material will be released to the environment. However, most of the spallation products are not highly volatile and would therefore remain in the water.

The probability of this event is based on the assignment of a Performance Category of 3 [17] to the facility. This corresponds to an annual probability of exceedance of about $10^{-4} /$ year for damage beyond which hazardous material confinement is impaired. In addition to that, it is assumed that the conditional probability of a LBLOCA is 0.1 . This results in a probability of $10^{-5} / y e a r$ for this accident scenario.

\subsubsection{LBLOCA With Total Failure of Active ECS and Loss-of-Heat Sink}

A more bounding source term was estimated by continuing the scenario described in Section 8.4.4.3 and assuming that all heat transfer to the secondary cooling system was lost at $1000 \mathrm{~s}$. This event is likely to be in the residual risk category. At $1000 \mathrm{~s}$, the remaining coolant inventory above the lower plenum is about $7400 \mathrm{~kg}\left(1.63 \times 10^{4} \mathrm{lb}\right)$ of heavy water. We assumed that the remaining coolant will boil off due to the tungsten decay heat. Calculations show that, if no other heat transfer mechanisms are considered, this will occur in a minimum of $13.6 \mathrm{~h}$; thus the tungsten rods may be uncovered 13.6 $\mathrm{h}$ after the LOCA. Without convective cooling of the rods, they will heat up due to decay heat. Radiation heat transfer calculations show that the average steady-state tungsten rod-bundle temperatures at 13.6 $\mathrm{h}$ vary from $1490 \mathrm{~K}$ (hot bundle) to $855 \mathrm{~K}$ (cold bundle) $(2220$ to $1080 \mathrm{~F}$ ). We estimate that the environment inside the bundles will be one in which the $\left[\mathrm{H}_{2} \mathrm{O}\right] /\left[\mathrm{H}_{2}\right]$ ratio is 5.3 , and where steam flow rates are less than $1 \mathrm{~m} / \mathrm{s}(3.3 \mathrm{ft} / \mathrm{s})$. Release fractions for different chemical elements from the tungsten have been calculated. These release fractions were integrated over $30 \mathrm{~h}$ using decay heat and temperature histories in the environment specified above [18]. These release fractions were then applied to the radioactive inventory of the tungsten rods as calculated by CINDER90. The inventory used for these calculations is that predicted to occur after 600 days of irradiation and after $8 \mathrm{~h}$ of decay. The release to the confinement was assumed to be constant over the $30 \mathrm{~h}$ following uncovering of the tungsten rods. Using this information, an aerosol decontamination factor of 2, and a 5 vol.\%/day leak rate from the confinement, the release to the atmosphere during the first $30 \mathrm{~h}$ after the tungsten rods were uncovered ( $43.6 \mathrm{~h}$ after the LOCA) was calculated. Tritium in the heavy water lost through the break was assumed to be completely released to the containment. The maximum amount of tritium was calculated based on a limit of $2.0 \mathrm{Ci} / \mathrm{L}$ in the heavy water [3]. The release of noble gases from the $\mathrm{D}_{2} \mathrm{O}$ coolant to the confinement was included in the release from the tungsten, although other isotopes were assumed to not be released from the $\mathrm{D}_{2} \mathrm{O}$ coolant lost to the confinement. 
Based on these analyses, a bounding source term to the environment was developed. This is provided in Table 8-4.

Although detailed analyses have not been completed at this time, the estimated frequency is based on the following. Estimates of Loss of Coolant Accidents (LOCAs) for nuclear power plants are $5 \times 10^{-4} /$ year for a Pressurized Water Reactor (PWR) for a leak rate of greater than $50 \mathrm{gpm}$ and $7 \times 10^{-4} / \mathrm{year}$ for a Boiling Water Reactor (BWR) for a leak rate of greater than $5000 \mathrm{gpm}$ [19]. These values are for leaks, whereas the high consequence accident begins with an instantaneous double-ended guillotine break. We therefore think that this probability is conservative. In addition to the LOCA in one of the coolant loops, active and passive cooling must fail in the second coolant loop and both of the residual heat removal systems must fail. The natural circulation in the second, independent, coolant loop could be inhibited by void formation in the piping or by failure of the piping. Similar failures would have to occur in the two independent residual heat removal systems. It is assumed here that the conditional probability each of these failures is 0.1 . The combination of these independent failures, using the largest frequency, results in an estimated frequency of $7 \times 10^{-7} / y e a r$.

\subsubsection{LBLOCA With Total Failure of Active ECS and Loss-of-Heat Sink and Loss of Confinement}

This scenario results in the same plant state as that described in Section 8.4.4.5 with the exception of the confinement failure due to an external initiator. The postulated source term to the environment is shown in Table 8-5 for this scenario.

The probability of this event is also based on the assignment of a Performance Category of 3 [17] to the facility. This results in a probability of $10^{-4} /$ year for damage due to a seismic event. In addition to that, it is assumed that the conditional probability of a LBLOCA is 0.1 . In order for the passive and active systems to fail to cool the target at decay heat levels, the unbroken loop of the Tungsten Primary Coolant System (TPCS) and both active cooling systems of the Tungsten Primary Residual Heat-Removal System (TPRHRS) must fail. The assignment of a probability of 0.1 to each of these failures results in a total probability of $10^{-8} /$ year for this scenario.

\subsubsection{He-3 Target Tritium-Extraction System}

The only BDBE considered is the release of the entire tritium inventory. The initiator for this event has not been defined. With the atmospheric cleanup system operational the environmental release would be less than $1000 \mathrm{Ci}$. With a failure of the cleanup system the release of the total inventory would be through the ventilation system stack. The dose at the site boundary would depend on whether the tritium was oxidized.

Total destruction of the facility by an earthquake, subsequent oxidation of the tritium, and the release occurring at ground level is the worst case accident. 
Table 8-4. BDBE Environmental Source Term for the He-3 Target With No Confinement Failure.

\begin{tabular}{|c|c|}
\hline Isotope & Released Activity (Ci) \\
\hline $\mathrm{H}-3$ & 1500 \\
\hline W-185 & 14500 \\
\hline W-187 & 10600 \\
\hline W-181 & 2840 \\
\hline $\mathrm{W}-178$ & 910 \\
\hline $\mathrm{Xe}-127$ & 51 \\
\hline W-177 & 47 \\
\hline $\mathrm{W}-176$ & 42 \\
\hline Cs-131 & 38 \\
\hline $\mathrm{Xe}-125$ & 29 \\
\hline Cs-129 & 25 \\
\hline Cs- 128 & 22 \\
\hline $\mathrm{I}-125$ & 21 \\
\hline Ar-37 & 11 \\
\hline $\mathrm{P}-32$ & 11 \\
\hline Cs-127 & 10 \\
\hline Te-121 & 9 \\
\hline $\mathrm{I}-123$ & 8 \\
\hline $\mathrm{Kr}-79$ & 7 \\
\hline Re-186 & 7 \\
\hline $\mathrm{Xe}-122$ & 4 \\
\hline $\mathrm{I}-131, \mathrm{I}-133, \mathrm{I}-135$ & $<1$ \\
\hline
\end{tabular}


Table 8-5. BDBE Environmental Source Term for the He-3 Target With Confinement Failure

\begin{tabular}{|c|c|}
\hline Isotope & Released Activity (Ci) \\
\hline $\mathrm{H}-3$ & 48000 \\
\hline W-185 & 925000 \\
\hline W-187 & 675000 \\
\hline W-181 & 181000 \\
\hline W-178 & 57900 \\
\hline $\mathrm{Xe}-127$ & 1640 \\
\hline $\mathrm{Xe}-125$ & 930 \\
\hline Ar-37 & 340 \\
\hline $\mathrm{Kr}-79$ & 220 \\
\hline $\mathrm{W}-177$ & 3000 \\
\hline W-176 & 2660 \\
\hline Cs-131 & 2440 \\
\hline Cs-129 & 1610 \\
\hline Cs-128 & 1380 \\
\hline $\mathrm{I}-125$ & 1340 \\
\hline Cs- 127 & 670 \\
\hline Te-121 & 590 \\
\hline $\mathrm{I}-123$ & 510 \\
\hline Re-186 & 420 \\
\hline $\mathrm{Xe}-122$ & 115 \\
\hline $\mathrm{P}-32$ & 710 \\
\hline
\end{tabular}


Intentionally Left Blank 


\subsection{DESIGN APPROACH FOR MEETING A RANGE OF PRODUCTION GOALS}

The primary reasons for evaluating a Phased APT approach are the possible benefits of earlier tritium production and reduced costs if future tritium goals are reduced. This section discusses the environmental impact of two APT facilities that would produce less tritium than the $3 / 8$ goal facility. The information contained in this section is preliminary because the phased approach is a relatively new concept and adequate design work has not been performed. Nevertheless, preliminary physics and engineering calculations were performed for the He-3 target and these form the basis for the values documented here. The scaling trends documented here are expected to be similar for alternate target designs that may evolve as part of the Phased approach. This section parallels the rest of the document (i.e., subjects are discussed in the same order).

\subsection{Overview of Phased APT Design}

The Phased APT approach consists of three design concepts: (1) Phase I, (2) Phase II, and (3) the $3 / 8$ goal facility. For a Phase I facility, the accelerator would be completed to an energy of approximately $500 \mathrm{MeV}$ and the beam current would be $100 \mathrm{~mA} \mathrm{CW}(100 \%$ duty). The beam current is one half of the $3 / 8$ goal facility, thus requiring only one injector leg and no funnel. The linac tunnel and aboveground support buildings would be constructed with extra length between the end of the accelerator and the beam transport system serving the target/blanket assemblies to allow for additional high-energy accelerator installation for Phase II or the $3 / 8$ goal facility. For the Phase II facility, as for the $3 / 8$ goal facility, the accelerator would be completed to an energy of approximately $1000 \mathrm{MeV}$. The beam current for the Phase II accelerator is $100 \mathrm{~mA}$ (only one injector leg) while it is $200 \mathrm{~mA}$ (two injector legs with a funnel) for the $3 / 8$ goal accelerator. The beam current, energy, power, and total electric power needed to operate the APT system are tabulated in Table 9-1. The differences between the Phases are illustrated in Figure 9-1.

Table 9-1. Phased APT Approach Characteristics

\begin{tabular}{||c|c|c|c||}
\hline & Phase I & Phase II & $3 / 8$ goal \\
\hline Beam Current & $100 \mathrm{~mA}$ & $100 \mathrm{~mA}$ & $200 \mathrm{~mA}$ \\
\hline Beam Energy & $500 \mathrm{MeV}$ & $1000 \mathrm{MeV}$ & $1000 \mathrm{MeV}$ \\
\hline Beam power & $50 \mathrm{MW}$ & $100 \mathrm{MW}$ & $200 \mathrm{MW}$ \\
\hline Plant AC power & $197 \mathrm{MW}$ & $355 \mathrm{MW}$ & $550 \mathrm{MW}$ \\
\hline
\end{tabular}

In Phase I the accelerator will consist of a proton injector (with backup unit), 7-MeV 350-MHz radiofrequency quadrupole (RFQ), 20-MeV 350-MHz drift-tube linac (DTL), $100-\mathrm{MeV} 700-\mathrm{MHz}$ bridge-coupled drift-tube linac (BCDTL), and 500-MeV 700-MHz coupled-cavity linac (CCL). The $500 \mathrm{MeV} 100-\mathrm{mA}$ beam will drift to the end of the tunnel in an evacuated pipe, with focusing applied by quadrupole magnets installed with the same periodicity as needed for the Phase II and $3 / 8$ goal linac extension. The Phase I target/blanket units will be designed and built for optimized 


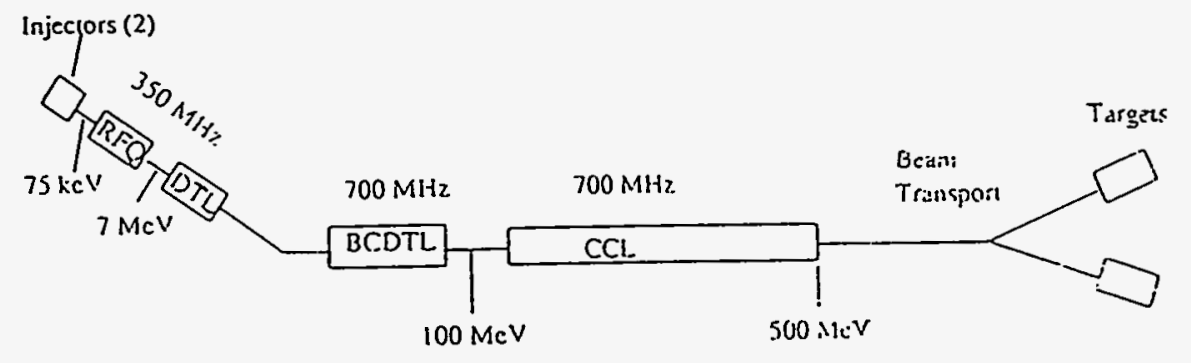

Pliase 1

. $100 \mathrm{~mA} \mathrm{CW}, 500 \mathrm{MeV}$

- Transpor line from $500 \mathrm{MeV}$ to targets

- Use downsized He-3 targel

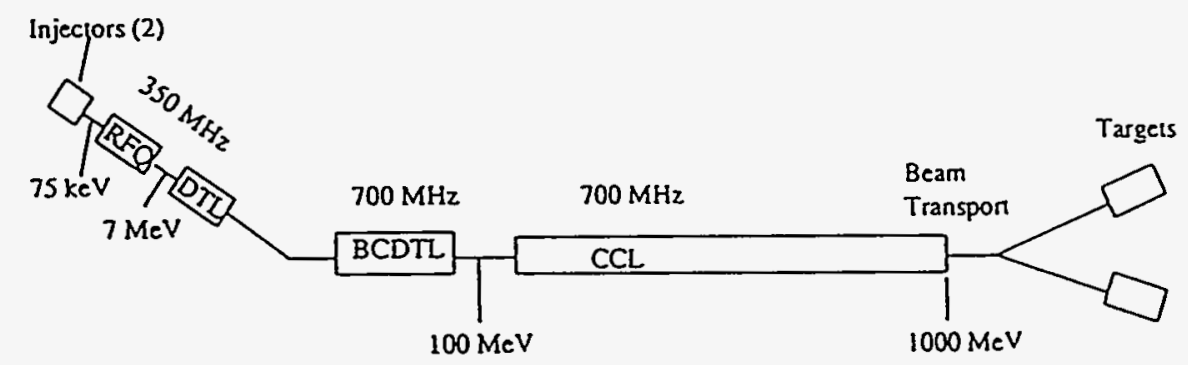

Phase II

- $100 \mathrm{~mA} \mathrm{CW}, 1000 \mathrm{MeV}$

- Use downsized He-3 target

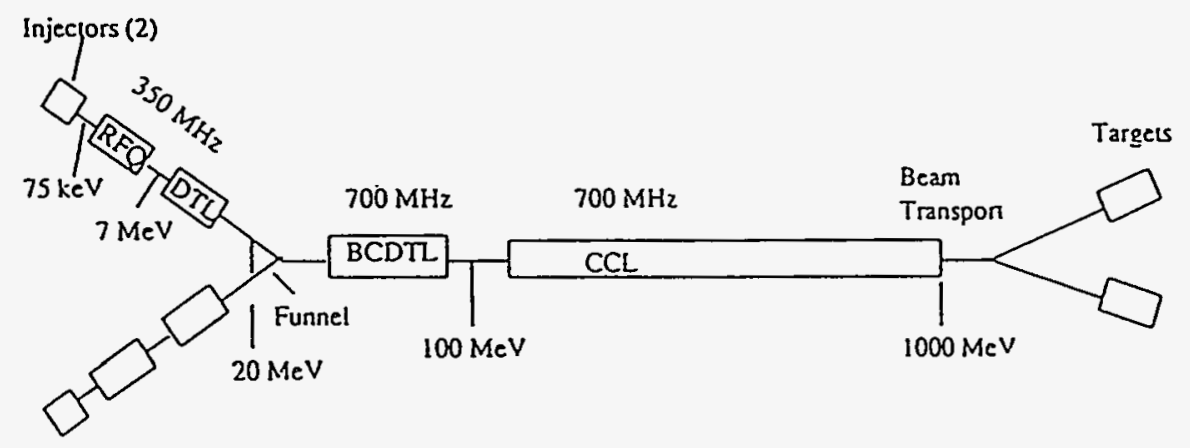

3/8 Goal APT

. $200 \mathrm{~mA} \mathrm{CW}, 1000 \mathrm{MeV}$

- Use full-sized He-3 target

Figure 9-1. Comparison of Phased APT Facilities. 
performance with the $500-\mathrm{MeV}$ beam, but the target housings and infrastructure will be sized to accommodate the larger geometry systems needed in the Phase II and the $3 / 8$ goal facility:

In Phase II, the coupled-cavity linac will accelerate protons to an energy of $1000 \mathrm{MeV}$ and the beam current would remain at $100 \mathrm{~mA}$. At this energy, neutron production is more efficient than at 500 $\mathrm{MeV}$, and tritium production will be increased by a factor of approximately 3 .

\subsection{Resource Needs during Construction}

The resource needs during construction for the Phase I and Phase II designs were estimated based on the underlying assumption that the Balance of Plant (BOP) and tritium extraction facilities will be roughly the same as for the $3 / 8$ goal design.

\subsubsection{Construction Resource Needs for the Accelerator}

The accelerator construction resource needs are shown in Table 9-2. The values in parentheses are the ratio of the resource needed to construct that facility to the resource needed to construct the $3 / 8$ facility.

Table 9-2. Construction Resource Needs for the Phased APT Accelerator.

\begin{tabular}{||c|c|c||}
\hline & \multicolumn{2}{|c||}{ QUANTITY } \\
\hline \hline RESOURCE & PHASE I & PHASE II \\
\hline Carbon Steel & $200 \mathrm{Mg}(0.50)$ & $400 \mathrm{Mg}(1.0)$ \\
\hline Stainless Steel & $130 \mathrm{Mg}(1.0)$ & $130 \mathrm{Mg}(1.0)$ \\
\hline Copper & $430 \mathrm{Mg}(0.50)$ & $830 \mathrm{Mg}(0.96)$ \\
\hline Klystrons & 115 units $(0.30)$ & 232 units $(0.60)$ \\
\hline Ion Pumps & 230 units $(0.50)$ & 460 units $(1.0)$ \\
\hline Wave Guide & $5000 \mathrm{~m}(0.50)$ & $10,000 \mathrm{~m}(1.0)$ \\
\hline
\end{tabular}

\subsubsection{Construction Resource Needs for the He-3 Target}

The construction resource needs for a single Phase I and Phase II He-3 target are based on preliminary physics and engineering calculations and are shown in Table 9-3. The $\mathrm{D}_{2} \mathrm{O}$ in the loops is assumed to be the same in the Phase I, Phase II, and 3/8 goal designs. The He-3 pressure in the chamber was assumed to be at $2.1 \mathrm{MPa}(300 \mathrm{psia})$ for the $3 / 8$ goal design and $1.8 \mathrm{MPa}(260 \mathrm{psia})$ for the other designs. The He-3 pressure in the blanket is assumed to be $690 \mathrm{kPa}$ (100 psia) and the average temperature of the He-3 was assumed to be $400 \mathrm{~K}$. The value in parenthesis is the ratio of the resource required for that Phase design to the resource required for the $3 / 8$ goal design. 
Table 9-3. Construction Resource Needs for the Phased APT He-3 Target.

\begin{tabular}{|c|c|c||}
\hline & \multicolumn{2}{|c|}{ QUANTITY } \\
\hline \hline RESOURCE & PHASE I & PHASE II \\
\hline Lead & $23 \mathrm{Mg}(0.32)$ & $54 \mathrm{Mg}(0.76)$ \\
\hline Stainless Steel & $9.3 \mathrm{Mg}(0.56)$ & $14 \mathrm{Mg}(0.84)$ \\
\hline Aluminum & $2.6 \mathrm{Mg}(0.47)$ & $4.4 \mathrm{Mg}(0.80)$ \\
\hline $\begin{array}{c}\text { HT-9 (in place } \\
\text { of Inconel) }\end{array}$ & $2.0 \mathrm{Mg}(0.40)$ & $3.8 \mathrm{Mg}(0.77)$ \\
\hline Tungsten & $340 \mathrm{~kg}(0.23)$ & $780 \mathrm{~kg}(0.52)$ \\
\hline Zircaloy-4 & $1.2 \mathrm{Mg}(0.28)$ & $2.3 \mathrm{Mg}(0.53)$ \\
\hline D $2 \mathrm{O}$ & $70 \mathrm{Mg}(0.81)$ & $80 \mathrm{Mg}(0.93)$ \\
\hline He-3 & $3.8 \mathrm{~kg}(0.27)$ & $7.6 \mathrm{~kg}(0.54)$ \\
\hline
\end{tabular}

\subsubsection{Construction Resource Needs for the He-3 Tritium Extraction Facility}

The resource requirements for the He-3 tritium extraction facility are assumed to be very similar to the $3 / 8$ goal design and are documented in Table 4-5.

\subsubsection{Construction Resource Needs for the Balance of Plant}

The construction needs for the BOP are assumed to be the same as for the $3 / 8$ goal design and are documented in Table 4-6.

\subsection{Resource Needs During Operation}

This section documents the operational resource needs for the accelerator, the target, and the balance of plant.

\subsubsection{Operational Resource Needs for the Accelerator}

The resource needs during operations for the accelerator are estimated in Table 9-4. The values in parenthesis are the ratio of the resource requirements for that phase to the resource requirements for a $3 / 8$ goal design. 
Table 9-4. Operational Resource Needs for the Phased APT Accelerator.

\begin{tabular}{|c|c|c|}
\hline & \multicolumn{2}{|c|}{ QUANTITY } \\
\hline RESOURCE & PHASE I & PHASE II \\
\hline Klystrons & 8 units (0.32) & 15 units (0.60) \\
\hline Ion Pumps & 10 units (0.50) & 20 units (1.0) \\
\hline
\end{tabular}

\subsubsection{Operational Resource Needs for the He-3 Target}

The annual operational resource needs for the He-3 target are based on those in Table 9-3 and a 2.2-year target lifetime. A makeup rate of $1 \%$ was used to estimate the amount of heavy water required for operations. The resource needs for the He-3 target are shown in Table 9-5.

Table 9-5. Operational Resource Needs for the Phased APT He-3 target.

\begin{tabular}{|c|c|c||}
\hline & \multicolumn{2}{|c|}{ QUANTITY } \\
\hline \hline RESOURCE & PHASE I & PHASE II \\
\hline Lead & $1960 \mathrm{~kg}(0.32)$ & $4660 \mathrm{~kg}(0.75)$ \\
\hline Stainless Steel & $4.2 \mathrm{Mg}(0.55)$ & $6.4 \mathrm{Mg}(0.84)$ \\
\hline Aluminum & $1.2 \mathrm{Mg}(0.48)$ & $2.0 \mathrm{Mg}(0.80)$ \\
\hline HT-9 (in place of Inconel) & $0.91 \mathrm{Mg}(0.40)$ & $1.7 \mathrm{Mg}(0.74)$ \\
\hline Tungsten & $160 \mathrm{~kg}(0.23)$ & $350 \mathrm{~kg}(0.50)$ \\
\hline Zircaloy-4 & $0.54 \mathrm{Mg}(0.27)$ & $1.1 \mathrm{Mg}(0.55)$ \\
\hline $\mathrm{D}_{2} \mathrm{O}$ & $0.64 \mathrm{~m}^{3}(0.35)$ & $0.73 \mathrm{~m}^{3}(0.41)$ \\
\hline
\end{tabular}

\subsubsection{Operational Resource Needs for the He-3 Tritium Extraction Facility}

The resource needs for operation of the $\mathrm{He}-3$ tritium extraction facility are assumed to be similar to the needs for the 3/8 goal design and are documented in Table 5-5. 


\subsubsection{Operational Resource Needs for the Balance of Plant}

The operational resource needs for the balance of plant are shown in Table 9-6. The electrical energy requirements are based on the $3 / 8$ estimate that $550 \mathrm{MW}$ would be required when in full operation. This reduces to $197 \mathrm{MW}$ for the Phase I design and $355 \mathrm{MW}$ for the Phase II design. The assumption is made that the power requirement when the accelerator is not operating is no more than $10 \%$ of the full power requirement. With a $75 \%$ availability, this results in $1.3 \times 10^{6} \mathrm{MW}$ h and $2.4 \times 10^{6} \mathrm{MW}$ $\mathrm{h}$ for each year for the Phase I and Phase II design, respectively.

The principal users of fuel during operations will be emergency diesel generators and motor vehicles. Based on the assumption that the number of people employed will be approximately the same for all phases, the fuel usage will be approximately the same as for the $3 / 8$ goal design.

The amount of sulfuric acid needed is dominated by the quantity required to maintain $\mathrm{pH}$ of the cooling tower circulating water. For this reason, the quantity was scaled with the amount of cooling water. The sodium hydroxide is only used to adjust the alkalinity of the makeup water for the closed loop $\mathrm{H}_{2} \mathrm{O}$ cooling systems. This has also been scaled with the amount of cooling water.

One of the primary uses of water is cooling tower makeup. The cooling water usage was estimated for both a wet and dry site using similar systems to the $3 / 8$ goal APT facility. This results in a water usage for the Phase II facility of $2.9 \times 10^{6} \mathrm{~m}^{3} / \mathrm{yr}$ and $5.4 \times 10^{5} \mathrm{~m}^{3} / \mathrm{yr}$ for the wet and dry sites, respectively [9].

Table 9-6. Operational Resource Needs for the Phased APT Balance of Plant

\begin{tabular}{||c|c|c||}
\hline & \multicolumn{2}{|c||}{ QUANTITY } \\
\hline \hline RESOURCE & PHASE I & PHASE II \\
\hline Electrical Energy & $1,300,000 \mathrm{MW} \mathrm{h}(0.35)$ & $2,400,000 \mathrm{MW} \mathrm{h}(0.64)$ \\
\hline Fuel & $50 \mathrm{~m}^{3}(1.0)$ & $50 \mathrm{~m}^{3}(1.0)$ \\
\hline Sodium Hydroxide & $70 \mathrm{~kg}(0.35)$ & $130 \mathrm{~kg}(0.64)$ \\
\hline Sulfuric Acid & $440 \mathrm{Mg}(0.35)$ & $800 \mathrm{Mg}(0.64)$ \\
\hline $\mathrm{H}_{2} \mathrm{O}$ (wet site) & not estimated & $2.9 \times 10^{6} \mathrm{~m}^{3}(0.64)$ \\
\hline $\mathrm{H}_{2} \mathrm{O}$ (dry site) & not estimated & $5.4 \times 10^{5} \mathrm{~m}^{3} / \mathrm{yr}(0.95)$ \\
\hline
\end{tabular}




\subsection{Employment}

The employment requirements during construction and operation are expected to be approximately the same for the Phase I and Phase II designs as for the $3 / 8$ goal design and are documented in Tables 6-1 and 6-2.

\subsection{Waste Effluent}

The amount of waste effluent for the Phased APT accelerator and target are discussed in this section.

\subsubsection{Waste Effluent for the Accelerator}

Estimates of the annual waste effluent from the Phase I accelerator are shown in Table 9-7. Similar estimates for the Phase II accelerator are shown in Table 9-8.

Table 9-7. Waste Effluent for the Phase I Accelerator.

\begin{tabular}{||c|c|c|}
\hline WASTE & MASS & VOLUME \\
\hline \hline High-Level Waste & 0 & 0 \\
\hline Transuranic Waste (solid) & 0 & 0 \\
\hline Low-Level Waste (solid) & $380 \mathrm{~kg}(0.64)$ & $0.2 \mathrm{~m}^{3}(1.0)$ \\
\hline Mixed Waste (solid) & $430 \mathrm{~kg}(1.0)$ & $0.4 \mathrm{~m}^{3}(1.0)$ \\
\hline Hazardous Waste (solid) & $340 \mathrm{~kg}(1.0)$ & $0.3 \mathrm{~m}^{3}(1.0)$ \\
\hline
\end{tabular}

Table 9-8. Waste Effluent for the Phase II Accelerator.

\begin{tabular}{||c|c|c||}
\hline WASTE & MASS & VOLUME \\
\hline \hline High-Level Waste & 0 & 0 \\
\hline Transuranic Waste (solid) & 0 & 0 \\
\hline Low-Level Waste (solid) & $470 \mathrm{~kg}(0.80)$ & $0.2 \mathrm{~m}^{3}(1.0)$ \\
\hline Mixed Waste (solid) & $430 \mathrm{~kg}(1.0)$ & $0.4 \mathrm{~m}^{3}(1.0)$ \\
\hline Hazardous Waste (solid) & $340 \mathrm{~kg}(1.0)$ & $0.3 \mathrm{~m}^{3}(1.0)$ \\
\hline
\end{tabular}

\subsubsection{Waste Effluent for the HE-3 Target}

The waste effluent for the Phase I and Phase II He-3 target was calculated in the same manner as for the $3 / 8$ design. The constituent waste streams were analyzed for their dependence on the changes 
in operating assumptions and resource requirements. These waste streams were then summed to produce the following tables for the Phase I and Phase II He-3 target waste effluents. Sewage and nonhazardous waste estimates remained the same as the $3 / 8$ goal based on the assumption that employment will remain approximately the same. Table 9-9 contains the waste effluent for the Phase I He-3 target and Table 9-10 contains the estimates for the Phase II target.

Table 9-9. Waste Effluent for the Phase I He-3 Target.

\begin{tabular}{||c|c|c||}
\hline WASTE & MASS & VOLUME \\
\hline \hline High-Level Waste & 0 & 0 \\
\hline Transuranic Waste (solid) & 0 & 0 \\
\hline Low-Level Waste (solid) & $18,700 \mathrm{~kg}(0.60)$ & $15.0 \mathrm{~m}^{3}(0.72)$ \\
\hline Mixed Waste (solid) & $3800 \mathrm{~kg}(0.35)$ & $0.9 \mathrm{~m}^{3}(0.45)$ \\
\hline Hazardous Waste (solid) & $340 \mathrm{~kg}(1.0)$ & $0.3 \mathrm{~m}^{3}(1.0)$ \\
\hline Liquid Sewage & $2.63 \times 10^{7} \mathrm{~kg}(1.0)$ & $2.63 \times 10^{4} \mathrm{~m}^{3}(1.0)$ \\
\hline Nonhazardous (solid) & $6.74 \times 10^{5} \mathrm{~kg}(1.0)$ & $840 \mathrm{~m}^{3}(1.0)$ \\
\hline
\end{tabular}

Table 9-10. Waste Effluent for the Phase II He-3 Target.

\begin{tabular}{||c|c|c||}
\hline WASTE & MASS & VOLUME \\
\hline \hline High-Level Waste & 0 & 0 \\
\hline Transuranic Waste (solid) & 0 & 0 \\
\hline Low-Level Waste (solid) & $22,700 \mathrm{~kg}(0.72)$ & $17.1 \mathrm{~m}^{3}(0.83)$ \\
\hline Mixed Waste (solid) & $7900 \mathrm{~kg}(0.73)$ & $1.5 \mathrm{~m}^{3}(0.75)$ \\
\hline Hazardous Waste (solid) & $340 \mathrm{~kg}(1.0)$ & $0.3 \mathrm{~m}^{3}(1.0)$ \\
\hline Liquid Sewage & $2.63 \times 10^{7} \mathrm{~kg}(1.0)$ & $2.63 \times 10^{4} \mathrm{~m}^{3}(1.0)$ \\
\hline Nonhazardous (solid) & $6.74 \times 10^{5} \mathrm{~kg}(1.0)$ & $840 \mathrm{~m}^{3}(1.0)$ \\
\hline
\end{tabular}

\subsubsection{Waste Effluent for the He-3 Target Tritium Extraction Facility}

The amount of waste produced by the Phase I and Phase II tritium extraction facilities is estimated to be comparable to the $3 / 8$ goal. These values are documented in Table 7-5. 


\subsection{Radioactive Releases}

Radioactive releases may occur during normal operations or under accident conditions. Estimates for both are discussed below.

\subsubsection{Routine Releases}

The amount of radioactivity released from the accelerator due to air leakage from the tunnel during normal beam operations and due to air exhaust from the tunnel following shutdown for maintenance has been scaled for the phased approach. For the Phase I design, the release scales with both current (a factor of 2 reduction) and beam energy (a factor of 2 reduction). Therefore, the release during normal beam operations is estimated at $22 \mathrm{Ci} / \mathrm{yr}$ (a scaling factor of 0.25 ) and the release following shutdown for maintenance is estimated at $21 \mathrm{Ci} / \mathrm{yr}$. For the Phase II design, the release scales with current (a factor of 2 reduction). Therefore, the release during normal beam operations is estimated at $44 \mathrm{Ci} / \mathrm{yr}$ (a scaling factor of 0.50 ) and the release following shutdown for maintenance is estimated at $42 \mathrm{Ci} / \mathrm{yr}$. The composition of isotopes released from the accelerator tunnel is the same as for the $3 / 8$ design and is documented in Table 8-1.

\subsubsection{He-3 Source Term}

The source term presented in Table 8-3 for the He-3 target has been scaled by inventory. The factors used are 0.21 for the Phase I design and 0.60 for the Phase II design. The accident itself has not been reanalyzed. Table 9-11 contains the source term for the Phase I design and Table 9-12 contains the source term for the Phase II design. The release of tritium was not modified since it is released from the heavy water. 
Table 9-11. Source Term for He-3 Phase I Target.

\begin{tabular}{|c|c|}
\hline Isotope & Released Activity (Ci) \\
\hline $\mathrm{H}-3$ & $1500(1.0)$ \\
\hline W-185 & $3000(0.21)$ \\
\hline W-187 & $2200(0.21)$ \\
\hline $\mathrm{W}-181$ & $600(0.21)$ \\
\hline W-178 & $190(0.21)$ \\
\hline $\mathrm{Xe}-127$ & $11(0.21)$ \\
\hline W-177 & $9.8(0.21)$ \\
\hline $\mathrm{W}-176$ & $8.8(0.21)$ \\
\hline Cs-131 & $8.0(0.21)$ \\
\hline $\mathrm{Xe}-125$ & $6.1(0.21)$ \\
\hline Cs-129 & $5.3(0.21)$ \\
\hline Cs-128 & $4.6(0.21)$ \\
\hline $\mathrm{I}-125$ & $4.4(0.21)$ \\
\hline Ar-37 & $2.3(0.21)$ \\
\hline $\mathrm{P}-32$ & $2.3(0.21)$ \\
\hline Cs- 127 & $2.1(0.21)$ \\
\hline $\mathrm{Te}-121$ & $1.9(0.21)$ \\
\hline $\mathrm{I}-123$ & $1.7(0.21)$ \\
\hline $\mathrm{Kr}-79$ & $1.5(0.21)$ \\
\hline Re-186 & $1.5(0.21)$ \\
\hline $\mathrm{Xe}-122$ & $0.84(0.21)$ \\
\hline $31, \mathrm{I}-133, \mathrm{I}-135$ & $<1$ \\
\hline
\end{tabular}


Table 9-12. Source Term for Phase II He-3 Target.

\begin{tabular}{|c|c|}
\hline Isotope & Released Activity (Ci) \\
\hline $\mathrm{H}-3$ & $1500(1.0)$ \\
\hline W-185 & $8700(0.60)$ \\
\hline W-187 & $6400(0.60)$ \\
\hline W-181 & $1700(0.60)$ \\
\hline W-178 & $550(0.60)$ \\
\hline $\mathrm{Xe}-127$ & $31(0.60)$ \\
\hline W-177 & $28(0.60)$ \\
\hline W-176 & $25(0.60)$ \\
\hline Cs- 131 & $23(0.60)$ \\
\hline $\mathrm{Xe}-125$ & $17(0.60)$ \\
\hline Cs-129 & $15(0.60)$ \\
\hline Cs-128 & $13(0.60)$ \\
\hline $\mathrm{I}-125$ & $13(0.60)$ \\
\hline $\operatorname{Ar}-37$ & $6.6(0.60)$ \\
\hline P-32 & $6.6(0.60)$ \\
\hline Cs-127 & $6.0(0.60)$ \\
\hline Te-121 & $5.4(0.60)$ \\
\hline I-123 & $4.8(0.60)$ \\
\hline $\mathrm{Kr}-79$ & $4.2(0.60)$ \\
\hline $\operatorname{Re}-186$ & $4.2(0.60)$ \\
\hline $\mathrm{Xe}-122$ & $2.4(0.60)$ \\
\hline I-131, I-133, I-135 & $<1$ \\
\hline
\end{tabular}


Intentionally Left Blank 


\subsection{REFERENCES}

1. $\quad$ "Balance of Plant Topical Report," LA-12665-MS, Los Alamos National Laboratory, Los Alamos, NM (September 1993).

2. G. Van Tuyle, "Preliminary Topical Report for Revision-1 of a Preconceptual Design for the Spallation-Induced Lithium Conversion (SILC) Target for the Accelerator Production of Tritium (APT)," ATD/APT94-0008 (Rev. 0), Brookhaven National Laboratory, Upton, NY (June 24, 1994).

3. $\quad$ "APT ${ }^{3} \mathrm{He}$ Target/Blanket Topical Report," LA-CP-94-27, Vol. 1, Revision 1, Los Alamos National Laboratory, Los Alamos, NM (March, 1994).

4. G. Lawrence, "Basis for APT Accelerator Resource Needs in Construction and Operations," memorandum AT-DO:GPL:93:8-23, Los Alamos National Laboratory, Los Alamos, NM (August 23, 1993).

5. L. A. Miller, letter to Dr. Kit Heung, Savannah River Site, 6413-LAM-93-002, Sandia National Laboratories, Albuquerque, NM (September 1, 1993).

6. G. J. Willcutt, "APT Volume and Mass Summary for Material Inside the Moderator Tank Boundary, Rev. 1," memorandum to J. R. Ireland, TSA-12-94-53, Los Alamos National Laboratory, Los Alamos, NM (February 16, 1994).

7. J.Barnes, "Tritium-Extraction System-Preliminary Environmental Impact Statement Supporting Data," memorandum to J. Ireland, MST-3-15-93, Los Alamos National Laboratory, Los Alamos, NM (August 30, 1993).

8. Bechtel Group, Inc., "Basis for Balance-of-Plant Data Provided in Support of Accelerator Production of Tritium Programmatic Environmental Impact Statement Input Submittal," BC/LANL-93-074, San Francisco, CA (June 29, 1993).

9. P. W. Lisowski, "Corrections to the Draft PEIS for Tritium Production and Recycling," letter to S. M. Sohinki, APT-95-074, Los Alamos National Laboratory, Los Alamos, NM (July 12, 1995).

10. TheEBASCO Team, "Reference Document in Support of the Defense Programs Reconfiguration PEIS (Draft 2)," NPR-15108 (December 1992).

11. S. D. Carson, P. Peterson, "Revised Process Waste Assessment," AAW-002.1, Sandia National Laboratories, Albuquerque, NM (August 1, 1994).

12. L. A. Miller, "Hazard Classification for APT Targets and Tritium Extraction Facilities," memorandum to J. E. Kelly, 6413-LAM-93-001, Sandia National Laboratories, Albuquerque, NM (October 18, 1993). 
13. U. S. Department of Energy, "Hazard Categorization and Accident Analysis Techniques for Compliance with DOE Order 5480.23, Nuclear Safety Analysis Reports," DOE Standard-102702, Washington, DC (December 1992).

14. G. Lawrence, "Estimate of Activated Air Releases from APT Accelerator Tunnel," APT Accelerator Technical Note 93-2-GL-1, Revision 1, Los Alamos National Laboratory, Los Alamos, NM (February 17, 1993).

15. T. Le, "Estimate of annual tritium releases for Tritium Extraction Facilities," interoffice correspondence to B. Jacobson, Fluor Daniel (September 9, 1994).

16. J. E. Hammelman, W. E. Bickford, H. E. Hootman, W. R. McDonell, "Support Facilities Descriptions for the New Production Reactor at Savannah River Volume 1, Heavy Water Reactor (U)," WSRC-RP-89-263, Version 4, Savannah River Site, Aiken, SC (April 5, 1991).

17. U.S. Department of Energy, "Natural Phenomena Hazards Mitigation," DOE Order 5480.28, Washington, DC (January 1, 1993).

18. K. W. Boyack, "Environment, Safety and Health Topical Report for the Accelerator Production of Tritium," Final, Rev. 1, Sandia National Laboratories, Albuquerque, NM (April 14, 1995).

19. Wright, R. E., Steverson, J. A., Zuroff, W. F., "Pipe Break Frequency Estimation for Nuclear Power Plants," NUREG/CR-4407, EGG-2421 (May 1987).

20. D. A. Siebe, "New TRAC LBLOCA Calculations for Revised PEIS Input," memorandum to J. R. Ireland, N-12-93-368, Los Alamos National Laboratory, Los Alamos, NM (June 29, 1993). 


\section{EXTERNAL DISTRIBUTION:}

(1) R. Lewis Steinhoff

U. S. Department of Energy, DP-25

1000 Independence Avenue S.W.

Washington, DC 20585

(2) Steve Stack

U. S. Department of Energy, DP-25

1000 Independence Avenue S.W.

Washington, DC 20585

(1) Paul Lisowski

Los Alamos National Laboratory

P. O. Box 1663, MS-H813

Los Alamos, NM 87545

(1) Jack Edwards

Los Alamos National Laboratory

P. O. Box 1663, MS-K551

Los Alamos, NM 87545

(1) George Greene

Brookhaven National Laboratory, Bld. 820M

12 South Upton

Upton, NY 11973

(1) Michael Todosow

Brookhaven National Laboratory, Bld. 475B

12 South Upton

Upton, NY 11973

(1) Sewell Rose

Los Alamos National Laboratory

P. O. Box 1663, MS-K551

Los Alamos, NM 87545

(1) Robert Taussig

Bechtel Corporation

50 Beall Street S.E., MS-5017C37

San Francisco, CA 94105-1895

(1) Dennis Slaughter

Lawrence Livermore National Laboratory

P. O. Box 808 , L-28

Livermore, CA 94550
(2) Benny L. Boggs

U. S. Department of Energy, DP-25

1000 Independence Avenue S.W.

Washington, DC 20585

(1) Brent Boyack

Los Alamos National Laboratory

P. O. Box 1663, MS-K551

Los Alamos, NM 87545

(1) Michael Cappiello

Los Alamos National Laboratory

P. O. Box 1663, MS-H813

Los Alamos, NM 87545

(1) Jim Anderson

Los Alamos National Laboratory

P. O. Box 1663, MS-H813

Los Alamos, NM 87545

(1) Robert Youngblood

Brookhaven National Laboratory, Bld. 475B

12 South Upton

Upton, NY 11973

(1) Greg J. VanTuyle

Brookhaven National Laboratory, Bld. 475B

12 South Upton

Upton, NY 11973

(1) George Lawrence

Los Alamos National Laboratory

P. O. Box 1663, MS-H813

Los Alamos, NM 87545

(1) Louis Guillebauld

Los Alamos National Laboratory

P. O. Box 1663, MS-H813

Los Alamos, NM 87545

(2) Eric Schweitzer

U.S. Department of Energy, DP-10

1000 Independence Avenue S.W.

Washington, DC 20585 


\section{INTERNAL DISTRIBUTION:}

MS 0720 S. Carson, 6626

MS 0736 N. R. Ortiz, 6400

MS 0739 D. C. Williams, 6421

MS 0742 J. E. Kelly, 6414

MS 0742 D. L. Miller, 6626

MS 0747 D. B. Mitchell, 6412

MS 0749 F. T. Harper, 6413

MS 0765 C. D. Jaeger, 5821

MS 1137 M. D. Allen, 6422

MS 1137 R. M. Elrick, 6422

MS 1137 T. J. Heames, 6422

MS 1139 K. O. Reil, 6423

MS 1145 P. S. Pickard, 9360

MS 1151 K. W. Boyack, 4271

MS 1165 J. E. Powell, 9300

MS 1175 L. A. Miller, 9364 (15 copies)

MS 1175 L. F. Restrepo, 9364

MS 1175 G. S. Rightley, 9364

MS 1175 J. H. Saloio, 9364

MS 1175 M. P. Sherman, 9364

MS 9018 Central Technical Files, 8523-2

MS 0899 Technical Library, 4414 (5 copies)

MS 0619 Print Media, 12615

MS 0100 Document Processing for DOE/OSTI, 7613-2 (2 copies) 